Florida International University FIU Digital Commons

3-24-2015

\title{
Public Service Motivation in Public and Nonprofit Service Providers: The Cases of Belarus and Poland
}

Palina Prysmakova

Florida International University, pprys001@fiu.edu

DOI: $10.25148 /$ etd.FI15032185

Follow this and additional works at: https:// digitalcommons.fiu.edu/etd

Part of the Civic and Community Engagement Commons, Eastern European Studies Commons, Models and Methods Commons, Organization Development Commons, $\underline{\text { Public Administration }}$ Commons, Quantitative, Qualitative, Comparative, and Historical Methodologies Commons, Social Welfare Commons, and the Soviet and Post-Soviet Studies Commons

\section{Recommended Citation}

Prysmakova, Palina, "Public Service Motivation in Public and Nonprofit Service Providers: The Cases of Belarus and Poland" (2015). FIU Electronic Theses and Dissertations. 1792.

https://digitalcommons.fiu.edu/etd/1792 


\title{
FLORIDA INTERNATIONAL UNIVERSITY
}

Miami, Florida

PUBLIC SERVICE MOTIVATION IN PUBLIC AND NONPROFIT SERVICE

PROVIDERS: THE CASES OF BELARUS AND POLAND

\author{
A dissertation submitted in fulfillment of the \\ requirements for the degree of \\ DOCTOR OF PHILOSOPHY \\ in \\ PUBLIC AFFAIRS \\ by \\ Palina Prysmakova \\ 2015
}


To: Dean Michael R. Heithaus

College of Arts and Sciences

This dissertation, written by Palina Prysmakova, and entitled Public Service Motivation in Public and Nonprofit Service Providers: The Cases of Belarus and Poland, having been approved with respect to style and intellectual content, is referred to you for judgment.

We have read this dissertation and recommend that it be approved.

$\begin{array}{r}\text { Allan Rosenbaum } \\ \hline \text { Milena Neshkova } \\ \hline \text { Mean-Claude Garcia-Zamor, Major Professor }\end{array}$

Date of Defense: March 24, 2015

The dissertation of Palina Prysmakova is approved.

$\begin{array}{r}\begin{array}{r}\text { Dean Michael R. Heithaus } \\ \text { College of Arts and Sciences }\end{array} \\ \hline \begin{array}{r}\text { Dean Lakshmi N. Reddi } \\ \text { University Graduate School }\end{array}\end{array}$

Florida International University, 2015 


\section{DEDICATION}

To

I dedicate this dissertation to my grandmother, Valiancina Zhurauliova. Without your support, patience, understanding, and most of all love, I would not have been able to travel so far in my life. You always have been an example for me of how one's strive for knowledge will change her life. 


\section{ACKNOWLEDGMENTS}

I wish to thank the members of my committee - Jean-Claude Garcia-Zamor, Allan Rosenbaum, Milena Neshkova and Markus Thiel - for their guidance and encouragement. I would like to acknowledge the support from several institutions, which made the data collection of my dissertation possible. First, the Dissertation Evidence Acquisition Fellowship and the Dissertation Year Fellowship from Florida International University that allowed me to focus on my dissertation through three semesters. Second, the Civil Society Scholar Award from Open Society Institute and the Graduate Student Research Grant from European Union Center of Excellence in Miami that covered my data collection expenses, mainly the costly long-distance flights across the ocean. I would also like to recognize the financial support and moral encouragement from the Belarusian diaspora in the United States, namely, Orsa-Romano Cultural and Educational Foundation, NY, and Krechevsky Foundation, NY. I would also like to thank my parents and my sister for their moral support and the Szeszko and the Volkau families for the hospitality that they showed when I was collecting data in their cities. 


\section{ABSTRACT OF THE DISSERTATION \\ PUBLIC SERVICE MOTIVATION \\ IN PUBLIC AND NONPROFIT SERVICE PROVIDERS: \\ THE CASES OF BELARUS AND POLAND \\ by}

Palina Prysmakova

Florida International University, 2015

Miami, Florida

Professor Jean-Claude Garcia-Zamor, Major Professor

The work motivation construct is central to the theory and practice of many social science disciplines. Yet, due to the novelty of validated measures appropriate for a deep cross-national comparison, studies that contrast different administrative regimes remain scarce. This study represents an initial empirical effort to validate the Public Service Motivation (PSM) instrument proposed by Kim and colleagues (2013) in a previously unstudied context. The two former communist countries analyzed in this dissertationBelarus and Poland - followed diametrically opposite development strategies: a fully decentralized administrative regime in Poland and a highly centralized regime in Belarus. The employees $(n=677)$ of public and nonprofit organizations in the border regions of Podlaskie Wojewodstwo (Poland) and Hrodna Voblasc (Belarus) are the subjects of study.

Confirmatory factor analysis revealed three dimensions of public service motivation in the two regions: compassion, self-sacrifice, and attraction to public service. The statistical models tested in this dissertation suggest that nonprofit sector employees exhibit higher levels of PSM than their public sector counterparts. Nonprofit sector 
employees also reveal a similar set of values and work attitudes across the countries. Thus, the study concludes that in terms of PSM, employees of nonprofit organizations constitute a homogenous group that exists atop the administrative regimes.

However, the findings propose significant differences between public sector agencies across the two countries. Contrary to expectations, data suggest that organization centralization in Poland is equal to- or for some items even higher thanthat of Belarus. We can conclude that the absence of administrative decentralization of service provision in a country does not necessarily undermine decentralized practices within organizations. Further analysis reveals strong correlations between organization centralization and PSM for the Polish sample. Meanwhile, in Belarus, correlations between organization centralization items and PSM are weak and mostly insignificant.

The analysis indicates other factors beyond organization centralization that significantly impact PSM in both sectors. PSM of the employees in the studied region is highly correlated with their participation in religious practices, political parties, or labor unions as well as location of their organization in a capital and type of social service provided. 
TABLE OF CONTENTS

CHAPTER

PAGE

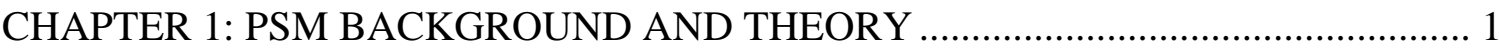

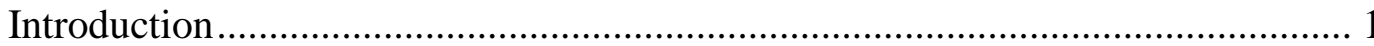

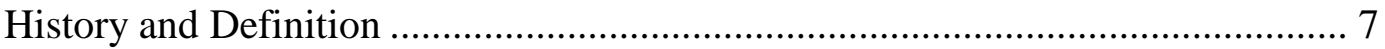

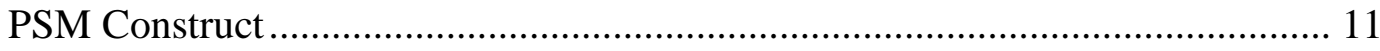

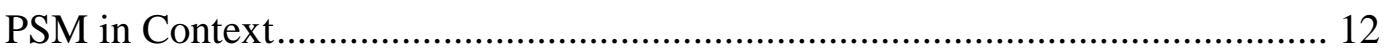

Differences between Countries: Decentralization Issues...................................... 17

CHAPTER 2: CENTRALIZED REGIMES AND MOTIVATION: EVIDENCE FROM THE COMMUNIST TIMES ………………………….................................... 22

Authorizing Environment and Public Values in Centralized Regimes................. 24

Motivation in Soviet Organization: From Management Intentions to Workforce

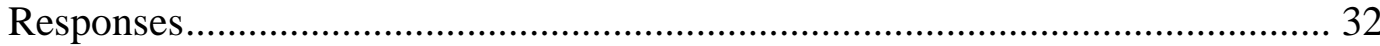

PSM in Centralized Soviet System ................................................................. 44

Motivation after the Fall of Communism ........................................................... 46

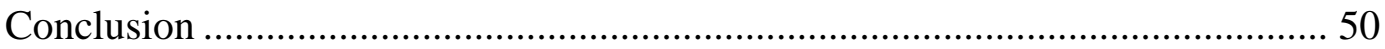

CHAPTER 3: NONPROFIT SECTOR AS A NEW PHENOMENON IN CENTRAL AND EASTERN EUROPE …………………………..................................... 52

Nonprofit Sector as New Phenomenon in Central and Eastern Europe................ 53

Working Definition of Nonprofit Organization ..................................................... 63

Public Values in Newly Established Nonprofit Organizations: External and

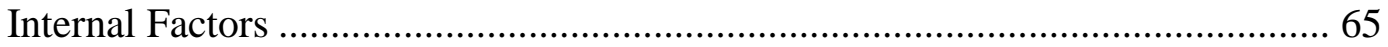

Motivation in Nonprofits vs. Public Sector .................................................... 72

Government Centralization and Sectoral Differences in Motivation ................... 79

Nonprofit-Public Relations in Decentralized Administrative Systems ................ 80

Nonprofit-Public Relations in Authoritarian Systems as Extreme Case of High

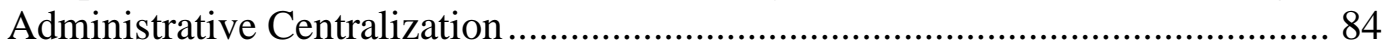

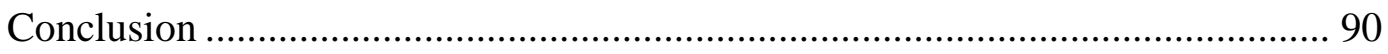

CHAPTER 4: METHODOLOGY AND EMPIRICAL STUDY DESIGN ........................ 94

Scale Translation and Content Validation Procedures........................................... 95

Sampling: Justification of Regions and Organizations Selection ......................... 98

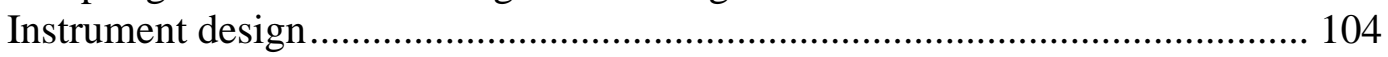

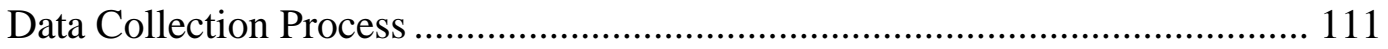

Summary of Data Collection ................................................................... 122

CHAPTER 5: DATA ANALYSIS AND RESULTS ………………………............. 124

Models and Measure Invariance between Countries ....................................... 124

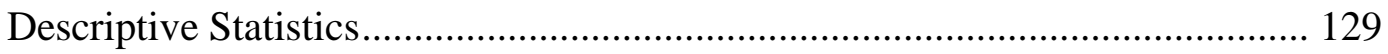

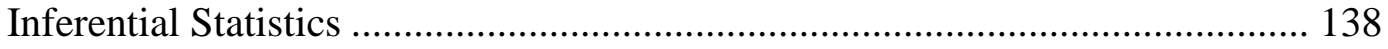


CHAPTER 6: CONCLUSION

REFERENCES .

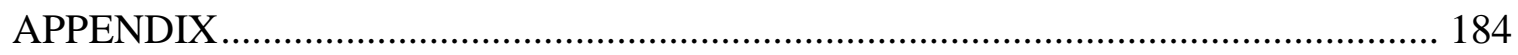

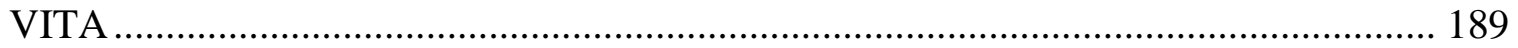




\section{LIST OF TABLES}

TABLE

PAGE

Table 1: Similarities and Differences Shaping Motivation in Public and Nonprofit

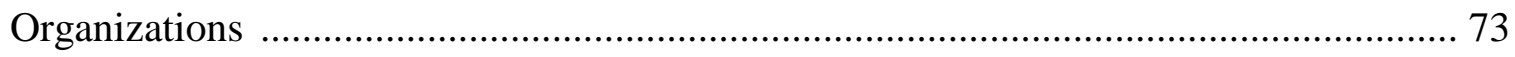

Table 2: Review of Relations between Public and Nonprofit Sectors .......................... 83

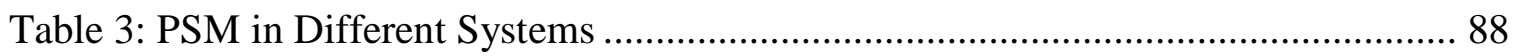

Table 4: PSM Dimensions and Items as Adopted from Kim et al. (2013) .................... 106

Table 5: Nonprofit Organizations that Provide Public Services in Bialystok .............. 107

Table 6: Summary of Data Collection .................................................................... 123

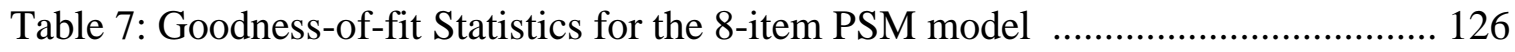

Table 8: Configurative Centralization Models ................................................... 128

Table 9: Metric Centralization Models ........................................................................ 128

Table 10: Means and Standard Deviations for Demographics ................................. 129

Table 11: Means and Standard Deviations for Job Characteristics ............................ 130

Table 12: Means and Standard Deviations for Pro-Social Activities .......................... 131

Table 13: Sample Descriptive Using t-test for Equality of Means between Sectors ..... 133

Table 14: Sample Descriptive Using t-test for Equality of Means between Countries . 134

Table 15: Summary for Regression Results for the total PSM Score ......................... 143

Table 16: Summary of Regression Results for Compassion .................................... 144

Table 17: Summary of Regression Results for Self-Sacrifice ................................. 145

Table 18: Summary of Regression Results for Attraction to Public Service ................ 146 


\section{LIST OF ABBREVIATIONS AND ACRONYMS}

$\begin{array}{ll}\text { BRUY } & \text { Belarusian Republican Union of the Youth } \\ \text { CSA } & \text { Center of Social Assistance } \\ \text { DE } & \text { Department of Employment } \\ \text { DWLS } & \text { Diagonally-Weighted Least Squares } \\ \text { EU } & \text { European Union } \\ \text { FIU } & \text { Florida International University } \\ \text { LO } & \text { Labor Office } \\ \text { NGO } & \text { Non-governmental Organization } \\ \text { OLS } & \text { Ordinary Least Squares } \\ \text { PA } & \text { Public Administration } \\ \text { PLO } & \text { Powiat Labor Office } \\ \text { PSM } & \text { Public Service Motivation } \\ \text { TCSSC } & \text { Territorial Center of Social Services for Citizens }\end{array}$




\section{CHAPTER 1: PSM BACKGROUND AND THEORY}

\section{Introduction}

The objective of this dissertation is to investigate how the sector of employment and a country's administrative system determine fluctuations in an individual's work motivation. The study follows the theory of Public Service Motivation (PSM) and comparatively examines the public and nonprofit sectors in Poland and Belarus. The study aims to determine whether employees in the two sectors are motivated by different values, despite a shared purpose of existence - that is, providing goods and services to the public.

Prior research has extensively studied the various dimensions of PSM (e.g., Bright 2008, Taylor 2005, Perry 1996, Kim 2005), yet mainly in the context of advanced democracies. The research presented in the dissertation tests the application of the PSM construct in post-communist systems by focusing on two countries, Belarus and Poland. Detailed studies of PSM in the Eastern European region valuably expand the scope of international research by adding new knowledge about the motivation of people who have experienced drastic political and economic changes in their lives. Current employees of public and nonprofits sectors grew up or-for the majority of their lifetimes-worked during the gradual collapse of communism and the post-Soviet

environment of the 1990s. Was their motivation to work influenced by the introduction of democratic values? Is the degree to which administration is centralized in administrative centralization level of the current government correlated to the work motivation of employees in public and nonprofit organizations? 
One of the main reasons Belarus and Poland were chosen for analysis is because they represent countries with different levels of centralization in their administrative systems. Despite the fact that these neighboring countries were formerly in the same communist bloc, after the fall of communism they took different paths in their administrative development. Even though there was a democratic movement toward decentralization in the beginning of the 1990s, Belarus reverted back to a highlycentralized governmental system. In contrast, after the fall of the communist regime, Poland took a steady path toward decentralization in a liberal-democratic setting. For the purposes of cooperation and further integration with the European Union (EU), in the 1990s, Poland undertook a number of decentralization reforms that aimed to harmonize its political and administrative system with EU regulations. Poland became an EUmember in 2004, which made its public and nonprofit organizations eligible for support from various EU funds.

Belarus and Poland share characteristics of European welfare states. Citizens of both countries view the government as a main provider of public services, while private service providers, for instance, educational or health institutions, are viewed as complementary. Yet, public sector services differ in the two countries by the centralization level of the administrative systems responsible for service provision. Public service organizations in Poland are mainly responsible to the local governments. For instance, Polish centers of social assistance, which provide various types of social care in Poland, are established by the smallest territorial units such as towns and villages. Meanwhile, the provision of public social services in Belarus is highly centralized. Following the same example, the Belarusian government has designated special 
hierarchies under the Ministry of Labor and Social Protection, which governs social issues. Belarusian social assistance centers are the representatives of the central government, and are responsible to the Voblasc Committee of Labor and Social Protection, which is under the direct supervision of the Ministry of Labor and Social Protection

At the same time for both countries, a partial delegation of social welfare to the nonprofit sector is a new phenomenon, mainly because of the novelty of the nonprofit sector itself. While the nonprofit sectors in these countries drastically differ from American nonprofits in their origins, the nonprofits in Belarus and Poland also differ from each other. In Belarus, the nonprofit sector is mostly represented by the organizations that emerged from the former Soviet pro-social organizations when they changed their type of registration from being public into nonprofit after the fall of communism. Small nonprofits of the new generation, in turn, are often seen as antigovernmental organizations, even if they have no political agenda and their only function is to provide services. In the present study, the analysis considers both new-generation and former-soviet types of nonprofits, because both of them are comparable in their functions and services to the nonprofits in Poland.

The tradition of Polish nonprofits derives from religious voluntary and charitable organizations that were able to provide public services even during the communist era. The scope of the present research is, however, narrowed to the modern type of the service providing nonprofits. A great number of them emerged in the 1990s and 2000s because of the availability of EU funds; Poland's EU membership opened doors to EU resources - distributed under various social funds and programs. Polish entrepreneurs 
saw the nonprofits as an employment opportunity that resulted in numerous nonprofits mushrooming with the support of, and to utilize, EU funds.

The aim of the present research is twofold. First, it seeks to assess the cross-sector (i.e. public vs. private) PSM differences in service providing organizations. And second, it seeks to test for the possible impacts of administrative and organizational factors on the individual PSM score. The outcome of this research can be used as a point of reference for further studies on the influence of the context on individual work motivation.

There were several main research questions that the study attempted to answer. The study distinguishes between centralization of not-for-profit organizations and centralization of service provision at the national level. Therefore, the first research question is related to the peculiarities of a country's institutions and systems that shape the work motivation of the individuals who live in that country. Specifically, the research addresses the variation between PSM levels in public and nonprofit organizations in countries with different degrees of regime centralization. The second research question raised concerns on the organizational level, and addressed the centralization of organizations in different sectors and its impact on individual PSM score. After examining whether public organizations are more centralized than nonprofit ones, the second question addressed PSM differences between the employees of organizations that provide similar services.

The literature review in Chapter 1 discusses different aspects of the PSM concept and how they have been studied in different countries. This dissertation fills in the gap on pro-social motivation of individuals working in public and nonprofit organizations in post-communist countries. It is a comparative study of the variations of PSM level in two 
different contexts. In order to answer the research questions, a survey was administered to the employees of more than 100 organizations involved in labor market and social assistance services in the cross-border regions of Belarus (Hrodna Voblasc) and Poland (Podlaskie Wojewodstwo). This dissertation focuses not only to the human resource capital of service providing organizations in the public and nonprofit sectors, but also organizational characteristics of these entities.

A critical overview of the peculiarities of work motivation that occurred during the communist regime is provided in Chapter 2 of the dissertation. Chapter 2 reviews the literature on the centralization of decision-making at institutional and organizational levels and how it is linked to the work motivation of employees. The analysis pays special attention to prior studies and reports conducted in the Soviet countries at different stages of the regime establishment. Chapter 2 serves as a historical overview of political, economic, and cultural changes that have been influencing public values and thus, work motivation, in Belarus and Poland through the last century. This retrospective synopsis facilitates the understanding of the public and nonprofit sectors' origins, and the workforce attracted by these organizations today.

Chapter 3 addresses the question of whether employees of different pro-social sectors share similar public values or possess the same motivation to tackle social problems. This part of the dissertation discusses the novelty of the independent nonprofit sectors in the former communist countries and also reviews the literature on how-in the modern world - public and nonprofit employees might fight with social issues at their workplace as well as guard and promote public values. 
Chapter 4 outlines the research methodology, giving justification of the choice of countries and sample organizations, and provides an overview of the instruments used to operationalize the study variables. The research is unique not only because it examines individual motivation in a new unstudied context, but also because it tests newly developed tools to measure PSM. Comparative research of PSM in the former Eastern bloc often uses proxies to measure PSM. Studies of Russia, Poland, Czech Republic, and Bulgaria used social survey items to operationalize PSM dimensions (Vandenabeele and Van de Walle 2008, Taylor and Taylor 2011). The recent study of PSM in Lithuania (Kim et al. 2012) is the only research in a post-communist context that applies a scale specially designed to measure PSM. Thus, the dependent variable of the dissertation is the level of PSM operationalized by using the 16-item index developed by Kim et al. (2013). The main explanatory variables are context-related: the research presented in the dissertation employs indicators for sector employment (public or nonprofit) and the type of administrative system (centralized or decentralized). The study also controls for a number of factors, such as demographics, job related aspects, and pro-social activities.

The objectives of the present research are both to rank the PSM level of individuals involved in work for public benefit in different sectors and administrative regimes, and to analyze whether centralization factors shape the differences. Details of the analyses of the first-hand data collected during site visits in the sample region are discussed in Chapter 5 of the dissertation. The concluding section sums up the results and discusses them in light of previous theoretical and empirical knowledge on PSM and work motivation. 
The interest in PSM context is the point of reference for the empirical research, and the evaluation of its nature in a cross-border Belarusian-Polish region is the ultimate objective of this study. Before proceeding to the primary objective of the research, it is necessary to justify the choice of the PSM definition and to review previous relevant studies. This part of the dissertation discusses the concept of PSM and provides concrete examples of its variations across sectors and cultures.

The rest of the chapter proceeds as follows. First, the "Public Service Motivation" concept is introduced. The presentation of the origins and theoretical evolution of the concept is followed by an analysis of several perspectives on individual work motivation from the mid-20th century. The short historical introduction and the PSM definition are followed by a brief description of the different dimensions constituting the PSM concept. Subsequently, the discussion moves toward the focal point of this chapter that is to review the existing knowledge of PSM variations across different sectors and countries.

\section{History and Definition}

Before emerging in the Public Administration (PA) agenda, the topic of work motivation had been examined by psychologists and social scientists alike. While psychologists mainly looked for answers in internal mental processes, sociologists acknowledged the role played by shared norms and values, historical tradition and community customs, and the impact of the presence or lack of formal freedom to associate, travel, protest, express opinions, etc. (Chimiak 2006). Thus, sociologists tried to incorporate psychological knowledge into the complex reality of modern human beings. 
Because the present empirical research is grounded in social science, the discussion of human motivation studies takes into account only some pieces of the relevant literature originating from sociology. Thus, already in the 1940s, scholars began to analyze motivation differences at institutional levels. Talcott Parsons (1940) proposed a theory of motivation for economic activities. In his work, Parsons mentioned the strong, shaping role of institutional factors, posing that the 'typical motivation' is organized around social institutions.

As interest in the concept of work motivation developed in the 1960s, sociologists began to differentiate between "social motivation" with emphasis on external and internal situational factors and "learned motive states" with internal and enduring characteristics present in each individual (Cofer \& Appley 1964). As for intrinsic motivation theories, most have originated from Abraham Maslow's (1970) concept of the hierarchy of human needs. Distinguishing between base and meta needs, Maslow theorized that once satisfied the needs of a certain group in a hierarchy lose their motivating capacity. Then, an individual turns to the higher group of needs to be fulfilled.

In organizational behavior and management literature, it was Charles Handy who-extending Maslow's Hierarchy—presented Motivation Calculus in his book “Understanding Organizations" (1976, revised 1991). Handy integrated various strands of different motivational theories that existed at the time and named three components to his motivation model as follows: needs (individual's own requirement), results (preferred outcomes), and effectiveness (energy, excitation, enthusiasm, emotion, expenditure, etc.). Handy's theory also suggests that decisions are undertaken within a psychological 
contract with other groups, where the contract is the mixture of coercive and cooperative types of behavior.

At the same time in the PA field, the New Public Administration movement of the 1960s also brought resistance to prevailing rationality and associated models of human behavior, redirecting research focus to differences in personalities, interests, motives, and attitudes that justify behavior patterns of individuals. Since then, numerous studies empirically investigated differences in reward motivations between public and private sector employees. Most of them confirmed that public sector employees rank social/personal rewards higher than monetary rewards, whereas the opposite is true for private sector employees (Dilulio 1994, Jurkiewicz, Massey \& Brown 1998, Kilpatrick, Cummings \& Jennings 1964, Rainey 1982, 1997, Wittmer 1991, Crewson 1997). Other studies have found public sector employees to possess more altruistic attitudes than private sector workers (Rainey 1997), and exhibit stronger feelings of civic duty (Conway 2000).

The theoretical tool used to measure the differences between sectors in the proposed study is Public Service Motivation (PSM). A common articulation of PSM is that public sector employees are characterized by an ethic to serve the public. Some authors have connected a multidimensional concept of PSM on theoretical and empirical bases to individuals' pro-social behaviors, their commitment to the public interest, desire to serve others and to self-sacrifice (Brewer and Selden 1998, Perry 1996, Rainey 1982).

Empirical studies, irrespective of how they define PSM, are typically imbued with the idea to do good for others and shape the well-being of society (Perry \& Hondeghem 2008, Kim \& Vandenabeele 2010). The definitions of PSM, however, vary among 
authors depending on the focus of a study: whether a researcher examines different correlates to PSM, origins of concept, or various types of PSM. The present study examines individual PSM in the organizational and institutional contexts, studying whether job rewards, which could be obtained by performing jobs in the public and nonprofit sectors, are important for individuals. Studies show that emphasizing intrinsic rewards over extrinsic rewards is a common phenomenon found in public institutions (Houston 2000, Perry 1997). From that perspective, the PSM is defined by the difference between extrinsic and intrinsic dimensions of job rewards, namely, as Crewson (1997) phrased it, PSM reflects a reliance on intrinsic rewards over extrinsic rewards.

The key PSM definition that frames this dissertation is the following:

"PSM is part of a behavioral process in which public service motives lead to behaviors that benefit the public" (Kim and Vandenabeele 2010, 703).

The definition most accurately suits the current research, because it does not distinguish between the public and nonprofit sectors, but emphasizes the service provided by both types of organizations. As mentioned by Perry and Wise (1990), public service should not be confused with government service, because "public service signifies more than one's locus of employment" (368). Yet, initially PSM was mostly associated with being a prerogative of the public sector, e.g., "an individual's predisposition to respond to motives grounded primarily or uniquely in public institutions and organizations" (Perry 1996, 6). However, with time, the thoughts developed in a way that PSM in both public and nonprofit sectors was acknowledged to be driven by PSM, and thus, motivation in them was contrasted to that in the private sector, which is primarily focused on increasing 
financial capital, but not necessarily public satisfaction (Kilpatrick, Cummings \& Jennings 1964, Houston 2000, Frank \& Lewis 2004, Rainey 1983, Crewson 1997).

Further PSM knowledge in this literature review is organized along two broad themes: PSM construct development and the context that determines PSM. In particular, the premise of this organization is to introduce the development of the PSM construct, as well as to review the existing research on how the context in which people work and live affects the level of PSM.

\section{PSM Construct}

Several scholars have addressed persisting content issues with the PSM construct. Perry (1996) considers PSM as a combination of four empirical dimensions, namely, attraction to policy making, commitment to the public interest, compassion, and selfsacrifice. Substantial research shows general support for Perry's initial dimensions (Bright 2008, Coursey \& Pandey 2007, Coursey et al. 2008, Kim 2009a, Liu, Tang, \& Zhu 2008, Ritz 2009, Vandenabeele 2008a, 2008b). However, research using Perry's model of the PSM construct has limitations that recur from study to study. Public administration scholars admitted that their findings do not fully confirm Perry's measurement model (Kim 2009a, Liu, Tang \& Zhu 2008, Ritz 2009, Vandenabeele 2008a, 2008b).

Public administration literature reflects recent attempts to adjust Perry's scale to global international research. Kim and Vandenabeele (2010) proposed an alternative way to examine PSM, considering it as a set of "three plus one" items. Public service motives, according to their review, are based on self-sacrifice dimension and fall into three categories: instrumental, value-based, and identification motives. Their ideas found 
further development in cross-national PSM studies. Advancing Perry's (1997) PSM dimensions, Kim et al. (2013) provided a more country-neutral and thus more universal measurement instrument for scholars to use as a starting point to study PSM in single country research. Their study combined the efforts of international PSM scholars to develop a measurement instrument for PSM based on tests conducted in twelve countries in North America, Europe, Asia, and Australia.

\section{PSM in Context}

PSM and Sectors of Employment. The present dissertation research is to a large extent an organizational behavior study, which traces the internal management of service providers. Theories of organizational behavior use two major approaches. One rejects the idea that public organizations fundamentally differ from private ones, suggesting that classical and contemporary management theories could be equally applied to public, private, and nonprofit sectors. Another approach suggests that studies of separate sectors require different concepts and techniques, because management and organization in government and private settings experience different challenges (Rainey 1991).

The PSM theories belong to the latter approach to organizational behavior. Public Service Motivation emerged as a comparative-contrasting concept between public and private sectors. An extensive body of literature suggests that motivation to work for the public interest is what distinguishes public organization workers from private sector employees (Kim 2005, Houston 2000, 2006, Jurkiewicz, Massey \& Brown 1998, Rainey 1982, Wittmer 1991, Crewson 1997).

Research shows that public sector employees have different motivations and rewards expectations than their private sector counterparts, despite the differences in 
operationalizations of reward motivation noted in separate studies. Various qualitative and quantitative studies present similar findings, whether research was conducted through interviews (Warner et al. 1963), case studies (Rainey 1982, Hall, Schneider \& Nygren 1970), or cross-sectional surveys (Guyot 1962, Crewson 1997). At the same time, a number of studies show equal values assigned to earnings and psychological rewards across public and private sector employees (e.g. Lyons, Duxbury \& Higgins 2006, Maidani 1991, Baldwin 1987, Gabris \& Simo 1995).

One reason for the inconsistent findings on job motivators is that research designs are frequently limited. Most of the results mentioned above are derived from the observation of small probability samples, usually limited geographically to a county, a city, or a state with samples that were no larger than 350 respondents (e.g. Baldwin 1987, Gabris \& Simo 1995, Jurkiewicz, Massey \& Brown 1998, Maidani 1991, Wittmer 1991). Crewson (1997) and Houston (2000) are notable exceptions because they both analyze survey data sets with large, national probability samples and estimate multivariate models with more complete sets of control variables. The findings of both Crewson (1997) and Houston (2000) confirm PSM, because they prove that motivational differences exist between public and private workers.

At the same time, the public sector is not the only place that offers jobs with meaningful public service; private and, especially, nonprofit organizations can offer such opportunities as well (Perry \& Hondeghem 2008, Taylor 2010). In short, "rather than simply a theory of public employee motivation, PSM actually represents an individual's predisposition to enact altruistic or pro-social behaviors regardless of setting"(Pandey et al. 2008, 91-2). Yet, the research on PSM and rewards preferences that compares public 
and nonprofit employees remains sparse (Lee \& Wilkins 2011, Light 2002, Rotolo \& Wilson 2006).

PSM across Countries. Enhancement of PSM measures, unfortunately, is not accompanied by their application in comparative studies. Administering full-item PSM surveys in comparable organizations across countries requires enormous effort and coordination from the scientific community. Existing research on PSM has only a few comparative studies that employ either Perry's (1997) or Kim et al.'s (2013) instruments. At the same time, most international comparative studies used some items from general social surveys as proxies for certain Perry's dimensions (Taylor 2010, Vandenabeele \& Van de Walle 2008, Park and Rainey 2008, Prysmakova 2014a, Prysmakova 2014b).

The majority of studies mentioned above were conducted in the United States. Despite the substantial knowledge on PSM in North America and some highly-developed Western countries, there is a gap in comprehensive comparative and case-study analysis of PSM in the developing world (with the exception of some Asian countries). Extending research into Europe, Asia, and Australia has raised concerns about use of existing dimensions and operational measures in non-U.S. contexts (Perry \& Hondeghem 2008b, Kim \& Vandenabeele 2010).

Despite the measurement difficulties, the concept of PSM began to spread around the globe. Originally tested in the United States (Bright 2008, Coursey \& Pandey 2007, Coursey et al. 2008, Perry 1996), Perry's scale has found application in many national and cross-national studies (e.g. Kim 2009b, Liu, Tang, \& Zhu 2008, Ritz 2009, Vandenabeele 2008c, Vandenabeele \& Van de Walle 2008). Research on PSM has been conducted in the following countries: France (Chanlat 2003, Castaing 2006), Great 
Britain (Georgellis, Iossa \& Tabvuma 2011, Horton 2006), the Netherlands (Leisink \& Steijn 2009), Switzerland (Ritz 2009), and Belgium (Vandenabeele 2008). The concept's development found application in practice. For instance, in South Korea, civil servants' recruitment procedures include questions on the prospective employers' public service motivation (Perry 2012).

The research literature, however, has indicated limitations or peculiarities for particular countries. For instance, several studies show that PSM observed in the United States by Perry (1996) cannot be entirely relevant to other countries. Kim (2009a) recently analyzed whether PSM observed in the United States by Perry (1996) can be generalized to South Korea. Kim's starting point is that Korea and the United States represent substantially different cultures. As a result of regression analyses, he found that rational motives are not entirely related to PSM in the Korean context, but rather, they can be explained by deeply rooted Confucian values and ideals, which have heavily influenced the Korean government and Korean attitudes toward the government.

In addition, although research on public service motivation has been recently conducted in different countries, these are often single-nation studies that are unable to explain the relevance of national context (Houston 2011, 761). Two cross-national studies are notable exceptions: Vandenabeele and Van de Walle (2008) analyzed survey data from thirty-eight nations, and Houston (2011) compared eleven nations. The comprehensive study of Vandenabeele and Van de Walle (2008) confirmed variation in average public service motivation scores among nations and world regions. Houston (2011) restricted his research to the Western world and conducted a two-year panel study of eleven North American and Western European nations. His comparison was limited to 
Belgium (Flanders), Canada, Denmark, Finland, France, Great Britain, Ireland, Norway, Sweden, Switzerland, and the United States. Yet in the two abovementioned studies, the following, main limitation remains: PSM is operationalized by proxies rather than fully developed measurement instruments.

Despite valuable conclusions, the question remains whether PSM observed in North America and developed Western countries can be generalized to Europe as a whole. Addressing this issue, Prysmakova (2014a) analyzed cross-sectional data from the 2008 and 2012 European Social Surveys where she compared the attitudes of workers in the public and private sectors in terms of the importance they assign to several work motives. The respondents were asked about the importance they place on being wealthy and helping others. Using samples from 26 European nations pooled from two survey rounds, the study found that PSM, indeed, occurs in the public sector across different European countries and regions. The analyses conclude that there are generalizable and stable differences in the reward motivations of public and private sector employees across Europe; PSM exists in all studied European countries, despite the internal social, cultural, political, and administrative differences.

Yet, another conclusion drawn from the Prysmakova (2014a) study is that the PSM level is not equal across countries, and that European nations also can be grouped in subregions according to the level of their PSM. In a subsequent investigation, Prysmakova (2014b) revealed that Eastern European countries show the most extreme results for the both questions regarding the importance to be rich and to help others. Prysmakova (2014b) showed that public service employees want to help other people more than employees in the private sector and this divergence is largest in Eastern European 
countries, namely in Russia and Ukraine. Her finding is in contrast to Vandenabeele and de Walle's (2008) results that showed low PSM level in Eastern Europe, which they explain by the least exposure to democratic practices .

As research evidence suggests, further international studies should devote particular attention to cultural meaning and connotations that can distort comparative findings (e.g. Kim \& Vandenabeele 2010, Prysmakova 2014b). This dissertation pays special attention to these issues of possible country divergences.

\section{Differences between Countries: Decentralization Issues}

As the abovementioned literature suggests the country's context plays a special role in determining the PSM of the employees in various sectors. While the current study refers to the differences of countries' regimes that might shape individual motivation, it is crucial for this dissertation to separate the concept of decentralization from other close concepts such as democracy or market reforms (Schneider 2003). While acknowledging that the latter concepts are equally important for the quality and quantity of services offered for the population, this study focuses on the technical administrative aspects of the services that are already in place in the case countries.

Despite the ongoing arguments about the definition of decentralization, as Schneider (2003) points out, most of them are constructed around the idea that decentralization includes the transfer of power and resources away from the central government. Most of the scholars that deal with the issues of the decentralization would also agree on the three dimensions of the concept:

- Fiscal decentralization refers to a larger proportion of expenditures by lower level governments than by the central government; 
- Administrative decentralization offers local jurisdictions autonomy from central control;

- Political decentralization emphasizes the significant role of political actors and issues at the local level, making them at least partially independent from those at the national level.

In decentralized systems, the central governments play a lesser role on all or on one of the dimensions. While three dimensions do not necessary overlap, there might be situations, when the decentralization occurs on one of the dimensions, while the others remain highly centralized. Such situations exemplify the relativeness of the concept.

The present dissertation mainly focuses on administrative decentralization relevant to the service provision. Administrative decentralization grants localities administrative autonomy including that of the personnel control (Rondinelli, Nellis and Cheema 1984). Human resources of public and nonprofit organizations are the main focus of this study.

Traditional literature on development names decentralization as a solution for number of issues in the developing countries. A major goal of decentralization in these countries is to effectively reach out to the poor. Yet, the study of Bardhan (2002) cautiously points out some negative sides of decentralization, mainly along its fiscal and administrative dimensions. While in standard literature, decentralization is often focused on allocation of funds, some points of Bardhan's (2002) list also refer to fiscal decentralization issues, which are impossible to separate from the administrative decentralization. Bardhan (2002) proposes to pay attention to the following when advocating for decentralization in the developing countries: 
1) Decentralization might be of little help to weak institutions of local democracy. While decentralization might mean less control, it might bring more bureaucratic corruption. Information and accounting systems of monitoring public bureaucrats on the local level are much weaker in low-income countries.

2) The poor and the minorities might be oppressed by the local power groups and therefore look to the central government for protection and relief.

3) Richer localities might not necessary spend more on the services than poor ones. As Bardhan (2002) posits, the connection between local revenues and spending is not always positive. Moreover, fiscal decentralization might fail in poor countries, because Tiebout (1956) model does not work properly: citizens are not mobile enough to move for better public services, especially, for social assistance.

4) Expertise and administrative capacity might be weaker at the service delivery level in smaller localities. This causes the information asymmetry (Bird 1995), where the central government may not know what to do and the local government may not know how to do it. In addition, as Bardhan (2002) claims, central bureaucracies attract better talent. Thus, the quality of professional and technical staff in the localities might be significantly lower, thus centralized service delivery might be a better solution to organize the services and keep them working efficiently.

In low income countries, the decentralization is usually about providing centrally collected revenues to lower levels of government rather that empowering the local governments to collect their own taxes. Not all state-mandated redistribution is unproductive rent creation. Centralized redistribution of human and capital resources to service delivery organizations in disadvantaged regions might be the only option for the 
population of those areas to receive services as compared to other more advantaged regions. In the country with the relevant homogeneity between regions, the centralized service provision might be more efficient. As Bardhan (2002) puts it: "The logic behind decentralization is not just about weakening the central authority, nor is it about preferring local elites to central authority, but it is fundamentally about making governance at the local level more responsive to the felt needs of the large majority of the population (202)."

Many empirical studies about the impact of decentralization on the delivery of social services are descriptive. They often suggest correlations rather than causality. Moreover, the empirical literature on centralized versus decentralized service delivery in developing countries offers ambiguous results. For example, Galasso and Ravallion (2001) studying a decentralized food-for-education program in Bangladesh, find little support for the view that the central government is more accountable to the poor than local communities. Alderman (1998) examines targeted social assistance program in Albania that was decentralized in 1995. He finds that there have been modest gains in targeting efficiency and cost-effectiveness following decentralization. Foster and Rosenzweig (2001) studied villages across India to examine the consequences of democratization and fiscal decentralization. They find that democratic decentralization has a positive effect on allocation of public resources to road construction, but a negative effect on irrigation facilities.

The current research takes into account the degrees of decentralization that exist in local service provision. While acknowledging the importance of all three elements of decentralization, the study mainly addresses administrative and, to a limited extent, 
political systems. For instance, neither political nor administrative decentralization occurs in Belarus. Meanwhile, the case of Poland represents a more complex mix of strong political decentralization and a certain level of administrative decentralization. The questions of fiscal decentralization - whether national funds constitute relatively large or relatively small part of the service providers' budgets - are left for the future research.

While there are some studies about the broader impacts of decentralization on the efficiency of the service delivery, the literature is silent on the questions how the administrative decentralization might impact the work attitudes of the employees that provide these services. In the following chapters, this dissertation will provide some theoretical and empirical evidence on how the administrative centralization of public service provision correlates with the motivation of the individuals employed in the public and nonprofit organizations. 
CHAPTER 2: CENTRALIZED REGIMES AND MOTIVATION:

\section{EVIDENCE FROM THE COMMUNIST TIMES}

This chapter analyzes the centralization of decision-making at institutional and organizational levels and how it is linked to the work motivation of employees. The chapter pursues a two-fold objective and contributes to the dissertation in two dimensions:

- it provides a step-by-step review of how the centralization of the country's and organization's administration can influence employees' individual motivation (i.e., to examine if and how centralization influences motivation);

- it provides a historical overview of political, economic, and cultural changes that have been influencing work motivation in Belarus and Poland through the last century, which facilitates the understanding of the public and nonprofit sectors' origins, and the workforce attracted by these organizations (i.e., to show how the past shapes today's motivation).

The first objective reflects the first research question of the dissertation: "How does the degree of government centralization influence employees' motivation in public and nonprofit service providers?" The expectation is that the centralization level of government affects public service motivation (PSM) of the individuals involved in public service provision. This chapter informs this hypothesis, which ultimately will be tested against empirical data collected for the study. It provides historical evidence in support of the argument that centralization affects PSM of employees. Namely, it examines the mechanisms of these relations in the accordance with Vandenabeele's et al. (2013) framework (See Figure 1) by analyzing the secondary data—reports and research articles. 
The second objective is to describe the context from which today's workforce in Belarus and Poland originated. Before determining the effects of a country's centralization/decentralization level on the work motivation, we must assess the initial condition of the motivation among employees of the public and nonprofit sectors after the fall of communism. To analyze whether (1) decentralization in Poland had an impact on the public values and PSM and (2) centralization in Belarus reinforced the public values established during the communist era, we must examine the state of the workforce right after the fall of communism. As it takes generations to change values and attitudes (Inglehart 1990, 1997), analyses of the past are important, because the motivation of employees today is more likely to be explained by the past.

This study acknowledges that Poland was not part of the original USSR and was only incorporated into the communist system after 1945 while still preserving its strong resistance labor movement and the church. Nevertheless, an overview of major communist ideas regarding the work culture and incentive systems still provides valuable background of work motivation in this country today.

The chapter proceeds as follows. Firstly, it will discuss the theoretical expectations about the effect of authorizing environment on public values and workforce motivation. Then, it will provide evidence from the centralized communist government. After a brief overview of the establishment of communist rule, the chapter will describe how communist politicians were changing the system of values by dismantling old and creating new institutions. Thereafter, the chapter proceeds with an analysis of the operation of a Soviet organization. It primarily emphasizes the role of an individual's motivation, which depends on the consistency between personal and organizational goals. 
The chapter provides historical evidence for the way the party's and organizational needs were addressed by the managers' actions, and how these actions were perceived by the workforce.

Figure 1: From Management Intentions to Organizational and Employee Outcomes

\begin{tabular}{|c|c|c|c|c|}
\hline \multicolumn{2}{|c|}{$\begin{array}{l}\text { Authorizing environment } \\
\text { - Politicians } \\
\text { - Stakeholders }\end{array}$} & \multicolumn{3}{|c|}{$\begin{array}{l}\text { Public values } \\
\text { - Institutional framework } \\
\text { - Cultural framework }\end{array}$} \\
\hline $\begin{array}{l}\text { Management } \\
\text { intentions } \\
\text { - Mission and } \\
\text { public value } \\
\text { strategy } \\
\text { - HR strategy } \\
\text { aiming to } \\
\text { build ability, } \\
\text { motivation } \\
\text { and oppor- } \\
\text { tunity to per- } \\
\text { form } \\
\text { - Operational } \\
\text { policy }\end{array}$ & $\begin{array}{l}\text { Management } \\
\text { actions } \\
\text { - Direct actions } \\
\text { senior mana- } \\
\text { gement (e.g. } \\
\text { budget) } \\
\text { - Direct actions } \\
\text { HR specia- } \\
\text { lists } \\
\text { - Line mana- } \\
\text { gers' enact- } \\
\text { ment of stra- } \\
\text { tegies }\end{array}$ & $\begin{array}{l}\text { Workforce } \\
\text { perceptions } \\
\text { - Individual } \\
\text { perceptions } \\
\text { of own psy- } \\
\text { chological } \\
\text { contract } \\
\text { - Collective } \\
\text { perceptions } \\
\text { of politics' } \\
\text { and manage- } \\
\text { ment com- } \\
\text { petence and } \\
\text { trustworthi- } \\
\text { ness }\end{array}$ & $\begin{array}{l}\text { Workforce } \\
\text { responses } \\
\text { - Opportunities } \\
\text { - Abilities } \\
\text { - (Public } \\
\text { service) } \\
\text { motivation }\end{array}$ & $\begin{array}{l}\text { Organizational } \\
\text { and employee } \\
\text { outcomes } \\
\text { - Public service } \\
\text { performance } \\
\text { - Employee } \\
\text { commitment } \\
\text { - Job satisfac- } \\
\text { tion }\end{array}$ \\
\hline
\end{tabular}

Note: Adopted from Vandenabeele et al. (2013)

\section{Authorizing Environment and Public Values in Centralized Regimes}

Theory. The present study distinguishes between the two types of centralization: centralization of organizations at the organizational level and centralization of the service provision systems at the country level. Since strong governmental administrative systems can undermine any democratic systems within the state (Foster 2001), both levels are linked. The more centralized the state administration is, the more likely it is that public 
sector organizations and nonprofit organizations subsidized by the government are centralized as well. Tschirhart (2006) concludes that in highly centralized regimes, strong dependency on governmental decisions undermine the degree of democracy within an organization: " ... if an association is linked to a non-democratic state through personnel, financial, decision-making, or operational procedures or arrangements, then state interests dominate member interests" (534).

Centralized climate of the state not only shapes management arrangements of an organization, but also frames employees' behavior, because the government has a leading role in determining what people — both service providers and their clients — collectively value (Benington 2011, 43-4). By defining social values, institutions directly and indirectly influence motives guiding individual behavior (Hughes 1939, Scott 1987, Friedland \& Alford 1987, Perry \& Vandenabeele 2008).

The value-creation role of the state should be especially visible in public organizations. As the mainstream public administration literature suggests, public servants are receivers of top-down public themes (Rubington \& Weinberg 2010,4) and guards of the regime values (Frederickson \& Hart 1985). Therefore, the state becomes a determinant of public values.

The present study is conducted from the perspective that public values are normative ideas or principles promoted by the government, and PSM refers to an individual behavioral orientation to do something good for the society (Andersen et al. 2013). By setting social values, institutions tend to standardize behavioral patterns (March \& Olsen 1989), but this does not always occur. While the state only determines what the public values are, each employee must decide whether to internalize these public 
values into reality (Lipsky 1980). On the one hand, if a public service employee considers values promoted by the government as proper, then, while behaving within an individual PSM, this employee also creates public value (Moore 1995). In this situation, complying with norms and values is satisfying and therefore motivates (Andersen et al. 2013). Richman (1963a) provides some evidence that employees in the communist countries had a high sense of moral obligation to the state. Thus, for example, despite the high level of centralization during the communist rule, those individuals who believed in the ideas of the party should have felt that complying with party directives leads to improvements in society, and thus those individuals should have possessed higher PSM level These employees could have exhibited high level of PSM, despite the fact that they previously worked for the totalitarian regime.

As research shows, a decentralized market model indeed does not always create the best environment for the PSM of employees. In a comparative study of the United States and New Zealand, Moynihan (2008) finds that the market model weakens public service motivation, because it appeals to the extrinsic/monetary motivation of public service employees. On the other hand, there are two possible patterns of behavior if individuals view public values promoted by the state as different from their own perception of what will benefit society. As employees of the public organization, these individuals would either follow their own PSM and behave in an inconsistent manner with the organizational tasks, or are simply discouraged from working. The following sections provide vivid examples for both types of reaction from the communist era.

Could it be that individual PSM has nothing to do with the public values promoted by the state? Following Andersen et al. (2013), this study assumes that possible 
separation of the PSM and public values concepts is difficult and overlapping of these concepts is unavoidable. Public values and PSM cannot be totally separated, because "values can be motivating and motivation is often oriented toward something desirable" (Andersen et al. 2013). Yet, the working definition remains that "PSM is part of a behavioral process in which public service motives lead to behaviors that benefit the public" (Kim \& Vandenabeele 2010), whether or not the PSM corresponds with the public values promoted by the government.

For this study, PSM refers strictly to the motivation of individuals to do good for others and society through public service delivery (Andersen et al. 2013). This motivation can be reduced by the centralized nature of the government and/or organization. Previous research shows that if not the entire PSM level, then at least some of its constituent dimensions are affected by the political situation in the country; the PSM level is reduced by the lack of democratic public institutions (Vandenabeele \& Van de Walle 2008). Studying PSM dimensions internationally, Vandenabeele and Van de Walle (2008) found that while the compassion dimension of PSM in Eastern Europe is similar to that in Northern and Western Europe, Australia and Asia, self-sacrifice and politics/policy dimensions are significantly lower.

Centralized government propagandizes public values down in hierarchy on public service providing organizations and the dependent nonprofits. In decentralized systems, public values are more likely to be shaped by the citizens, i.e., to originate from individuals and ascend to the government level, rather than to be dictated from above by the state. Such an alignment might create an environment, in which public values coincide with the employee's views of how to improve society. On the basis of these 
assumptions and the findings above, this study hypothesizes that PSM level within the public and nonprofit sectors might differ depending upon the type of administrative system. Moreover, implementing Inglehart's $(1990,1997)$ 'scarcity' theory, which states that generations must pass before gradual change of values can occur, the PSM level of employees today is also determined by the values established by previous regimes. In the case of an Eastern European region - the region being analyzed in this dissertationPSM today should to a certain extent reflect public values established by the highly centralized communist government. The following section depicts the authorizing environment in which the centralized communist government was adjusting public values to its needs.

Historical Evidence. The totalitarian rule of communist politicians recognized forcible change of the value system as a necessity, assuming that any means that lead to the desired results could be applicable. Under the new regime, the stakeholders were limited to (a) Communist Party members and (b) working class and peasants. The first group constituted the centralized administration, and the second consisted of poor underprivileged and non-entrepreneurial citizens. Elites and successful businessmen were eliminated once communist rule was established. The subsequent subsections clarify some crucial changes of public values brought by the new authorizing environment.

Institutional Framework: Dismantling Old Institutions and Creating New Ones. For Central and Eastern European countries, the creation of the Soviet Union and expansion of its influence on the neighboring countries marked the beginning of the great transformation of public values and institutions in the 20th century. Thus, the first transformation arrived with changes in values previously determined by religion and 
traditions, which were replaced with communist visions of world order. This period was characterized by the breaking of old value system and exchanging it them for new one. The Russian rural and urban work force was conditioned by a traditional collectivist mentality even before the Soviet revolution (Tidmarsh 1993). Meanwhile, Belarusian and Polish people previously enjoyed more freedoms and had a longer history of running individual farms and businesses. People from that region were accustomed to individual decision-making and personal responsibility for centuries. Thus, the period of communist rule before World War II was characterized by the government's struggle to change deeply rooted individualistic values. The value-change enforcement took various forms from liquidation of successful individual farming ("razkulachvanie") to deportation of the intellectual and business elites to Siberia — or sometimes even their execution.

The second transformation of institutions began after World War II and was embedded in the process of reforms aimed to maintain and strengthen communist rule. Public values had been addressed not only by the enhanced propaganda, but shaped by implementation of the changes in rewards systems and incentives. That period was characterized by the efforts to maintain the values established before the war, with a simultaneous effort to modernize the economy and the society.

\section{Cultural framework: Creating and Maintaining Communist Work Culture.}

Because the national culture plays an important role in determining what motivates people (Fey 2005), communist culture strongly affected employees' work mentality. During the establishment of the communist system, scientists and politicians were already aware of the importance of the cultural surroundings, realizing that social context significantly molds an individual's personality. The communists believed in a basic 
educational theory, which stated that the new ideology could be indoctrinated into the child from birth; this theory was actively practiced (Schultz \& McFarland 1935).

Even though, in the communist countries, much attention was paid to the importance of work, which was considered the most honored activity (Ardichvili 2009), and while unemployment was labelled as 'parasitism' (Aslund 2007), few studies were completed about the impact of human motivation on the enterprise environment (Richman 1963a). The lack of interest in the topic is not surprising since, during the communist era, attention to the human side of an organization was usually neglected (Luthans et al. 2000). In communist countries, an interest in organizational performance was superior to individual performance.

While denying individualism at the workplace, communist work culture still had to implement some capitalist features, whose importance was especially recognized after World War II. At that time, the communist countries encountered severe difficulties in structuring their economies to provide managers with the proper incentives to obtain desired results. Adherence to communist ideology and the difficulties encountered in developing an integrated and workable plan had led to serious operational problems. The 1950s were marked by the ineffective performance of managers of the industrial enterprises, which resulted from the overall defective economic, cultural, and institutional environment (Richman 1963b). Undesirable managerial behavior was not a question of incompetence, but the framework in which the manager had to operate. Evidence for the malfunction of the system will be provided in subsequent sections.

Soviet communism created a demoralized and low PSM work force. A capitalistic principle that the more productive worker must receive higher pay did not work out in the 
Soviet reality. Communist ideology_ "From each according to his ability, to each according to his needs" — created a situation that benefited those being less productive. Therefore, countries under communist rule tended to exhibit an ascription culture, where status was based on who or what a person was, and which connections the person had, rather than how well the person performed functions.

Did the communists successfully change public values and working culture? Richman (1963a) shows that employees in communist countries developed a sense of moral obligation to the state. A cross-national study by Stam, Verbakel \& De Graaf (2013) even reveals that work ethic with time became stronger in former communist countries than in western ones. The authors apply modernization theory to explain how the former communist countries share traditional conformity values, one of which is feeling a necessity to work, compared to socio-economically developed countries that instead emphasize post-modern values-for instance, self-expression. At the same time, it should be taken into account that believing everyone should work is not the same as working hard yourself. Thus, on the other hand, several authors (e.g. Lipset 1992, Neimanis 1997, Pucetaite \& Lamsa 2008) suggest that communist ideology negatively affected personal work effort, motivation, and productivity.

In one way or another, the culture in communist countries has been formed by the authorizing political environment for decades, and it is fair to assume that it will take decades to change it. Thus, the theoretical part of this chapter follows the Inglehart's (1990, 1997) "scarcity hypothesis," which argues that changes in values do not simultaneously occur with changes in socio-economic conditions, but values change gradually when older generations die out and younger generations take their place. 


\section{Motivation in Soviet Organization: From Management Intentions to}

\section{Workforce Responses}

The sections above overviewed the centralized authorizing environment created by the communist politicians and public values determined by the newly established system of institutions and organizational culture. Most important for the analyses of the individual motivation, however, is how the authorizing environment and public values influenced management intentions and actions, and workforce perception and responses, as well as organizational and employee outcomes in highly centralized communist states. Simply said, why would an individual work in a communist country?

Communist countries maintained high level of centralization of the state and of the organizations, which were mainly public. Under pressure from the authorizing communist environment, management needs in public service providing organizations had to align with the public values propagandized by the regime. As concluded from the previous section, those values would not necessarily coincide with the public service motivation of an employee. The previous research on individual work motivation in communist countries, indeed, reveals controversial findings. On the one hand, some studies recommend that the work ethic in the communists' settings with time became stronger in comparison to the western countries (Stam, Verbakel \& De Graaf 2013). On the other hand, several authors suggest that work effort of the soviet employees as well as their motivationand productivity were deteriorated by communist ideology (Lipset 1992, Neimanis 1997, Pucetaite \& Lamsa 2008). Assuming that the work culture and management practices absorbed pros and cons of the centrally-governed society, this section examines employees' reaction to how managers approached organizational and 
party needs, i.e. how the centralized managerial actions would curve work motivation in general, and PSM in particular.

On the basis of analyses of the historical evidence (reports and research articles), this section illuminates the "communist heritage" of the Eastern European workforce, and explores its origins applying the framework proposed by Vandenabeele et al. (2013). It stresses the importance of the administrative context and its particular characteristics that shaped work motivation and work outcomes in the public sector under the communist rule. The selected materials belong to different decades starting from the establishment of communism after the October Revolution in 1917 through the fall of the communist bloc in the 1990s, and they are analyzed to ascertain the factors that might have influenced individual motivation. The analyses reveal actions that managers undertook to meet a particular central government need, perception of these actions by employees, and-most importantly - the reaction in their motivation to work.

Need 1: Redirect/Eliminate Profit Motive. In order to eliminate profit motives, Soviet leadership applied various techniques. For instance, ubiquitous liquidation of successful individual farming known as "razkulachvanie" (also known as dekulakization) took place from 1929 to 1932 . Razkulachvanie was a campaign of political repressions, including arrests, deportations, and executions of millions of the wealthy peasants and their families, which were labeled kulaks and considered class enemies. From 1930-1931 alone, more than 1.8 million peasants were deported from their native villages and towns (Werth 1999). Simultaneously consolidating individual land and labor into collective farms, the stated purpose of the 'razkulachvanie' campaign was to establish centralized control over the agriculture sector and individual peasants. 
Other widely applied methods to reduce profit motives among the workforce were deportation of highly educated and entrepreneurial individuals to Siberia-or their execution. As entrepreneurial individuals were able to recognize that they had to be eliminated from the society, in the years following the revolution the remaining skilled and unionized European-style workforce had to emigrate abroad. The government constantly attacked those who stayed with propaganda aimed to suppress "economic" (i.e. rational) motives: "profit is a sin and to be rich is anti-social" (Schultz \& McFarland 1935, 289).

Workforce perception of administrative actions was determined by the boundaries of adaptability of human nature to the new environmental settings. The workforce negatively reacted to the governmental attempts to redirect monetary motivation, which could be explained by an "economic man" rooted in human nature as described in writings of John S. Mill, Adam Smith and David Ricardo. Workforce response is captured in a popular expression across the communist countries: "you pretend to pay, we pretend to work". In reality, the administration was successful only in redirecting the form, but not the substance, of an individual's enrichment strategy. Since employees were not allowed to discuss larger salary as a driving factor for choosing a career, successful individuals would choose between careers that provide more social benefits. Consequences for the quality of the workforce in Soviet organizations were detrimental. Lack of entrepreneurship underpinned work lethargy, shirking behavior became a widely accepted norm.

The effectiveness of propaganda was undermined by the fact that it was designed by politicians, not psychologists - so the methodology was inherently flawed (Schultz \& 
McFarland 1935). For example, communist propaganda was not intended to appeal to basic traits of human nature. The party found it easier to scare employees with the negative consequences of shirking rather than motivating them to work for the equivocal "common good." At the same time, despite the constant ideological tactics utilized in communist countries to bring employee behavior in line with the wishes of the state, material incentives remained the most prominent motivational force-discussed in future sections of this dissertation (Richman 1963b).

Need 2: Substitute Individual Competition by Group Competition. Originating from communist ideology, attempts to replace individual competition with group competition became another pervasive operational policy in Soviet enterprises. Propaganda would constantly encourage people to work for the "common betterment of the society" rather than for personal enrichment. Central and local governments would promote competitive atmosphere and request that senior managers demonstrate the superiority of their organizations: "between hospitals as to the efficiency and effectiveness of their work, and between schools as to the quality of their art, sculpturing, or handicrafts" (Schultz \& McFarland 1935, 289). The only question regarding personal motivation the management was interested in was how that motivation could be translated into improved organizational performance.

The substitution of competition skewed individuals' perceptions of their own psychological contract, since direct individual benefits became detached from the work completed. Depersonalization of success undermined individual abilities and desires to help others. Moreover, it negatively affected collective perceptions of management competence and its trustworthiness. Removing competition provoked distrust in 
government policies, which would punish ambitious employees: "Not only were individual efforts virtually unrewarded but any display of initiative could be dangerous. Forced labor camps nurtured a universal revolution for work among prisoners and guards alike. This "Gulag complex" eventually spilled over to grip the entire country." (Tidmarsh 1993,70)

The workforce reacted with a general indifference to work. Unable to compete with other employees in work-tasks, initially unambitious employees became even more discouraged to be creative or display initiative. A display of individual PSM or its constituent elements like self-sacrifice was condemned and remained unnoticed by management.

Need 3: Suppress Feelings of Class, Racial and Individual Differences and Superiority. Minimizing any feelings of superiority remained one of the key communist missions through the entire period of the regime's existence. Among other instruments, the government and management of public organizations pursued that goal through the equalitarianism in wages. In the Soviet Union in the late 1950s and early 1960s, the difference between the highest and lowest wage fell from 3.5 times to 1.5 times (Tidmarsh 1993). Thus and so, in workforce perception, wages lost their ability to be a material incentive.

Undertaking more responsibility at work was unrelated to increases in pay. Lack of opportunity to increase individual remuneration through career advancement played a destructive role in working-class professionalism (Tidmarsh 1993). Even though leverage in wages was already recognized as a dangerous movement in the 1930s (Schultz and McFarland 1935), it was practiced until the fall of the regime. After World War II, 
narrowing of pay differentials regardless of skill and output wiped out the last remains of the experts and specialists.

\section{Need 4: Replace Religious Concepts with Beliefs in Social Betterment and}

Certainty. The communists were able to successfully replace religious concepts with Marxist-Leninist ideology. Within the central government strategy, in addition to education and mass media, citizens were approached at their workplaces through the party and trade union channels (Richman 1963a).

Soviet HR specialists ensured that the ideology would penetrate every moment of an employee's life. Numerous meetings and conventions devoted to communism indoctrination - collective newspaper readings and similar activities - took place directly at jobsites.

The main tool remained ubiquitous propaganda: work ethic was proclaimed a moral duty for all persons in society (Stam, Verbakel \& De Graaf 2013). Richman (1963a) mentions ideology indoctrination as one of the three most important motivational devices widely used in communist countries.

Collective workforce perception of management competence and trustworthiness of the strategies pursued by the party especially increased after the Soviet victory in World War II. Employees in communist countries developed a sense of moral obligation to the state and had considerable pride in their country and progress (Richman 1963a). In this situation, public service motivation should have increased together with raised popular enthusiasm in the face of hardships (Stam, Verbakel \& De Graaf 2013).Even today, former communist countries share traditional conformity values, one of which is feeling a necessity to work, compared to socio-economically developed countries that 
instead emphasize post-modern values-for instance, self-expression (Stam, Verbakel \& De Graaf 2013).

In terms of organizational and employee outcomes, the literature suggests a positive influence of propaganda of collective "building of a brighter future" on employees' commitment and job satisfaction (Richman 1963a). That was especially visible after World War II and the Era of Stagnation-or Brezhnevian Stagnation-a period of economic, political, and social stagnation in the Soviet Union that began during the rule of Leonid Brezhnev and lasted till Gorbachev's perestroika. At the same time, there is a lack of reliable records of public service performance improvement. Moreover, it should be taken into account that making citizens believe that everyone should work is not the same as making them work hard (Stam, Verbakel \& De Graaf 2013).

Need 5: Assure Highly Productive Workforce, Encourage Greater Effort. As an HR strategy pursued by any other regime, the communist plan of action was equally aiming to build ability, motivation, and opportunity to perform for employees. However, through the long history of communist domination, to achieve these goals, the Soviet administration would often use techniques that were quite antithetical to their ideological principles. Initially, the direct actions of management were within the classic communist techniques. It was against the party's ideology to openly advertise individual monetary benefits as a reward for hard work. While in Western countries, capitalism emphasized individual competition and the profit system with individual rewards, in Soviet systems, salary could not be claimed as the main motivator to work.

In order to improve individual and group performance, enterprise managers would create a competitive atmosphere of "who works harder," simultaneously bringing social 
attention to those who fell back: "In factories and even in scientific institutes the workers' names may be posted on a bulletin board opposite to a bird, deer, rabbit, tortoise, or snail relative to the speed with which they turn out their work" (Schultz \& McFarland 1935, 289).

However, the communist countries encountered severe difficulties in obtaining desired results when they utilized purely communist incentives. Adherence to Communist ideology and the difficulties encountered in developing an integrated and workable plan led to serious operational problems. The 1950 s were marked by the ineffective performance of managers of industrial enterprises, which resulted from the overall defective economic, cultural, and institutional environment (Richman 1963b). Undesirable managerial behavior was not a question of incompetence, but rather the framework in which the manager had to operate.

The government recognized the importance of capitalist techniques with the special attention to them after World War II. Surprising to the capitalist observer, the communist administration widely used monetary incentives to encourage greater effort (Richman 1963a). High level of performance, as communists' leaders would advocate, should be rewarded with more pay. Both Lenin and Stalin emphasized the significance of material self-interest and both asserted that moral incentive is not enough (Ekonomicheskaya Gazeta 1962). Another leader, Khrushchev also emphasized that it was wrong to oppose material incentives to moral ones, because they are strongly linked: "We should remember V. I. Lenin's directive that we be able, if necessary, to learn from the capitalists, to adopt whatever they have that is sensible and advantageous" (N.S. 
Khrushchev in the newspaper Pravda, November 20th, 1962, as quoted by Richman 1963a).

In order to encourage managerial behavior to suit the changing economic conditions, the government had to modify the "rules of the game" for enterprise managers. The Soviets started to ubiquitously utilize monetary incentives as a key motivation device. Monetary compensation for work took two basic forms: (1) wages and bonuses linked to performance, (2) remuneration linked to the profits derived from employees' implemented suggestions (Richman 1963b). In 1959, the Soviet Union introduced "success indicator" reform. The premiums were now awarded not solely for the gross output, but, for instance, for the assortment indices, quality, and product and service delivery schedules. As for remuneration suggested by employees, yet still related to payroll, it was to encourage employees to participate in planning and decision making. It partly balanced the dysfunctions of general monetary based incentive schemes, because in addition to the salary bonus, it encouraged employees through the public recognition of their work and the prestige that came with such recognition.

Workforce perception of management actions should have been extremely positive: employees were finally able to receive public recognition of their work and the prestige that came with it (Richman 1963b). That incentive should have increased overall motivation to perform assigned tasks. However, the general dysfunctions of monetary based incentive schemes created obstacles for improved motivation: in the absence of a market-price mechanism, capitalistic profit motivators only blocked efficient resource utilization and the satisfaction of citizens' needs and demands (Richman 1963b). Optimistic Richman's (1963b) anticipations that in the long run the communist and 
capitalist systems might become more similar were condemned to failure, because the negative effects caused by the lack of the free market were further intensified by early mentioned payment equalitarianism and elimination of profit-motivated individuals. Moreover, in reality, the capitalist techniques were introduced at only relatively few enterprises (Richman, 1963b). As a result, personal motivation, work effort and productivity were further undermined by the communist ideology (Lipset 1992, Neimanis 1997, Pucetaite \& Lamsa 2008).

Need 6: Establish Centralization of Command. To maintain its power, the Communist Party had to assure subordination on every level of society. Everything was determined by the regulations, rules, directions, and plans of the party-ranging from what type of clothes people should wear to where they should spend their vacations.

To establish absolute control, centrally planned economies pay a special attention to coordination and enforcement of production goals (Smith \& Gronbjerg 2006, 223). One of the ways for the communist regime to achieve absolute control was to reject the market-price system. In the communist countries the suppliers and quantities of goods and services were determined not by the need, but by the plan. Because alternative sources of the supply did not exist, it negatively affected the behavior of managers with positions that were highly dependent on compulsory plan fulfillment: "the manager often had to obtain supplies through bribery, personal influence or by whatever illegal means he could" (Richman 1963b).

Another direct action of the Soviet administration that aimed to strengthen the centralization of command was the liquidation of horizontal links among professionals and other groups. 
The party understood that the role of civil society-associations, clubs, unions, churches-is to sustain and mobilize political opposition under authoritarian rule (Clemens 2006, 210), and thus, all civil institutions in Communist societies remained controlled by and closely identified with the state (Mishler \& Rose 1997). Nongovernmental organizations - for instance, independent trade unions - were placed under the strong subordination of the party and re-obtained their autonomous status only after the fall of the regime. In the 1980s, the Polish case confirmed the party's fears about the resisting and conflictive role that labor unions could play in the fall of the communist regime.

The system of incorrect work indices based on plan fulfillment caused conflict between morality and material incentives related to performance standards, which was openly acknowledged by the state mass media (Richman 1963a). Moreover, neither able to influence centralized plans through the civil society organizations nor having an opportunity to stop working for the system (see Need 7 further in the section), fear and overall sense of helplessness confronting the party dominated collective perceptions of the organizations' management.

Affecting organizational and employee outcomes, the centralization of command placed institutions and individuals employed in them in constant competition for limited facilities and resources, while they would shirkany nobler goal or motivation (Tidmarsh 1993).

Need 7: Provide Full Employment. As mentioned in the previous subsection, communist countries operated under a planned command economy, which also entailed guaranteed full employment. Through numerous propaganda channels, the government 
aimed to build an understanding that work was considered the most honored activity (Ardichvili 2009). At the same time, unemployment was labeled as 'parasitism' (Aslund 2007).

In individuals' perceptions of their own psychological contract, a physical presence at work became more important than the results of work. Without having an option to wait, individuals had to accept positions well below their professional capabilities, which had a strong demotivating effect on the desire to provide high quality products and services.

As a result of the full employment policy, some studies show that just before the fall of the communist system, more than half of unskilled jobs were filled by workers with more than obligatory primary schooling (Tirmarsh 1993).

Need 8: Low-Wage, Low-Skilled, and Low-Productivity Workers. A labor policy depending on low-wage, low-productivity employment tends to require low skills and low education. However, in reality, governmental and management actions would go against operational needs. Within the established public values, learning was promoted as a crucial part of the building of communism. Corresponding to a famous Lenin motto in Soviet countries - "Eat, sleep and breathe studying" — higher education establishments would admit even more students than there were positions at job sites. Thus, the paradox is that the well developed and structured education system in communist countries was producing a larger number of skilled workers than needed.

The paradox directly affected individual attitudes toward work. Once out of school, individuals would have to accept positions well below their professional capabilities. The workforce found itself possessing high abilities but lacking 
opportunities for career advancement in the obtained profession-a situation, which had a strong depressing effect on individual motivation to perform within the production industries and to help others within the service industries. An overqualified workforce was discouraged by the prospect of being stuck performing low grade tasks until the end of their careers. Tirmarsh (1993) points out that the absurd mismatch in the number of professionals educated and the number of positions available was particularly striking in the medical service sector, where government costs to educate an employee were particularly high.

\section{PSM in the Centralized Soviet System}

If democracy is a necessary determinant of public service motivation (Vandenabeele \& Van de Walle 2008, Vandenabeele 2008), did public sector employees during the Soviet era feel no moral obligation to work for their people? Is it possible that employees of the ubiquitous public sector in the communism-led society were public service motivated? Contemporary studies show variation in motivation levels across different political parties (Pedersen 2014). In democratic societies, the variation is natural and can be explained by differences in party policy agendas: a person has the right to choose whether to belong to a political party and if yes to which one. The communist regime was marked by the lack of choice: individuals were only exposed to the Communist Party, and membership did not necessarily mean sharing entire list of communist values. Yet, in the communist one-party system a person might have participated without supporting it or even having contrary beliefs. Not everybody in the system was faithful to the ideals of the party. This is evidenced, for instance, by the constant emergence of "enemies of the people" within the system. Because support for 
the system and the party's values and approaches was not universal, it is natural that some individuals were devoted to moral democratic ideals.

Very often, employees would not articulate their personal beliefs and values publicly, but in private conversations, they showed their hesitations about the properness of party values. The doubts were especially strong in countries "occupied by Russians," like Belarus or Poland. Doubts were not openly expressed, not only because of fear of being sent to Siberia or executed, but also due to regime loyalty as one of the public values "in the constellation of values associated with the behavior of a public servant" (Jorgensen \& Bozeman 2007).

Stating that "there were no PSM in the communist countries" would be equal to stating "there were no professionals at all." Tidmarsh (1993) indeed points out that communist countries were characterized by the breach of professional traditions. Does this mean the absolute absence of professionals devoted to the code of values that comes with their job? Were the professionals in social work or education serving the regime or the public? A professional is someone who does a job that requires special training, education, or skill and who is guided by specific knowledge and a set of values related to that particular job. For example, a professional attorney should defend a client and a professional doctor should provide medical help to a suffering person (as a part of the Hippocratic Oath, at least), etc. While the communist system provided very good professional education and training, the professionals enjoyed very limited freedom to independently practice obtained skills.

Communist countries were not the ideal place for narrowly qualified professionals. Advanced mastery of any kind meant an ability to be independent and, thus, was not 
highly valued by the one-party system. What attitude toward highly educated professionals would you expect in a country of "workers and peasants"? Yet, it does not mean that there were no professionals, because the country would not function without them. Previous research shows that communist countries had competent individuals, but they were not able to perform effectively within the framework established by the government (Richman 1963b). The professionals were overused and underpaid, sometimes performing imposed duties that were contrary to their individual moral beliefs, usually under the pressure of threats. In the context of limited freedoms, talented individuals were not able to refuse the party's requests. For example, the fact that a famous Belarus sculptor Zair Azgur created hundreds of statuaries of Lenin and Stalin, and was even invited to create a sculpture of Mao Zedong, does not necessarily mean he

was fascinated by the ideas of these leaders. Sculpting them, however, was the only way to stay in the profession, to have access to the work materials, and to have an art studio (Belsat 2010).

\section{Motivation after the Fall of Communism}

After the fall of the communism, production industries and public service providing organizations had to transition into a market economy. In addition to internal organization problems — such as lack of capital, resource shortages, prohibitive costs of needed technology and equipment-employees of public and newly established nonprofits faced the necessity to change work values. While under the former regime, the main goal of public organizations was to satisfy requirements of the party, the challenge of the 1990s became to find ways to meet the needs of citizens. 
Luthans et al. (2000) show that the legacy of communist ideology per se was not a problem, and refer to China's case as an example. The difficulties in changing the work motivation occurred more likely because of complex cultural issues, which resulted from the ways communist ideology was implemented in practice. The work culture in modern Poland and Belarus is not driven purely by individual values and morality, but rather results from complex factors that were in place for decades in those countries under the communist regime. These factors consist of a malfunctioning system of appraisals, rewards, and salaries not connected to the complexity of the tasks performed, propaganda, and discouragement of individual competition, while emphasizing group competition (e.g., norms, five-year plans).

The impact of the Soviet regime on public servants was to a certain extent destructive: "For three generations a negative selection process systematically weeded out workers of the greatest drive, know-how and resilience, giving rise to a pervasive, cowed apathy and scheming work ethic, with the liveliest initiatives directed at seeking maximum personal gain with a minimum expenditure of effort" (Tidmarsh 1993, 67).

Soviet communism has left a demoralized and low individual PSM culture, which after the fall of the regime started to change, given the fact that capitalistic novelties made individuals value individualism (Trompenaars 1995). Employees’ work motivation reflected a new-found entrepreneurial spirit (Luthans et al. 2000).

In the mid-1990s, studies of former Soviet countries showed that individuals in general are depicted as being high in power distance (acceptance of authority), uncertainty avoidance (value security), collectivism (value group membership) and feminity (care for others, low stress), and having a short time perspective (Puffer 1994). 
Contrary, Trompenaars (1995) found that the former Soviet countries were high on individualism, meaning that people in these countries tend to look after themselves and their immediate family and expect others to do the same. They do not feel responsible for the welfare of the group, like in case of communitarians.

Contextual factors of the communist environment continue to shape motivation of public service providers in public and nonprofit sectors. Work culture in countries from the former Soviet bloc reflects former Soviet norms to a large extent. For example, it is still considered socially acceptable to not work, but still receive pay. This state of values that came as a communist heritage is shared with the younger generation, which was raised after the fall of the regime. In everyday conversation, young employees emphasize how little they work and how many breaks they could take, and mention different possibilities to avoid performing their duties. A popular expression "rabotka ne pylnaja" (literary, "the job is not dusty" meaning it does not require a lot of effort) is a good description of the "ideal" job place.

Another communist characteristic inherited by the current job market is the preference of "protégé" over an individual with proper qualifications. The system of "making connections" or "networking" is equally suitable to the Western world. The main difference in the Soviet style "protégé" is that a person might not possess any proper qualifications, but would be recommended anyway. The recommendation overshadows any qualification deficits in the prospective employee, which, as commonly believed, can be obtained at the work place.

Luthans et al. (2000) claim that individual employee motivation in former Soviet countries must still be changed. The Soviet framework of labor-management relations 
was not eliminated in the collapse of the communist system: "it is [was] not easy for these people to grasp that the market mechanism does not function by the planners' fiat and that new methods of consultation and remuneration are needed to motivate an inert labor force" (Tirmarsh 1993, 75). For instance, in Belarus, many jobs in public sector services still apply a lavish bonus system not related to performance as the main motivator to perform duties. In Belarus, monthly salary bonus in the health, education, or the militia (Belarusian version of the police) often equals the amount of the base salary itself. This misbalance between salary and bonuses negatively influences the system of work values of an employee. Employees develop a sense that their work costs little, but due to the generosity of the supervisors or the president (e.g. special presidential bonuses) an employee can survive.

Public services suffer from the lack of work culture, Soviet attitudes about work, and undeveloped human relations, which take generations to nurture. The process of change is slowed by employees' inertness, caused by decades of Soviet rule; employees became accustomed to the fact that the responsibility taken from them and delegated to the administration of the state. A survey among 120 workers in industrial establishments showed that they perceived their material improvement would not come due to any change in their own motivation but rather as the result of some administrative action taken by the state: "The institutional change alone will not suffice to extricate millions of ... workers from the mind-set created by many years of subordination to communalist and command systems" (Tidmarsh 1993, 76-77).

This chapter provided some evidence that individual motivation to work and management practices had to adjust to the centralized authorizing environment in the 
country. The question for the empirical part of the dissertation is to test whether the high centralization level of the past continues to shape motivation of public service employees in today's Central and Eastern Europe: after the decentralization reforms in Poland and after strengthening of centralization in Belarus. Taking in the consideration the humanistic idea of the nonprofit sector, another question is whether the nonprofit sector became the retreat for the individuals with a high PSM level that were not able to selfrealize their pro-social motives in the overwhelming public sector of the communist system, or whether it occurred just an opportunity to utilize EU funds as in the case of Poland or to confront the government as in the case of Belarus.

In short, the review of the literature allows for the conclusion that PSM levels within the same sectors might differ depending on the type of administrative system. Based on the above, the first hypothesis of this dissertation is formulated as follows:

Hypothesis 1: The centralization level of the government affects PSM of the individuals involved in public service provision.

\section{Conclusion}

The communist evidence provided in this chapter suggests that the centralization of the state and the centralization of the organization might determine individual work motivation in the public sector to a great extent. The chapter approached organizations in centralized systems with the following questions: how do organizational actors make sense of public values established by the centralized government? How do organizational actors manage the multiplicity of these values, potential tensions, and their responsibilities to the public domain? How do organizations manage to follow centralized rules, while meeting citizens' demands? 
The review of the selected articles and reports suggests that malfunctions of communist motivation system were caused by the discordance between management intentions and management actions. While ensuring full employment, HR strategy aimed to raise motivation and create an opportunity to perform within the communist ideology. Managers' difficult mission was to eliminate the profit motive, substitute individual competition with group competition, suppress feelings of individual superiority by equalizing pay among high and low-skilled employees, replace religious concepts with beliefs in social betterment, and yet, encourage greater effort at the workplace.

Yet, direct actions of the communist administration at both governmental and organizational levels led to the liquidation of entrepreneurial individuals and discouraging detachment of individual benefits from the work completed. The workforce developed a sense of helplessness confronting the party and realization that presence at work was more important than the results or work. Dysfunctions of monetary based incentive schemes caused overwhelming work lethargy with shirking employees, discouraged from being creative or displaying initiative.

The chapter concludes with examples of how the inherited work attitude continues to influence employee motivation after the fall of the communism. It also suggests that the newly emerged nonprofit sector might have become an employment solution for highly motivated individuals - the hypothesis that will be further tested in the empirical part of the dissertation. 


\section{CHAPTER 3: NONPROFIT SECTOR AS A NEW PHENOMENON IN}

\section{CENTRAL AND EASTERN EUROPE}

In times when civil society organizations become the principal structures of decentralized governance and public administration, successful public service provision depends on an effectual dialogue between the public and nonprofit sectors. Cooperation between local governments and nonprofit organizations nurtures fresh solutions, unlocks new potential, and provides innovative services that meet dynamic needs. Yet, is an efficient dialogue even possible if employees of these organizations are motivated by different reasons? Could they indeed work together to solve social issues? In former communist countries, prior to encouraging nonprofit-public partnerships at the institutional level, we must check whether dialogue is achievable at the organizational and individual levels. Do employees of different pro-social sectors share similar public values and possess the same motivation to tackle social problems?

The previous chapter analyzed working attitudes in communist countries, and revealed how the highly centralized regime determined individual motivation. Meanwhile, this chapter is devoted to the motivation of current employees of public and nonprofit sectors, who grew up and — for the majority of their lifetimes—-worked during the gradual collapse of communism and in the post-Soviet environment of the 1990s and 2000s. Were employees in both sectors able to absorb Western democratic values and equally incorporate them in their working patterns? Does the centralization level of the current government determine the motivation of employees in public and nonprofit organizations? Prior to being able to answer these questions empirically, the existing literature on the motivation to serve society must be reviewed in light of how sector 
affiliation and the centralization of the government determine this motivation. This chapter serves this purpose by analyzing the existing literature along two hypotheses

Hypothesis 2: In former communist countries, nonprofit sector employees will exhibit higher levels of PSM than their public sector counterparts; and

Hypothesis 3: The level of government centralization intensifies the sectoral differences in degree of PSM.

The chapter proceeds as follows. The first section provides a historical overview of the nonprofit sectors in Poland and Belarus and sets the context for further debating whether nonprofits became a new institutional formation for highly motivated individuals. The second section narrows the broad scope of civil society and nonprofit organizations, defining the particular type of nonprofits to be analyzed in the study. Subsequently, public values in the newly established nonprofits in post-communist countries are discussed, serving as an introduction to the comparative analyses of the public service motivation in the public versus nonprofit sectors. The last section examines to the centralization and decentralization of government as a factor that can undermine both civil dialogue between sectors and public service motivation in each of them.

\section{Nonprofit Sector as a New Phenomenon in Central and Eastern Europe}

The nonprofit sectors in Poland and Belarus drastically differ from American nonprofits in their origins, functions, and scope. The main difference lies in the direction of causality in establishing the democratic regime and the subsequent introduction of the nonprofit sector itself. In the United States, the strongly developed nonprofit sector to a great extent preconditioned democracy (Chimiak 2006). Although the concept of 
"nonprofit organizations" dates back only to the 1970s, charitable and educational organizations have been functioning in the United States since colonial times: "Philanthropy and volunteer service—giving money and time-were also features of early American life" (Dobkin 2011, 4). With varying degrees of success in different states, nonprofit organizations ubiquitously spread around the country and played an important role in the American Revolution. In the early nineteenth century, New England states became national centers for education, culture, and science mainly due to the strong support for nonprofit colleges, hospitals, libraries, and museums via the flourishing economy (Dobkin 2011).

Milestones in establishing the American democracy were achieved while this country already had a developed and active nonprofit sector in the background. Contrary to the United States, to build new functioning democracies, the former communist countries had to develop a functioning nonprofit sector after gaining independence: they had to ensure that civic initiatives would reflect other purposes than the movements for liberation (Chimiak 2006).

It cannot be said that the nonprofit sector was completely suppressed by the communist regime in the past. On the contrary, the regime supported certain types of civil institutions, insuring that they were thoroughly controlled and closely identified with the state (Mishler and Rose 1997). Organizations founded by the state administration and the party were called to complete the tasks of the latter and to promote its ideals. While some organizations resembled Western nonprofits only to a certain extent (like the Western Boy Scouts and Soviet Pioneers), others fully corresponded to organizations operating in 
the West. Examples of the latter are some small-scale philanthropic organizations and hobby or sports groups (Chimiak 2006).

The reorganization of the economy, for instance, transitioning from a central planning to a competitive market and vice versa, comes with a significant change in the relations between the government and the nonprofit sector. In order to survive, the old nonprofits had to adjust to the new governmental activities and to the mechanisms the government applies to carry out its policies (Smith and Gronbjerg 2006). In most of the cases, new nonprofit organizations emerged for those purposes. The liberalization of the 1990s allowed for buying and selling state property. While some public service providers indeed became privatized, others changed their re-registered as nonprofit organizations. For workers with an entrepreneurial spirit, creating organizations became an option that would provide self-employment, which was a new form of activity unknown/illegal before. For those highly motivated to help others and society, but still entrepreneurial enough to create an organization from scratch, the new political system offered a special sector: the nonprofit sector. Thus, newly emerged nonprofits gathered people willing to help others or to fight a particular social problem, especially if it had not been addressed by the communist system (e.g., special assistance for individuals with Down Syndrome, elderly care, educational courses for the entrepreneurial, adjustments to the job market, requalification, etc.). In addition to the development of new initiatives, the introduction of certain democratic rules and freedoms also caused widespread initialization of the selforganized groups, which operated clandestinely before (Chimiak 2006). Therefore, it was after 1989 that civil society could begin fully developing in Poland and Belarus, often 
with the support of foreign governments or international organizations ${ }^{1}$ (for Poland: Kurczewski, Dzieniszewska-Naroska, Laciak, Smigielska \& Zakrzewski 2000).

At least from the human resources perspective, both public and nonprofit organizations in modern Poland and Belarus have originated from the public sector. For some representatives of the younger generation born in the late 1970s and in the 1980s, nonprofit work could have been their first and only job. However, the majority of the workforce consisted of an older generation that experienced "work transition" from public organizations to the newly created nonprofits. Both voluntary and involuntary transitions from the public into the nonprofit sector took place in the former communist countries (Fouad \& Bynner 2008). As for voluntary transition, individuals believed that nonprofits fit better individual motivation and needs, whereas, involuntary transitions occurred when public employees were forced to leave the public service sector, for instance, due to their political beliefs. They would have to continue their work through the "nonprofits." For example, one such person was a former docent at the Public University of Hrodna in Belarus, Dr. Aliaskandr Milinkevich, who also served as a deputy mayor of Hrodna City. After losing in the presidential election of 2006, where he ran as a candidate of the united opposition, together with the like-minded, he launched the Republican civil union "Movement for Freedom". The organization became the civil union of democratic forces in Belarus, which Milinkevich has since chaired.

\footnotetext{
${ }^{1}$ Many service-providing nonprofits were established with the help of foreign nonprofit organizations or with the support of foreign governments or international organizations. For instance, the Swedish or the Germans would come to Belarus or Poland to assist a startup of a service providing nonprofit and to facilitate its further development. Here, international learning from foreign practices took on an important role, because it brought not only the funds and established a management system for such novel organizations in the former Soviet context, but also implanted a system of values and motivation as reasoning for the organizations to function.
} 
Contrary to the United States, where nonprofits possess a high degree of publicness, in Europe, the public and nonprofit are seen as distinct sectors (Steen 2008). The United States has a greater tradition of voluntary associations and communities providing public services (Steen 2008). Citizens of Belarus and Poland view the government as a main provider of the public services, while private service providers such as educational or health institutions are viewed as complementary. Yet, these countries share characteristics of the European welfare state to different extents.

Even though there was a democratic movement toward decentralization in the beginning of the 1990s, Belarus reverted back to the highly-centralized governmental system. Today, the government of this country is known among its neighbors as having a strong welfare state approach that also shapes the nature of institutional relations and determines the scope and the types of the nonprofit organizations present in the country. Even though the Belarusian government relatively eased some pressure on civil society groups after 2012, the number of registered organizations remains relatively low when compared to the neighboring Poland: in 2012, there were 2,477 nongovernmental organizations registered in Belarus, including 229 international, 688 national, and 1,560 local organizations. In addition, there were 31 associations of nonprofit organizations and 139 foundations (United States Agency for International Development, 2012).

As the research of DiMaggio and Powell (1983) suggests, societies dominated by large bureaucratic institutions may favor a nonprofit sector that operates with similar structures. Their proposition explains why in Belarus, the nonprofit sector is dominated by larger pro-governmental political entities. For instance, Belaya Rus (Belarusian for "White Ruthenia") is a Belarusian public association with a membership of over 130,000 
founded in 2007 to support President Alexander Lukashenko. It is based on the ideals of Vladimir Putin's United Russia Party, but is registered as a nonprofit organization. Another example of a successful nonprofit organization in Belarus is the Belarusian Republican Youth Union (in Belarusian: BRSM), which is a youth organization aimed to promote patriotism and to instill moral values into the youth of Belarus. The BRSM is the largest youth group in Belarus (from different sources: membership is more than 100,000) and is strongly supported by the Belarusian government. In 2011, the organization absorbed $98 \%$ of the funds allocated by the state for youth policy (Belsat 2011). Both BRSM and Belaya Rus emerged from former Soviet organizations and the government remains the main source of financing.

Both organizations mentioned above mainly perform political functions and, thus, have a good justification to receive financial supported from the government. Yet, funding situation differs greatly for the nonprofit organizations, whose primarily goal is to fight social problems. The question of their funding sources remains difficult to answer, because such nonprofit organizations are often reluctant to reveal their funding sources for security reasons. A former chair of a Belarusian human rights center - an organization that provided free legal services - Ales Bialatski spent three years in prison after he was arrested under charges of tax evasion of foreign funds for his nongovernmental organization. Meanwhile in the interviews, nonprofit leaders usually refer to international private sponsors and institutions, which would financially support ethics related projects. Since the international donors are not able to directly cooperate with the government, they work through the nonprofit organizations. Therefore, there is some supportive evidence to assume that a lot of the Belarusian nonprofit projects are 
funded by private international donors. Another source of funding frequently used in the nonprofit sector in Belarus is membership fees of the organization participants. In addition, in such organizations, members often work on the projects volunteeringly and the money resources gathered from the fees usually are used for the statutory expenses, as for example, a rent of an office space.

The scope of nonprofit projects largely depends on the type of funding the projects could receive and also whether they are welcomed by the national government. The latter is not always the case in Belarus. While the demand of the Belarusian population for constant social care grows, some areas, for instance psychological assistance for the elderly, remain highly neglected by the public sector. Belarusian nonprofits run their own projects on the side of the government. Nonprofit also have to be project initiators, because due to the long established culture rooted in the Soviet past and a current lack of relations between public and independent nonprofit sector, the Belarusian public administration sees contracting the nonprofits for governmental projects as unacceptable. Thus, continuing the Soviet tradition, the current Belarusian government takes skeptical attitudes toward the development of an independent nonprofit sector. Small-scale local nonprofits funded from abroad are often seen as anti-governmental organizations, even if they have no political agenda and their only function is to provide services. Larger national pro-social nonprofits - for instance, those that assist elderly people, individuals with disabilities, or war veterans - must mainly rely on membership fees and corporate fundraising, while they are left without any governmental support or subsidies. The information about their projects is not publicly distributed; their activities are not 
advertised. An average Belarusian has limited knowledge about these organizations, unless the person is in need of assistance and therefore, tries to establish contact.

At the same time, advocacy nonprofits and the movements for liberation became the most visible organizations in the independent nonprofit arena - after Belarus returned to the authoritarian style of administration. For example, an umbrella institution for the nongovernmental (NGO) democratic organizations in Belarus named an "Assembly of NGOs" has 300 member-organizations, which constitute the majority of pro-democratic NGOs and advocacy groups active in Belarus (NDA Assembly 2014).

The unfavorable situation of Belarusian independent service providers is typical for strongly centralized authoritarian states, where nondemocratic regimes are usually suspicious of an independent nonprofit sector. For example in a centralized regime in China, clearly humanistic and liberal undertone of social work practice has posed a potential threat to the Communist Party of China in its capability to manipulate social work to its own advantages (Leung et al. 2012).

In contrast to Belarus, after the fall of the communist regime, Poland took a steady path toward decentralization. For the purposes of cooperation and further integration with the European Union (EU) in the 1990s, Poland undertook a number of decentralization reforms aiming to harmonize its political and administrative system with EU regulations. These steps are also consistent with the welfare pluralism approach, whereacknowledging complexity and interdependence of social problems - the state actively collaborates with society to find solutions to these problems (e.g. Mendoza 1995).

Social, political, and economic changes in Poland affected the nonprofit sector, which advanced through several stages after the fall of communism. Initially, different 
international actors, for example, the World Bank and the national Soros Foundation, supported various nonprofit activities. Despite the well-established position of some foreign donor organizations, after joining the European Union in 2004, Poland has advanced beyond the stage where its nonprofits were mainly financed from abroad, typically from the United States (Pastwa 2014).

Even with the changes in the financing scheme and an elaborate bureaucratic registration process that favors larger organizations, the number of the third sector organizations in Poland remains very high with the total of more than 200 registered civil society organizations, 114,000 associations, and 14,000 foundations (Sustainability Index 2012). These organizations operate with a fair degree of independence and management flexibility. The external actors, mainly the EU, continue to facilitate their dialogue with the government. Assuring a positive environment for coalitions as recommended by the European Commission's Strategy 2020, the government has to accept the role of nongovernmental actors as a partner. Numerous networks are active in this comprehensive socio-economic EU initiative: as for 2012, some 250 organizations joined to support these goals and in close cooperation with government devised plans for programming, monitoring and assessment of a variety of programs. An interesting development has been the creation of civil society organizations' support and resource centers in both urban and rural areas.

As the literature suggests, societies dominated by large bureaucratic institutions may provide organizational space for those that serve as mediators between the individual and other impersonal, formal structures (e.g. Berger and Neuhaus 1977, Van Til 2008). In the case of Poland, the EU became a large bureaucratic institution that among other 
channels to implement its policies works through the nonprofit sectors of the membercountries. EU membership opened doors to EU money available through various social funds and programs, but it also changed the face of this sector. Funds from the international development organizations became limited or were substituted by the internal EU funds. The smartest NGOs were able to convert their financing scheme, while others just expired (Pastwa 2014).

Several scholars and experts emphasize that during the last decade, the nonprofit sector in Poland has experienced a thorough transformation. On the one hand, the nonprofit sector in Poland became more institutionalized and mature and now attracts another kind of individuals than those who founded the first nonprofit organizations (Chimiak 2006, Kazanecki 2014). Polish public administration scholars and practitioners admit that nonprofit organizations in Poland can be more open and more sensitive to these issues, and that they have a better understanding of the problems surrounding public administration and society (Wenclik 2014, Pastwa 2014).

On the other hand, the nonprofit sector does not always complement the public sector in addressing social issues. EU funds that are equally available for public and nonprofit organizations made these sectors competitors for the resources. In Poland, the funds from various EU programs are often open for government and self-government administration, entrepreneurs, businesses, nongovernmental organizations, and educational and higher education institutions. Participation of the organizations other than public administration might indicate the existing demand for government improvements coming from the citizens, but also might also represent artificially created demand coming from the nonprofit organizations in their pursuit of profit maximization. 
Thus, a great number of service providing nonprofits emerges due to the availability of EU funds when Polish entrepreneurs see nonprofits as an employment opportunity. As a result, numerous nonprofits materialize with the support-and for the utilization - of EU funds. Polish experts argue that a great number of nonprofit organizations are led by their profit maximization, rather than noble ideas to improve society. Often, the missions of such organizations are short-term. In his interview, a Polish civil servant and diplomat, currently the president of the National School of Public Administration, Jan Pastwa (2014), revealed the details of a popular Polish scheme to create a nonprofit organization namely, to establish a "bush" company (in Polish: firmakrszak). Such an organization is created for a one particular contract and is usually closed or transformed into another company afterward. Having well prepared documentation, this company wins the contract for a particular project. Afterwards, for the purpose of this procurement, the company seeks an additional grant to pay its employees and usually seeks available EU resources.

\section{Working Definition of Nonprofit Organization}

Various definitions of nonprofit organizations reflect different types of activities and purposes of the organizations that constitute this sector. This subsection narrows the scope and provides the definition of nonprofit organization that will be used in the further analyses of this study.

First, this study concerns the nonprofit organizations that promote non-political and non-religious values (Salamon and Anheier 1994). Second, this study put a special emphasis on the function performed by an organization. The study focuses on civil 
society organizations that have a service providing function. Thus, it excludes voluntary organizations such as research and advocacy organizations, self-help groups, clubs and societies for leisure interests, intermediary bodies, political parties, and trade unions (Handy 1998). Engagement in the organizations, which is the focus of this research, allows active citizens to pursue goals that they share with similar-minded fellow citizens (Chimiak 2006). Furthermore, the beneficiary of the concerned organizations can be an individual who is not necessarily a member of these organizations.

Another important characteristic for this study is that nonprofit organizations must offer a service that is also alternatively provided by the government. Because of the necessity to have a comparable sample of organizations across Belarus and Poland, the research mainly focuses on nonprofits that are equally present in both countries-those fostering biological and social development and those that prepare beneficiaries to perform social and vocational roles (Zaluska 1996) ${ }^{2}$. The research focuses on nonprofit organizations that operate to improve the common public good rather than those with a narrowly defined group interest, such as associations formed on the basis of shared hobbies. Umbrella nonprofit organizations are also excluded from the analyses because they do not work directly with beneficiaries.

Nonprofit activities in Poland are not limited to supporting the poor, healing the sick, and educating the unemployed (Chimiak 2006). Yet, nonprofit organizations usually take over the tasks of the welfare state, and therefore this sector is usually perceived as

\footnotetext{
${ }^{2}$ M. Zaluska (1996) names the following functions of nonprofit organizations: fostering biological, social, and cultural development of the individual; enriching human life, distributing knowledge and embodying the idea of democracy; preparing its members or beneficiaries to perform social and vocational roles.
} 
only consisting of such organizations. The current study also focuses on the traditional welfare functions of the nonprofits, because these organizations will be compared to the governmental entities providing similar services. As for the Belarusian nonprofit sector, this study will consider independent small-scale nonprofits, which provide public services and which are more comparable to nonprofits in Poland.

An important concept in this study is civil society that refers to individuals involved in the betterment of society. Civil society is broader than the nonprofit sector and includes individuals that can be employed in any sector. For instance in Poland, where civil society is quite developed, a number of civil society activists are currently employed in the public sector, came from the public sector, or switched to the public sector from the nonprofit sector. The phenomenon of switching the sector of employment is especially visible at the local level because in Poland, the nonprofit sector together with the local self-government constitutes the two basic pillars of civil society (Sicinski 1999, Kazanecki 2014). The civil society in Belarus is in its initial formation stage, where a new generation of public service and local government employees begin to slowly realize the benefits of cross-sector cooperation.

Public Values in Newly Established Nonprofit Organizations: External and

\section{Internal Factors}

In the 1990s, Helmut Anheier (1995) noticed that nonprofit organizations perform an important function in a country's development process, both in terms of their advocacy roles and in their capacities as service providers, that they became major actors in the international system of development assistance. The question remains as to what type of development these organizations bring. While the economic development is 
usually estimated by the increased production output, the success of public service provision is more difficult to assess. It is usually measured by the public value created by the service providing organizations (Moore 1995).

Development literature often draws from a popular school of thought that economic development is associated with adaptation of democratic freedoms and norms. Within this framework, modernization theory posits that economic development increases chances for a transition to democracy and therefore, adaptation of democratic values. Inglehart and Welzel (2005) argue that a broader process of human development leads to democratization. Salamon and Anheier (1994) seem to fall in line with modernization theory when they name the level of social and economic development as one of three important external factors that shape the nonprofit sector. The typology they use to classify nonprofit organizations internationally - in addition to the level of social and economic development-also mentions type of legal system and degree of political centralization, therefore suggesting that variations in governmental and public administration systems to a large extent account for variations in the size and scope of nonprofits.

While type of legal system sets the legal norms for organizations' registration and operation, the degree of political centralization might directly determine public values created by a nonprofit organization. Degree of political centralization is immediately correlated with the freedom of individuals to gather in a nonprofit organization. As Vernis et al. (2006) described it, civil involvement in independent nonprofits should remain civil and volunteer because no public administration can take any credit for mobilizing volunteers. Thus, it is questionable whether pro-governmental organizations 
that support a centralized, authoritarian Belarusian government and apply so-called "voluntarily compulsory" techniques to attract new members can truly promote public, but not central-government values. Thus, for instance, the Belarusian Republican Union of the Youth (BRUY) cannot be called an independently functioning nonprofit because the membership, among other benefits, gives young public university applicants priority to be selected. The education benefits do not promote fairness, but rather it teaches youngsters to comply with the rules from above. In addition, the BRUY openly declares its affiliation with the government: the statute of this organization includes such a function as dissemination of political information through the promotion of the ideology established by the central government (BRUY 2010).

Thus, the independence of the nonprofit sector remains a crucial characteristic to promote public values. Contrary to the public sector organizations that are created to implement governmental policies, the nonprofits are neither established by Parliament nor by local nor central government. The nonprofit sector by its very nature is a bottomup sector, which should not set any requirements for the participants to be involved (Barnett 2006). The only requirement would be a desire to start up or to join a nonprofit organization, which exists because an individual or group perceived a need and set out to meet it (Barnett 2006).

Because initiatives in the nonprofit sector come from the ground up, even though the economic development process paves the way for the nonprofit sector expansion, it cannot guarantee that these organizations work toward desired public values. The internal values dominated inside nonprofit organizations can overshadow the favorable external climate created by the government and international donors. Being a crucial component 
of the decentralized public administration, nonprofit organizations nevertheless could promote quite contradictive values, which should be expected from the associations that vary in size, scope, political affiliation, socio-economic level of its members, reasons for organization creation, etc.

The type of public values that a nonprofit creates through service provision might to a larger extent depend on the level of social and economic development of the organization's members rather than the country overall. Ideally, nonprofit services should be able to be grouped under the label "to help others." As one of these idealists, Andrew Barnett (2006) believes that the quality and effectiveness of the help provided are highly determined by the passion of a nonprofit's members and their closeness to the needs of the beneficiaries. Yet, other scholars have noticed that passion itself might be insufficient drive to engage oneself in the promotion of public values. Moreover, as Jenkins (2006) described it, "Overreliance on solidarity also runs the risk of goal diversion" (320). Wilson (1995, as cited by Jenkins 2006) distinguishes different organizational incentives for different social groups. According to him, the more educated middle and upper classes are more receptive to moral appeals (passion). Devoting themselves to nonprofits out of passion reflects the economic security of these classes. The lower class is more receptive to a mix of the purposive appeals with material interests and solidarity (Jenkins 2006, Wilson 1995).

Similarly, if the members of the organization mainly pursue the satisfaction of the government and other donors, but not the citizens, their projects might create little public value. Vernis et al. (2006) observe that the beneficiary satisfaction of social assistance services suffers when an organization is responsible to the donor but not the customer. 
The situation worsens when inputs from the customers are also ignored because result assessments are not based on customary services provided by social organizations. In addition, as noticed by Vernis et al. (2006), the nonprofits become very similar due to the fact that donors (public agencies or foreign sponsors) need nonprofits to meet several requirements that are meant to ensure nonprofits' standardization. Sadly, despite the democratic freedoms and administrative independence most of the former communist countries obtained after the fall of the regime, compliance with the procedures standardized by the donors usually remains a main priority for nonprofit organizationsrather than the creation of public values. For instance in the case of EU projects, a collaboration between funding institutions and nonprofit organizations is generally limited to submitting proposals to win contracts, and, once contracts are awarded, expense reports are submitted upon service completion.

Vernis et al. (2006) suggests that in order to fix the malfunctions of this system, both public and private organizations need to be driven by solidarity of its members and not exclusively by their desire for the organization to survive. Finding the right driving force becomes a complicated issue because as some other scholars suggest, the overreliance on solidarity also runs the risk of goal diversion (Jenkins 2006).

In order to determine whether a particular nonprofit organization creates a public value, it might be helpful to look into the reasons why individuals launched the organization firsthand. Was the creation of the nonprofit organization informed by public values or is public service delivery simply driven by the self-interest of employees? If the organizations were established to indeed pursue public values, are nonprofit services 
complementary to the public services? Do they oppose public services, or are they competitors of the public organizations?

DiMaggio and Anheier (1990) note that there is a natural division of labor across sectors that comes with the distribution of functions between businesses, nonprofits, and public agencies. They further suggest that the nonprofit sector has apparent disadvantages with respect to incentives (compared to businesses) and revenue generation (compared to government), which may influence the decision of individuals to group in the nonprofits. Assuming that despite acknowledging weak sides of nonprofit incentives and revenues, the individuals nevertheless establish nonprofits; they do so either because they feel the organizations guard public values or simply to pursue their own lucrative desires. Simply stated, they either launch a nonprofit because of their PSM or for money.

Firstly, there is some evidence that explains why individuals might launch a nonprofit; namely, they see the possibility for personal gain. Researchers and practitioners often mention the occasional utilization of funds for personal matters as a driving factor for nonprofit activation. Empirical evidence shows that many nonprofits were created because of employment opportunity or political reasons (e.g., to oppose government). In her empirical study of Polish NGO leaders, Chimiak (2006) showed that a person-who possessed an understanding of how to utilize funds offered by Western foundations and organizations - will create a nonprofit organization not only to ensure its success, but also to enjoy personal lucrative gains. Taking into consideration that socioeconomic development of the population determines the reasons why individuals would start a nonprofit organization (Salamon and Anheier 1994), it is natural that some of the nonprofits in Poland and Belarus are launched simply for reasons other than public 
value creation, because most of the nonprofit organizations in these countries are run by the middle-lower class (Jenkins 2006, Wilson 1995). Nonprofit sectors in the former Eastern bloc cannot rely on solidarity alone because economic security in the developing post-communist countries is questionable. Moreover, upper and upper-middle classes are on their formation way.

At the same time, there is some support for another more popular justification for establishing a nonprofit: the opportunity to pursue an individual call to help society. The internal call matches the definitions of PSM used in the current study, and therefore, this study argues that the reason to create a nonprofit might be an expression of individual PSM. Several scholars claim that a personal-fit approach, which implies an active involvement in the work of the nonprofit sector, should be interpreted as an expression of an individual's personality (Chimiak 2006). If there is a fit between an individual and an organziation, social commitment that comes together with flexibility, agility, and proximity might "turn the nonprofit sector into a sound option in an environment shaped by deep social changes and transitions" (Vernis et al. 2006, 67). Referring to Inglehart's (1997) theories discussed in previous research, social changes come through gradual establishment of new values: the process which, as this study argues, allows PSM to occur and/or further develop. The literature suggests that creating public values and public service motivation (PSM) indeed cannot be totally separated (Andersen et al. 2012). As public values can become a motivation for individuals to launch a nonprofit, so they could realized their PSM by doing good for others and society through public service delivery. The following subsections further elaborate on cross-sector differences and similarities reflected in individual motivation. 


\section{Motivation in Nonprofits vs. Public Sector}

In recent decades, researchers around the world have been addressing the distinctions in motivation between the public and private sector in their studies. Some scholars claim that motivation of individuals employed in government differs little from the private sector because both sectors have problems motivating managers and employees, experience pressures from unions, exhibit selfish and unethical behaviors, and have ineffective bonus and merit-pay systems (Rainey 1991). At the same time, most of the research suggests motivational differences between sectors (Kim 2005, Houston 2000, 2006, Jurkiewicz, Massey \&Brown 1998, Wittmer 1991, Crewson 1997). Yet, relatively little research has been conducted that compares nonprofit and public organizations (Lee \& Wilkins 2011, Light 2002, Rotolo \& Wilson 2006). The subsections below provide theoretical reasoning for why similarities and differences in work motivation might occur and also present evidence from several empirical studies. Table 1 serves as a summary for this part of the chapter.

Similarities between Sectors that Influence Motivation. Nonprofit and public sectors are similar in their differences with the private sector. The similarities between public and nonprofit sectors are determined by the fact that these sectors usually provide services that are not exchanged on economic markets, but are justified on the basis of general social values, the public interest, and politically imposed demands of groups (Rainey 1991). 
Table 1: Similarities and Differences Shaping Motivation in Public and Nonprofit Organizations

Nonprofit Sector

\section{Differences}

- Adjusting to multiplicity of the society's values

- Oversized and bureaucratic rules reducing organization efficiency

- Image of public services dependent on the general opinion about the government

- Traditional superiority over nonprofits

- Better employment benefits, e.g. career advancement and retirement plans
- Serving the donor's single priority

- Flexible in reaching customers due to the weaker external control

- Independent image of the sector

- Viewed as a subordinate of the public sector

- Unpredictable future of the employees

\section{Similarities}

- Not-for-profit-sectors

- Dedication to public values, orientation toward increased citizens' assistance

Firstly, both nonprofit and public sectors consist of not-for-profit oriented institutions. As the value these organizations produce is measured in terms of mission fulfillment (Moore 2000), employees of these organizations are motivationally distinct from businesses. The outcomes of Goodin's research (2003) shows that managers are not merely maximizing profits or managerial efficiency, but are also highly committed to "the cause". Because maximizing profits is not a primary aim of the employees in public organizations, these employees pay less attention to their lower salaries. Hartman and Weber (1980) studied high-level officials who entered public service because of their desire to perform public service — rather than a desire for material rewards — and face the 
challenges that accompany such service; these individuals knew the new jobs would pay lower salaries than their previous employment. Comparative studies of public service motivation (PSM) between sectors also suggest resemblance in commitment found in the public and nonprofit sectors. The study of Crewson (1997) revealed that profit-seeking firms are likely to be dominated by economic-oriented employees while public-service organizations, both public and nonprofit, are likely to be dominated by service-oriented employees.

The second main characteristic differentiating the public and the nonprofit sectors from the private sector is the dedication to the public value, which comes with the orientation toward increased social assistance. Even though it is usually assumed that each sector addressed social issues in its own unique way, some scholars argue that the public sector today has become even more similar to the nonprofit sector. Smith and Gronbjerg (2006) explain this by the recent ubiquitous involvement of the public sector in addressing social issues: "Motivation of the public sector should have become different, since government is now more extensively involved in efforts to regulate economic cycles, stimulates, growth, support families, protect health and safety, and invest in human capital that fifty years ago" ( 222).

While the extent of homogeneity in the ways public and nonprofit sectors tackle social problems is debatable, public-sector employees indeed resemble nonprofit employees in having more pro-social motivations than their public sector counterparts. Employees of public and nonprofit organizations are more dedicated to do their job for the benefit of others than individuals working in the private sector, which is proven in several empirical studies, e.g. Rotolo and Wilson (2006) and Vernis et al. (2006). In 
addition, public servants share more similarities to nonprofit workers than private employees in terms of their PSM and civic participation. Public and nonprofit workers displayed significantly higher PSM levels than private workers (Taylor 2010, Houston 2006, Lyons et al. 2006). Moreover, the findings of Houston (2008) suggest that public and nonprofit workers show similar patterns of PSM-related attitudes.

Differences between Sectors that Influence Motivation. Despite some strong similarities between public and nonprofit sectors, these organizations operate in different environments that determine motivation in these organizations. For example, public organizations prioritize satisfying all citizens, while nonprofits are responsible for a particular target group that they select themselves; the structures of public organizations are regulated from above in comparison to more flexible structures of nonprofit organizations. These and other distinctions between each sector will be discussed in further detail in this subsection.

(1) Moore (2000) names organizational mission as a distinctive characteristic of both public and nonprofit sectors. Yet, the divergence in their missions determines the differences in the values that the organizations intend to produce for their shareholders and for society at large. Thus, the nonprofit organizations aim to achieve their social purpose and simultaneously satisfy donors' desire to contribute to the cause that organizations embody. For nonprofits, the process of priorities setting is relatively simple. Nonprofit organizations are not required to adjust to the multiplicity of values found in a society. An organization sets one value as the priority, finds a donor that shares this priority, and arranges its activities around it. Clearly defined priorities narrow the professional experience required from the job candidates, which makes nonprofit 
employees more specialized in particular issues than the public sector employees (Vernis, et. al 2006).

At the same time, the governmental organization completes "the politically mandated mission" by fulfilling "citizen aspirations that were more or less reflected in that mandate" (Moore 2000, 186). The variety and fickleness of citizens' inclinations leads to the conflict of values constantly experienced by public organizations. The environment of public organizations is characterized by the "multiple, conflicting, and often abstract values that public organizations must pursue" (Rainey 1991, 121; also Rainey 2009). Cherniss (1980) suggests that in public service provision, professionals typically experience stress and burnout caused by the conflict of their motivation to help their clients and of their attempt to comply with bureaucratic systems. Rainey (1991) likewise notes that "for many public managers, a sense of valuable social purposes can serve as a source of motivation, although in many agencies, they appear to face impediments in fulfilling this motive" (p.129).

(2) Motivation of public organizations also differs from nonprofits due to the type of the external oversight and processes that impose structures, rules, and procedures on the public organization. While, as mentioned above, nonprofits mainly aim to satisfy their donors, public organizations have to operate within government rules regulating not only the desired outcome, but also employees' pay, promotion, and discipline and rules that affect training and personal development (Rainey 1991). In order to overcome an oversized bureaucracy and resulting inefficiency issues, public administrations often resort to nonprofits to outsource public services (Vernis et al. 2006). Thus, nonprofits undertake roles that neither the state nor the market can perform. The nonprofit sector 
differentiates from the public sector with its flexibility, which also allows reaching out to inaccessible customers (Vernis, et.al 2006).

(3) According to some scholars, public service motivation appears to vary over time with changes in the public image of government service (Rainey 1991). The environment of public sector employees indeed could be darkened by a negative opinion of the government by the population. Even though there should be no direct relation between elected officials and street-level bureaucrats, with the latter recruited based on merit, for the general population, public servants and public service employees remain the agents of the politicians in power. In these situations, motivation of individuals that work for the public sector can be shaped by general attitudes toward taxes, government, and government employees. For example, in the United States, the external political climate became sharply negative during the 1970s and 1980s, which influenced the prestige of jobs in the public sector (Rainey 1991).

(4) The working climate is likely to be influenced by the superiority of public organizations over nonprofit organizations, especially when the funds for the nonprofits come from these public organizations. Despite some blurring between the sectors, government organizations remain restricted to certain functions. Public agencies decide whether they will produce the services they have already decided to provide, if they intend to sell, run, manage, and control these services. Each provision and production activity could be outsourced separately from the nonprofit sector (Vernis et al. 2006). Hierarchy—when the nonprofit sector is a subordinate of the public sector-is likely to shape work motivation in these organizations. 
(5) The final fact that might influence motivation of employees is that public organizations usually have better future benefits than the nonprofit organizations. Lee and Wilkins (2011) confirmed that indeed public managers, more than nonprofit ones, prioritize extrinsic incentives such as pension and retirement plan.

While the overview above shows motivational differences and similarities between public and nonprofit sectors at the institutional level, values and motives can differ at the individual level across sectors. As some interviews with NGO leaders and service providing private organizations in Poland and Belarus reveal, while not all NGO employees are safeguarding civil society, some employees in the public sector are an active part of it (Prysmakova, forthcoming). This proposition is also supported by empirical evidence from Lee and Wilkins (2011), who found that public managers value intrinsic motivations such as the ability to serve the public and the public interest more than nonprofit employees.

The hypotheses in this chapter represent a perspective that the work motivation should be higher in nonprofits because they are placed further from the government and thus, are less affected by it, even in situations where their funds are mainly coming from the public programs. Despite being traditionally seen in the region as public sector subordinates or complimentary service providers, nonprofit organizations enjoy an image as entities that stand separate from the government's politics. Moreover, even though employees of these organizations have a less predictable future, they have more freedom to prioritize the organization's mission than public sector employees, who are required to comply with rules and requirements of government. A hypothesis that assumes sectoral 
differences in PSM level between public and nonprofit employees in service providing organizations is formulated:

Hypothesis 2: In post-communist countries, nonprofit sector employees will exhibit higher levels of PSM than their public sector counterparts.

\section{Government Centralization and Sectoral Differences in Motivation}

The most academically interesting question, however, is the simultaneous effect of sector and centralization of the government on motivation. Increase in the centralization level of the government might (1) equally diminish PSM level of the employees involved in public service provision in both public and nonprofit sectors; or (2) crowd out highly public service motivated individuals from the public sector to the nonprofit sector. In the latter scenario, service provision employees in the country with the centralized government are likely to exhibit extreme levels of PSM.

Because the sectors do not cooperate, the difference in PSM between sectors is likely to become even larger. On the other hand, in decentralized countries, where two independent sectors are willing to work together, the cooperation might align PSM levels. In this chapter, the simultaneous effect of the sectoral system and country's administrative system on the level of PSM will be tested using the following hypothesis:

Hypothesis 3: The level of government centralization intensifies the sectoral differences in the degree of PSM. In other words, we expect to register the lowest level of PSM among public sector employees and the highest level of PSM among nonprofit sector employees in the centralized administrative system.

Whether this hypothesis is correct for administratively decentralized Poland and centralized Belarus will become evident later in the quantitative empirical research. This 
chapter examines the possible antecedents, which are likely to increase the motivational differences between sectors in centralized regimes-with special emphasis on authoritarian regimes as an extreme case of centralization. The differences in environment, in which public and nonprofit organizations operate, are likely to mold the motivation of employees in these organizations. For instance, the way the political structure is organized in a country is likely to influence public-nonprofit relations, which in turn will affect motivation in both sectors and their abilities to create public values. Smith and Gronbjerg (2006) explain that the relations between government and nonprofits are "penetrated with political ideologies about the proper role of government and priorities that reflect values of fairness, equity, equality, choice, and opportunities" (222).

This subsection proceeds as follows. First, the relations between public and nonprofit sectors are defined for decentralized systems. This subsection also analyzes how these relations are reflected in the motivation of employees in service providing organizations. Secondly, the attention turns to the centralized systems and examines relations between public and independent nonprofit sectors in them. Here, the PSM in both public and nonprofit service providers is also discussed for the case of limited relations between sectors.

\section{Nonprofit-Public Relations in Decentralized Administrative Systems}

Vernis et al. (2006) claim that contemporary democratic societies are built around three sectors: public administrations, business corporations, and nonprofit organizations. Expanding their ideas, the current chapter is written from the perspective that the presence of the sectors themselves does not determine the democracy, but the 
contemporary democracy relies on the dialogue between these three sectors. The proponents of public-nonprofit cooperation dominate contemporary literature on governance.

Government that shares its power with other sectors has to build a mutual dialogue with these groups. Tamsin Cox and Daniel Harris (2011) argue that democratic societies have the potential to create truly democratic dialogue on important issues. These authors also assume that in this dialogue, the voluntary sector may find itself uniquely well positioned as the broker in sector provision. Castineira and Vidal (2003) further suggest that the quality of services provided by third-sector organizations helps to legitimize democratic systems. According to their propositions, in democratic systems, when public administrations, businesses, and nonprofits share some common goals, they must search for common consent in their actions while not jeopardizing their individual identities.

Why would democratic societies need cooperation between sectors that differ in their missions and organizational structure? Assuming that the government shares its power, how is administrative decentralization important for public services? Supporters claim that stronger dialogue between civil society and government is necessary to bring real benefits to society, for instance, by providing a "deep well" of voluntary sector knowledge and experience to help government solve and prevent difficult problems, or by helping to ensure that public services meet different needs (Slocock 2011). Wellestablished cooperation channels between the government and civil society will facilitate finding fresh solutions, unlocking new potential, and providing innovative services which meet different needs (Slocock 2011). Joyce Moseley (2011) further suggests that 
voluntary organizations in all their diversity are a 'credible partner' and a 'critical friend' to any government with ambitions for social changes.

Vernis et al. (2006) also support intensive relationships between sectors and propose their model of collaboration. According to their model, a successful partnership is based on mutual agreement on the system of needs (social dimension) and the shared goal, which is to provide quality services (learning dimension) for users over a lengthy period of time (time dimension). It is necessary to underline here that the cooperation of the two independent sectors can be obtained only by providing certain levels of decentralization in the country, which ensures that the two sectors are independent and are willing to cooperate.

Public Service Motivation in decentralized systems. When public and nonprofit organizations share the same goal, a civil dialogue between them is easier to establish. The interaction, for instance through information exchange, assures that these sectors complement each other in solving social issues without overlapping in their functions and tasks. In addition to complementation of services, in a decentralized administrative system, constant cooperation between sectors comes with a constant flow of individuals between the public and nonprofit sectors.

The enhanced cooperation between sectors allows for easier flow of employees between public and nonprofit sectors, and therefore, the PSM between sectors is more likely to be similar. Third sector leaders possess a huge diversity of experience because they have often worked in the public and private sectors. Previous work experience in different types of organizations ensures a natural cultural bridge between sectors (Board 2011). Levels of PSM sharpen during the process of working for the sector. If an 
individual believes that his or her position in the public sector does not fully allow him or her to fulfill his or her PSM needs (self-sacrifice, compassion, but also power, influence of politics), this person is able to establish a nonprofit organization or move to an existing one, and vice versa.

Table 2: Review of Relations between Public and Nonprofit Sectors

\section{Decentralized Systems}

- Government shares the power

- Well-established channels of cooperation

- Nonprofits as credible partners and critical friends

- Mutual agreements on citizens' needs

- Independent sectors willing to cooperate

\section{Centralized Systems}

- Exercising its power, government destroys civil society and suppresses nonprofits

- Nonprofits are not allowed to fill the gap by providing missing services

- Nonprofits as mistrustful and dismissive competitors

- Power elites protect own interests, not interests of the society

- Superiority of the public sector

So far, this section elaborated on different reasons that explain how decentralized government could positively affect motivation to serve citizens in both public and nonprofit sectors. In order to avoid biases, some negative sides of decentralization should be mentioned as well. Despite the number of advantages of increased public-nonprofit cooperation, the decentralized system also has some weaknesses. For instance, the high level of decentralization can negatively influence the capacity of government to adequately fund and regulate voluntary service agencies. The research shows that in the Netherlands, which has a more centralized structure and largely national financing of voluntary services, has been able to offer much more extensive services to the elderly than decentralized Germany (Smith and Gronbjerg 2006). 
Moreover, a decentralized administrative system also has some limitations when it over-relies on the nonprofit organizations for service provision. In decentralized service provision, the differences in motivation between sectors can be weakened due to the abundance of relations between sectors. For instance, the increased responsibility that falls on the nonprofit organizations might demotivate individuals employed in this sector. Moreover, if adjusting to governmental funding, a nonprofit organization operates from a short-term perspective; its employees might become PSM discouraged because they do not see the lasting effect of helping others. Therefore, working closer with the government and being highly dependent on governmental funds might create a clash of short-term political agendas and planning horizons with civil society's commitment to achieving long-term change. Nick Wilkie (2011) points out that "some of society's most valuable work takes place in profoundly unstable circumstances because non-profits are overstretched and under-capitalized, partly because of inflexible, project-based funding tied to short-term, narrow outputs." In such situations, extended civil dialogue in reality can create obstacles in successful creation of public values by the nonprofit sector service providers.

Nonprofit-Public Relations in Authoritarian Systems as Extreme Case of

\section{High Administrative Centralization}

Contrary to the countries with decentralized governments, the more centralized the structure, the less room there is for a coherent nonprofit sector, and vice versa: the less centralized the structure, the greater the opportunity for the operation of extensive nonprofit organizations. Salamon and Anheir (1994) provide the following evidence for this. Germany, which has a federal administrative structure, has a quite vibrant nonprofit 
sector, whereas France with a more centralized government has had a much more limited nonprofit sphere historically. Similarly in terms of degree of centralization, the United Kingdom evolved a far more centralized political and institutional structure than the United States and this has limited the space available for the development of the nonprofit sector (Salamon \& Anheir 1994).

Speaking of even stronger centralized regimes, namely authoritarian ones, exercising their powers can simply destroy civil society because such regimes usually reduce the ability and willingness of individuals to organize for mutual benefit or political purpose (Scott 1998). Especially, if from the perspectives of the regime, it “doesn't seem logical for public administrations to entrust them [nonprofits] with certain activities" (Vernis et al. 2006, 49). When the power elite protect their own interests, government-nonprofit relations are also used to benefit a narrower group rather than the entire population. Contrary to that, a counterbalanced regime allows for the full spectrum of interests in the policy-making process.

Thus, the attitude of the public sector toward the nonprofit sector will deviate between highly centralized democratic governance in Western Europe and highly centralized administrations that apply to some authoritarian means in certain Eastern European countries. In the centralized United Kingdom, where public service provision was largely delegated to the nonprofit sector during Thatcher's reforms, a key question for the government is whether it prefers small-scale community engagers and advocacy organizations or large-scale deliverers (Bath 2011). In Eastern European countries, with their long history of well-established service provision by public sector organizations, the question for the government is whether it allows nonprofits to fill in the gap by providing 
missing services, to substitute existing public services, or to compete with them. In connection with competition, the research shows that the more centralized the government is, the more often it acknowledges the nonprofit sector as a competitor rather than a partner. Julie Bishop (2011) reports that in the United Kingdom, civil servants find civil organizations becoming dismissive, mistrustful, and hostile. A civil servant complained about 'the arrogance of these organizations undertaking 'research' and then expecting us [public sector] to consider it.

As mentioned earlier, the nonprofit sector can be "a credible partner and a critical friend" to a government with ambition to be an enabler for social change (Moseley 2011). Thus, we cannot expect governments in centralized nondemocratic regimes to cooperate with independent nonprofit organizations. Ensuring the continuity of its power, the government would rather preserve social order in the conditions they were in when this power was obtained,

Since a centralized government would prefer to not share its power with another sector, the nonprofit sector is likely to be suppressed. For example, research from China shows that a clearly humanistic and liberal undertone of social work practice has posed a potential threat to the Chinese party state in its capability to manipulate social work to its own advantages (Leung et. al 2012). In a situation, where the people are unable to question the government's decision making for fear of penalty, there is no room for cooperation between this government and an independent nonprofit sector. The main role of civil society associations in such regimes becomes to sustain and mobilize political opposition under authoritarian rule (Salamon \& Anheier 1994, 210). 


\section{Public Service Motivation in public and nonprofit organizations. Limited}

cooperation between sectors, or even the suppression of the nonprofit sector by the public sector, is likely to affect the morals and values of employees in both sectors as well as their motivation to provide public services. Even if a service providing organization in the public sector is not directly intervening in political affairs, the administrative systems of the centralized government undermine the democratic attitudes of its employees regardless. A wide body of literature suggests that operating in an authoritarian regime and having close linkages to the state can undermine the degree of democracy within an association: "if an association is linked to a non-democratic state through personnel, financial, decision-making, or operational procedures or arrangements, then state interests dominate member interests" (Foster 2001, 534).

The way dominating state institutions operate and maintain their power determines not only the public organizations, but also whether the nonprofit sector takes on visible and formalized functions, including special recognition within the legal structure (Smith \& Gronbjerg 2006). In a strong centralized regime, as in Belarus, independent nonprofit organizations constantly face obstacles from the government - for instance, difficulty in obtaining official registration. From the personnel perspective, this means that individuals participating in such organizations must accept negative consequences of their affiliation with the independent nonprofit sector. When individuals accept a position in an independent nonprofit organization, it might be difficult for them to apply for a position in the public sector afterward. Individuals that participate in nonprofit organizations - regardless of the disadvantages and obstacles they face, such as employment history that may hinder future cross-sector mobility—should possess a very 
high PSM level because they consciously take an unfavorable side in the confrontation between the nonprofit and the public sectors.

Table 3: PSM in Different Systems

Decentralized System

\begin{tabular}{cc}
\hline Public Service & Nonprofit Service \\
\hline Motivation reflects more general goals & Motivation focused on particular goals
\end{tabular}

- Employees' flow creates a natural bridge between sectors

- When an individual motivation is crystalized, a person might switch to a nonprofit to focus on this priority

- Abundance of relations might weaken PSM: e.g. by increased responsibility of nonprofits, or short-term perspectives based on public funding

\section{Centralized System}

Public Service

Enjoyment of the power undermines willingness to help
Nonprofit Service

(a) motivation suppressed by the government's discouragement, or

(b) high motivation allowing to work for the underprivileged sector

- With no workforce exchange, PSM serves as a precondition to choose the sector of employment

The centralized regimes are typically characterized by the lack of workforce exchange between sectors. Douglas Board (2011) notices that three quarters of Permanent Secretaries [in Britain] have only ever worked in government. Such a permanent separation of the workforce in highly centralized regimes strengthens the cultural barriers that occur due to the lack of workforce exchange. In centralized nondemocratic systems, the lack of civil dialogue is either substituted by a unilateral relationship when the 
nonprofits unquestionably fulfill the orders of the government in the exchange for official recognition, or the sectors minimize mutual recognition and responsiveness at all (Civil Society Contact Group 2006). In both situations, the motivation to work together to tackle the same social issues can be easily undermined.

With no exchange in the workforce between sectors, cultural barriers between the sectors become difficult to break down. Observing the relations between the highly centralized British government and the nonprofit sector, Tamsin Cox and Daniel Harris (2011) emphasize obstacles in the communication between these sectors due to the closeness of the public sector and openness of the volunteer sector: "Government works in silos, while the voluntary sector often works across government institutional boundaries, making communication difficult, especially for smaller organizations" (as cited by Slocock 2011, 4).

The situation when two sectors speak different "value languages" might influence the individual motivation in two possible ways. Employees will either select the sector based on their level of PSM, or they will be equally PSM-discouraged in both sectors. Rainey (1991) suggests that constraints on the performance of public services among other conditions are likely to be determined by the type of individuals who choose to work in public organizations. Following his approach, in the first scenario, highly motivated individuals would be more likely to choose to work for the independent nonprofits, and those with lower PSM are more likely to end up in governmental organizations. Because in centralized systems, the flow of human resources between sectors is virtually nonexistent, PSM level became a precondition for choosing a sector of employment. Another scenario is that due to the constraints of highly centralized systems, 
employees in both sectors might get equally discouraged to work for common good. In addition, influencing its own public employees, authoritarian regimes can also destroy civil society by greatly reducing the ability and willingness of individuals to organize for mutual benefit or political purposes (Smith \& Gronbjerg 2006).

\section{Conclusion}

The aim of this chapter was to gain greater understanding about the differences in public values and motivation in public and nonprofit organizations generally, and in the context of the centralized and decentralized administrative systems in particular. Thereby, the literature on these issues was reviewed not only in light of public-nonprofit relations, but also by examining how these relations might determine employees' motivation across sectors in Poland and Belarus.

As the evidence from previous empirical studies and the theoretical reasoning suggest, public and nonprofit service organizations share some similarities such as being not-for-profit or oriented toward public interest. Yet, these sectors reveal even more differences that might determine employees' motivation-unique to each sector. For instance, positive image about the current government or a better employment benefits package might serve as more attractive incentives to join public organizations than pure willingness to solve social problems. Yet, the ambiguity of goals and an overall bureaucratization might discourage highly motivated individuals from joining public organizations. At the same time, independent image of the nonprofits is less affected by government showdowns and the goals are narrower than in the public sector. Meanwhile, nonprofits might be to a larger extent dependent on donors in setting their priorities and 
planning their activities. Moreover, the motivation of nonprofit employees can be affected by the unpredictable future of their employment.

Further analysis of the literature reveals that differences and similarities in Public Service Motivation among public and nonprofit employees might indeed be intensified by the political and administrative regimes of the countries where these organizations are located. In decentralized systems like in Poland, public sector organizations serve larger goals, while allowing the nonprofits to focus on particular problems. The intensive public-nonprofit relations support employees' flow between sectors. Meanwhile, the abundance of relations might weaken PSM of nonprofit employees. For example, the nonprofit employees might be overwhelmed with the simultaneous responsibility before the citizens and the government, or discouraged by short-term perspectives based on public funding.

Centralized systems like Belarus limit workforce exchange between sectors, therefore making PSM a precondition when choosing between jobs in different sectors. For public employees, the opportunity to exercise power could become more attractive than the willingness to help. Meanwhile, the motivation of nonprofit employees would either be suppressed by the government's discouragement, or would become even higher because these individuals consciously choose to work for the underprivileged sector. Moreover, as the American experience shows, negative opinion of the government might spread to the public sector as a whole. Thus, a negative political climate might unfavorably influence the prestige of the jobs in the public sector, which to a certain extent has been occurring in Belarus. The negative opinion of the public sector 
furthermore has been spreading to nonprofit organizations that receive funds from the government.

Because of the lack of any empirical analyses on the differences in motivation between the sectors in these two countries, it is difficult to unambiguously name exact factors that influence PSM in practice. Although the theory offers many distinctive motives for public and nonprofit employees, findings from the few empirical studies conducted to compare motivation between the sectors provide differing results. More research is needed to fill the gap in the comparative knowledge, especially taking into consideration that PSM differs from job involvement, organizational commitment, and other generic concepts developed in organizational behavior research-in ways that should be better understand (Rainey 1991).

The review of the relevant theoretical and empirical literature helped to formulate hypotheses that will be empirically tested in the following chapters. This literature review provides a sound foundation allowing for the assumption that employees of public and nonprofit organizations indeed speak different 'languages.' Moreover, it shows that these differences might be intensified by institutional conditions. In decentralized administrative regimes, the 'languages' of the sectors originate from the same 'language group,' meaning that with some effort, the employees can communicate across sectors and work toward the same goal. Meanwhile, the hierarchical relations between sectors in highly centralized systems pressure employees to develop their own incomparable 'languages' and, thus, leave less chances for mutual understanding. By enjoying a superior power, the public sector in centralized systems neglects the fact that nonprofits might become partners and, therefore, share some part of the work load. Nonprofit 
employees feel no support from the government in their activities, and therefore, become discouraged, while, public employees might lose their motivation to serve the citizens because they are overwhelmed by the responsibility to address all social issues simultaneously.

Decentralized systems also do not provide a unique solution to improve the motivation level of service providers. Abundant cooperation between nonprofits with the public sector in decentralized systems might limit nonprofits' independence and dictate the ways in which they address social issues in exchange for funding guarantees. The motivation of such nonprofits to help others might also decrease. Thus, in one administrative system or another, the freedom and the independence of the nonprofit sector remains the key factor that determines the abilities of service providing employees in both sectors to adhere to and prioritize the public values. 


\section{CHAPTER 4: METHODOLOGY AND EMPIRICAL STUDY DESIGN}

The study presented in this dissertation is cross-sectional, non-experimental, and involves collection of primary data using self-administered paper and online surveys. The research process comprised three major stages: translation and adaptation of items into native languages of respondents, collecting data from the sample of individuals in Belarus and Poland, and statistical examination of the survey results. The data collection commenced after the researcher received approval from the Institutional Review Board at Florida International University and approval from organizations in Poland and Belarus, which gave the researcher permission to conduct the present study. This chapter describes the scale translation and validation procedures, the strategy used to recruit samples and collect data for this study, and the measures for the constructs of interest.

The purposeful sampling strategy was used to recruit study participants who were employees of public and nonprofit organizations in the border region in Belarus and Poland. Because of the possible regional and functional differences between public and nonprofit organizations in Poland and Belarus, random sampling procedures could not be applied. Moreover, purposeful sampling tends to be the most common approach in the PSM studies. Review of previous studies on PSM in international contexts suggests that researchers have often used non-random samples and included only members engaged in organizations or types of organizations that were in the interest of their study (e.g. Perry 1996, Coursey, Pandey \& Yang 2012, Liu, Tang \& Zhu 2008, Taylor 2007, Andersen, Jorgensen, Kjeldsen, Pedersen \& Vrangbaek 2012).

On the basis of the personal expert recommendations, the feasibility concerns, and the length of the final questionnaire, which included sixteen PSM items, three 
organizational centralization items, and ten demographics and control items, the researcher aimed to survey approximately four hundred or more respondents. To ensure protection of the survey participants as well as to maximize the response rate, the procedures were tailored to each local context and conducted in consultation with local experts and the leaders of the public and nonprofit organizations. The data were collected during the summer months in 2014.

\section{Scale Translation and Content Validation Procedures}

The guidelines of the International Test Commission for adapting instruments (ITC 2010) suggest that the adaptation of existing instruments to new cultures should fully account for linguistic and cultural differences among the populations for whom adapted versions of the instrument are intended. The ITC also suggests that nonequivalent questions between versions intended for different populations may enhance content validity of the measure for new populations. To address these issues, this study used procedures suggested for scale validation and international adaptation (e.g. ITC 2010, Rubio, Berg-Weger, Tebb, Lee, \& Rauch 2003, Wombacher, Tagg, Burgi, \& MacBryde 2010).

The multi-step item adaptation involved collaboration with translators in Belarus and Poland, a panel of Belarusian and Polish content experts with expertise in social science research and with experience on service providing organizations in public and nonprofit sectors, and a panel of researchers in the United States. First, the original sixteen items of the PSM scale (Kim et al. 2013) and three items of the Organization Centralization scale (Aiken \& Hage 1968) were translated into Belarusian, Russian, and Polish languages by experienced translators who deeply understand the respective 
cultures and socio-political contexts. For Belarus, the survey was prepared in the two official state languages of the country, which are Russian and Belarusian. The Belarusian experts were fluent in both of these languages.

The central task in translating the survey items was to create culturally appropriate "equivalents" of the original English items. As pointed out by Harkness (2003), meanings are context-bound, and therefore instead of mere translation, the aim was to make the items meaningful in the context of public service provision in Belarus and Poland. The translators were provided with information about the construct, its definition, and scales.

The scale validation process began with assessing the face and content validity of the PSM items in Belarusian, Russian, and Polish languages. Rubio and colleagues (2003) recommended using two panels of content experts and lay experts, which should include three to ten members each. In this study, four Polish and five Belarusian researchers and professionals with degrees in social sciences and with expertise in social science research were invited to serve as content experts. Some of these experts were also bilingual in their native language and English and had a chance to compare the English items with the translated versions. Initially, the content experts were asked to review the translated items in terms of the clarity and cultural appropriateness of item wording and the overall comprehensiveness of the entire measure. The experts were encouraged to make suggestions about how the measure could be improved. Their comments were returned within a week and reviewed by the researcher and translators. Because the sample of experts was small, the analysis focused on whether a given item was found problematic and if any of the reviewers suggested that the item be modified. After the 
initial review, the problematic items were modified. Then the researcher and one additional Polish and two Belarusian content experts reviewed these items in a joint meeting. They reached a consensus to improve wording of some items.

Efforts were made to tailor the items to the experiences of Belarusian and Polish residents. For example, the combination of words "public service" can be translated in Belarusian, Russian, and Polish languages, but it has different meanings and loses its meaning as "service for society." Therefore, the expression "public service" was substituted with "social service." Another example was the adaptation of the word "community." Although there are Belarusian and Russian words that can be translated as "community," they have different meanings. The word "Abshchyna" (in Belarusian) and "Obshchina" (in Russian) means an organized community with a council or some other governing and decision-making body of representatives who are usually informally elected by community residents. Most communities in Belarus do not have such an organized form of community governance and the residents are not trained to use such terminology in relation to participation in specific collective problem-solving procedures. According to the Belarusian experts, the concept of "Abshchyna/Obshchina" would not be familiar to the respondents. More commonly, community is understood as a unity of people co-habiting in the same neighborhood, district, or village, and who are perceived as sharing similar concerns, experiences, and resources. Therefore, as suggested by both panels of content experts, in the questionnaire, the word "community" was substituted by "neighborhood," "district," or "village."

In addition, all experts agreed that the questionnaire does not have any direct political connotations, which was especially important for the personal security of 
respondents from the public sector in Belarus, who might feel endangered by sharing their true political attitudes and avoid the potential problems that might occur at their job place if they deny the loyalty to the regime in their answers.

After these revisions, the instrument was pre-tested with a small sample of three Polish and five Belarusian residents. They reported whether the items and survey instructions read naturally and were clear and easy to understand, and the researcher assessed whether these respondents were able to complete the survey on their own. On the basis of their feedback, a few wording simplifications were made. Next, the items were translated back into English and reviewed by researchers in the U.S., who were members of the dissertation committee. Their review ensured that the modified Polish, Belarusian, and Russian items represented the intended meanings. The final questionnaire included sixteen items intended to examine dimensions of PSM and three items intended to examine organization centralization adapted to the context of the public and nonprofit organizations in Belarus and Poland. These items were used to collect data and analyze PSM level of the individuals involved in public service provision. Demographic and control items utilized in this study were translated in the same manner with their face and content validity similarly reviewed by content experts.

\section{Sampling: Justification of Regions and Organizations Selection}

Region Justification. The study uses the results for a purposive sample from the border regions in Belarus and Poland that mirror each other to a large extent. Podlaskie Wojewodstwo is a territorial and administrative unit in Poland that lies in the eastern part of the country and borders with Belarus; Hrodna Voblasc is a territorial and administrative unit in Belarus that lies in the western part of the country and borders with 
Poland. Historically, territories in both regions were together under various rulers and regimes (e.g., Polish-Lithuanian Commonwealth, Russian Empire, and Eastern Bloc). Today, the regions are separated by the border with several check points, which remains the only one at this latitude from the east to the west of the Eurasian continent. The regions are connected with the regular railway and bus transportation. Inhabitants often have a family across the border, while the citizens from both sides need a visa to cross it.

Being inhabited by approximately one million people each, the regions also resemble each other in socio-demographic features. Both regions are characterized by the medium-high urbanization level: $60 \%$ for Podlaskie Wojewodstwo and $69 \%$ for Hrodna Voblasc. Roughly, around one-fourth of the inhabitants of Hrodna Voblasc declare themselves to be Polish and similarly around one-fifth of the inhabitants of Podlaskie Wojewodstwo are Belarusians. These minority groups speak their native languages at home and practice customs and traditions (including religious practices) inherent to each nation. The main cities of the regions are Bialystok (in Poland) and Hrodna (in Belarus) with 295 and 338 thousand of inhabitants, respectively. Podlaskie Wojewodstwo has seven and Hrodna has five towns with more than twenty thousand inhabitants.

The region is currently divided between two opposite regimes. Despite some democratic movements in the beginning of the 1990s, Belarus reverted back to the highly-centralized authoritarian system. In contrast, after the fall of the communist regime, Poland took a steady path toward democratization and decentralization, which led to EU-membership in 2004.

Organization Justification. Studies of individual motivation are not limited to a single approach to compare human resources across sectors. Testing the data from the 
large cross-state or cross-national samples, researchers often pool together respondents from different organization types and different positions, ensuring only that one group consists of public sector employees and another of private sector employees (e.g. Houston 2001). At the same time, Rainey (1991) suggests that factors-such as task or function, or industry characteristics - can influence an organization more than government auspices. Thus, some researchers indeed collate motivation of individuals according to the function they perform in the organization. For example, Rainey (1982) and Rainey and Bozeman (2000) studied managers employed in public and private organizations, whereas Lee and Wilkins (2011) focused on the comparison of public and nonprofit managers. Other researchers compared employees in public and private organizations within functional categories, e.g., hospitals (Savas 1987) and schools (Chubb \& Moe 1988).

Following the functional approach in this study, public and nonprofit organizations that provide the same target population with similar services might be more alike across sectors than public organizations that perform different tasks aiming at different population groups. In order to test whether Rainey's reasoning was accurate and whether the hypotheses stated in the previous chapters are correct, the study seeks a sample of responses from nonprofit and public organizations that perform similar services to the population. Moreover, sample collection requires identification of service providers that are equally well represented in both sectors in Belarus and Poland. Therefore, public and nonprofit organizations should be selected through purposive rather than random sampling, ensuring the comparability of the samples. Such a dataset should 
present an opportunity to make direct comparisons between public and nonprofit sector employees that provide services addressed to a similar target population.

What services should be chosen as a sample for analyses? Comparable services must pursue the same public interest. While the boundaries between businesses and governments are becoming more obscure, provision of such services remains often reserved for public and nonprofit organizations (Rainey 1991). The business sphere avoids offering these services, because these activities lack potential to earn profit. These services are often related to solving social issues: the unemployed do not have money to pay for requalification; poor elderly individuals receive insufficient retirement funds and are unable to hire private nurses; a homeless shelter requires fundraising for its operation rather than bringing revenues. Rainey (1991) noticed that "for the most part, they [public organizations] provide services that are not exchanged on economic markets, but are justified on the basis of general social values, the public interest, and politically imposed demands of groups" (24). Yet, these services are not reserved for the public sector only. In an administrative system that allows mixed or hybrid forms of service provision, there are also third-sector organizations that perform functions similar to those of the government. These nonprofit organizations have similar aims and goals as public entities: "like many government agencies, many nonprofits obviously have no profit indicators and incentives and often pursue social or public-service missions" (Rainey 1991, 20-21).

For the present study, organizations in the public and nonprofit samples perform pro-social functions in the broad sense of this word. In particular, respondents are drawn from a variety of public organizations that offer labor market services and social assistance. These organizations aim to liquidate inequalities caused by social issues and 
to support the underprivileged: the unemployed, families with many children, the elderly population, handicapped individuals, veterans, children from poor families, etc. In addition, they facilitate regional development through the employment activation of these population groups.

Labor market services and social assistance were selected for theoretical and practical reasons. First, these groups can be found in both public and nonprofit sectors and across the countries under study. Second, given the short history of the nonprofit sector in post-communist countries, these services are relatively well established in the nongovernmental sector. Therefore, the services represent a valuable sample that will be instrumental in answering the main research questions. In addition, there is a large number of organizations within each group and country, which will allow the researcher to administer a large $\mathrm{N}$ survey sufficient for statistical analysis.

A Polish nonprofit umbrella institution, Klon/Jawor, conducted surveys in 1993 that revealed the most significant growth among newly established nonprofits in the fields of social assistance and health services. In 1997, there was also a significant increase in the number of nonprofits declaring "education" as their activity. The fast steps toward decentralization of the Polish government partly explains the development of these particular services. Despite certain positive outcomes, the decentralization also resulted in decreasing the capacity of the Polish state to provide centralized welfare services to its citizens. Moreover, the results could also be interpreted by increased awareness of a vast area of problems encompassing social, economic, political, moral, and ideological issues: "Entirely new market of ideas was imported from the West or was no longer suppressed by the totalitarian regime" (Chimiak 2006, 94). In Belarus service 
providing nonprofits are of the two types: either national nonprofit organizations established in the 1990s that to a large extent owe international organizations for their creation, or the local nonprofits of the new generation that represent citizens' initiative. The national nonprofits usually have a chapter in every city; yet, each chapter might consist only of one employee that provides services to the beneficiaries in this particular town, which are also usually registered as the members of this organization. Local nonprofits are usually grass-roots enterprises that often face certain administrative obstacles from local governments.

Public service organizations in Poland are mainly responsible to the local governments. Established by the smallest territorial units as required by Polish law, Centers of Social Assistance (CSA) provide diverse types of social care. Labor Offices (LO) belong to another type of public organizations, which work with the underprivileged. On the contrary, the provision of public social services in Belarus is highly centralized. The Belarusian government has designated special hierarchies under the Ministry of Labor and Social Protection that deal with social issues. Organizations that directly deal with the unemployed locally are town branches of Departments of Employment (DE), while Territorial Centers of Social Services for Citizens (TCSSC) provide social support. Both types of organizations have one branch in each district. These organizations are the representatives of the central government, and work under the direct supervision of the Voblasc Committee of Labor and Social Protection, which in their turn are controlled by the Ministry of Labor and Social Protection. 


\section{Instrument design}

Theoretically sound and empirically supported instruments are necessary to examine how various contextual factors influence Public Service Motivation in former communist countries. Selection of the variables and instruments was guided by theory and previous similar studies that validated the measures of PSM in North American and international contexts.

The unit of analysis is the public service employee, defined here as a staff member of the public or the nonprofit organization that provides public services. The survey was prepared for individuals in different positions in the organizational hierarchy and who perform various functions. The surveyed group includes managers at different levels, employees who work directly with the citizens and also the staff responsible for technical support. Such a broad selection of employees is explained by the fact that these groups are equally important for the continuous functioning of an organization. Moreover, as the result of limited human resources, which is especially true for smallscale nonprofit organizations, these functions and tasks usually overlap. Chimiak (2006) in her study underestimates the role of the technical staff in Polish nonprofits-for instance, she excludes the accountants of the nonprofits from her analysis, stating that their job is not related to the tasks of the organization. Contrary to her approach, this study comes from the perspective that technical support is equally important for continuous service provision, because the insufficient work of the technical personnel can block the normal functioning of an entire organization. For example, mistakes in accounting, or computer system malfunctions, can interrupt the on-time delivery of services to citizens. 
In addition, the survey covers both paid and unpaid staff. It is not feasible to limit the analysis to the paid staff only, because unpaid or partly-paid staff can also be very active in the management of an organization, ensuring steady functioning of an organization and continuous provision of services. For instance in the nonprofits, some staff members could be not paid and could work solely on volunteer basis. Yet, these individuals are different from typical volunteers because their involvement in the organization is not temporal and spontaneous, but of a constant nature. They are recognized as staff members of an organization and usually take the position of the organization chairs or official leaders.

In 1997, Klon/Jawor conducted another survey which showed that up to sixtythree percent of associations and foundations in Poland do not officially employ anyone, whereas their studies done in 2000, 2002, and 2004 suggested that forty-six, fifty-five, and sixty-seven percent of organizations respectively function on a volunteer basis. The situation resembles that of Belarus, where nonprofits usually cannot afford to pay for the services provided by their workers. This might occur due to limited knowledge about different ways of applying for funds and, as in case of Belarus, due to extensive taxation constraints on donations.

At the same time, ongoing commitment to pro-social activity in the nonprofit organizations is often regarded as "work," rather than "serious leisure." A study focusing on solely paid staff would not provide sufficient grounds for judging the individuals working for the nonprofit sector in Eastern Europe, and—by extension—about the nature of public service provision in this region. 
Operationalization of dependent variable. The dependent variable is the level of PSM operationalized by using the sixteen-item index developed by Kim et al. (2013) (See Table 4 for the summary of items). This scale was chosen for the study due to its modernity and its comparability for international and cross-national comparative contexts, which is explained in detail below.

Table 4: PSM Dimensions and Items as adopted from Kim et al. (2013)

Attraction to Public Service (APS)

APP5: I admire people who initiate or are involved in activities to aid my community APP7: It is important to contribute to activities that tackle social problems

CPI1: Meaningful public service is very important to me

CPI2: It is important for me to contribute to the common good Commitment to Public Values (CPV)

CPV1: I think equal opportunities for citizens are very important

CPV2: It is important that citizens can rely on the continuous provision of public services

CPV6: It is fundamental that the interests of future generations are taken into account when developing public policies

CPV7: To act ethically is essential for public servants

Compassion (COM)

COM2: I feel sympathetic to the plight of the underprivileged

COM3: I empathize with other people who face difficulties

COM5: I get very upset when I see other people being treated unfairly

COM6: Considering the welfare of others is very important

Self-sacrifice (SS)

SS2: I am prepared to make sacrifices for the good of society

SS3: I believe in putting civic duty before self

SS4: I am willing to risk personal loss to help society

SS7: I would agree to a good plan to make a better life for the poor, even if it costs me money

In their research, PA scholars addressed abiding content issues of PSM. The most

well-known is an American scholar James L. Perry (1996) who proposed that PSM is a four-dimensional construct. The four dimensions are: attraction to policy making, 
commitment to the public interest, compassion, and self-sacrifice. Substantial research finds some support for Perry's initial dimensions (Bright 2008, Coursey and Pandey 2007, Coursey et al. 2008, Kim 2009b, Liu, Tang, \& Zhu 2008, Ritz 2009, Vandenabeele 2008a, 2008b). However, research using Perry's PSM construct has limitations that recur from study to study. PSM scholars admitted that their findings do not fully confirm Perry's measurement model and, in particular, the proposed items do not properly work simultaneously (Kim 2009b, Liu, Tang, \& Zhu 2008, Ritz 2009, Vandenabeele 2008a).

Recent PSM literature has attempted to adjust Perry's scale to global international research. Kim and Vandenabeele (2010) proposed an alternative way to examine PSM, considering it as a set of "three plus one" items. Public service motives, according to them, are based on self-sacrifice and fall into three categories: instrumental, value-based, and identification motives. Their ideas found further development. Kim et al. (2013) provided a more country-neutral and thus more universal measurement instrument for scholars to study PSM in single country research. Their study combined the efforts of international PSM scholars to develop a measurement instrument for PSM based on tests conducted in twelve countries in North America, Europe, Asia, and Australia.

Operationalization of independent variables. The main explanatory variables of this study are context-specific dummy variables. The study employs indicators for sector of employment (public or nonprofit) and type of administrative system (centralized or decentralized). Measurements for these variables are not included in the survey, and information is recorded based on whether a survey was obtained from a public or nonprofit organization, in a country with a centralized or decentralized regime. 
At the same time, the survey includes the measurement of centralization of an organization operationalized by the three-item scale of Aiken and Hage (1968). Scholars specializing in human resources and organizational behavior research have adopted this scale to measure centralization level in organizations that provide services. For example, Raub (2008) applied it to assess the influence of centralization on "helping" behavior in the Swiss hotel industry. Marino and White (1985) surveyed hospital employees and included Aiken and Hage's scale to examine the relation between structural characteristics of an organization and perceived job stress.

Among other hypotheses, this study will test the relationship between the centralization level of an organization and public service motivation of employees involved in pro-social industries. The instrument is also structured on a 5-point Likerttype scale and the items are formulated as follows:

(CEN1) There can be little action taken here until a supervisor approves a decision;

(CEN2) In general, a person who wants to make his own decisions would be quickly discouraged in this organization;

(CEN3) Even small matters have to be referred to someone higher up/supervisor for a final answer.

Operationalization of control variables. The study also controls for a number of factors that are likely to influence individuals' engagement in pro-social activities for the sake of public benefit. Namely, it includes basic demographics (gender, age, highest degree of the education completed) and employment-related items (time spent with a particular organization, position, simultaneous employment in another sector, etc.). 
Previous research found different directions of gender relations with separate PSM dimensions and PSM-related notions. For instance, in the case of the commitment dimension, some studies show no gender impact (Chusmir 1986), others suggest that males are more committed than females (Rosenthal 1982) or vice versa (Mowday, Porter $\&$ Steers 1982). Empirical results suggest that male are less likely to value meaningful work (Houston 2000), while scores for the public interest/civic duty and self-sacrifice items are likely to be higher for men than for women (Perry 1997). Andersen et al. (2012) included public managers' gender, expecting different values on some PSM dimensions for female managers than for males. However, they have only addressed the theoretical implications of this control variable and never elaborated on how it was verified in the empirical tests of their study.

In previous studies, age as a control variable also revealed rather ambiguous results. On the one hand, Taylor (2010) found that age is negatively correlated with prosocial acts. On the other, some studies have shown that as individuals grow older, they tend to develop more altruistic values and motivation (McAdams \& de St. Aubin 1992, Pandey \& Stazyk 2008). Yet, empirical findings and theoretical propositions suggest that gender and age should have some impact on various PSM dimensions, and therefore, these variables are included as controls in the current study.

Education level often occurs as a control variable in PSM studies, however, only a few researchers ever addressed its empirical implications in their conclusions. Houston (2000) found that with each additional year of education an individual placed less emphasis on the importance of high income and job security, but stronger emphasis on 
meaningful work. At the same time, more educated workers could have greater commitment to a profession than to the organization itself (Steers 1977).

The survey prepared for this study includes categorical variables that reflect social activism, religion, and altruism. A respondent could indicate if she or he is a member of a union, a professional association or society, and a political party; whether she or he practices religious or spiritual activities or whether she or he performs voluntary service or charitable donations. Previous research shows that belonging to labor unions, professional associations, or societies significantly correlates with PSM, yet had it different directions for different dimensions: negative relation was found with attraction to policy making and positive relation was found with civic duty and self-sacrifice (Perry 1997). Perry (1997) also found negative correlation between church involvement and PSM. At the same time, Houston's (2000) observations suggest that church attendance had little effect on the sectoral differences in personal interests in high income, job security, and meaningful work.

Rurality as a control variable is not included in a questionnaire, but could be identified by observing where a survey was filled out. It would be interesting to test this variable in the context of Eastern Europe. Previous research, for instance, in Australia shows that living in the metropolitan area has a negative result on pro-social acts (Taylor 2010).

A separate group of control variables constitute the organizational characteristics of job, namely, additional employment, managerial position, job related experience abroad, number of subordinates, organizational task, longevity in an organization, and parental sector of employment. While all of them have been included in previous studies, 
details will be mentioned for selected results that have stronger empirical and theoretical support.

Thus, the study controls for the organizational task performed by an employee of a service providing entity. A respondent may choose a category: service delivery organizational task; regulative/administrative task; or technical personnel. As mentioned earlier in this section, technical personnel includes individuals that perform tasks not related to the main goal of organization, but which are, nevertheless, important for the continuity of service provision (accounting, computer systems, etc.). Andersen et al. (2012) also controlled for the self-reported main task of the organization because "the place you sit" has been shown to have a significant influence on motivation (e.g. Steinhaus \& Perry 1996).

Longevity in the organization is also likely to influence individual motivation, as with time, individuals could become socialized with problems and social issues that their organization deals with. Crewson (1997) similarly hypothesized the impact of tenure, asserting that high levels of commitment should be inherent to employees who have been socialized successfully to accept the organization's values.

\section{Data Collection Process}

Research in each sector in Poland and Belarus has its own specificities in terms of methods to contact sample organizations and to distribute surveys. At the same time, in each case, participants were informed that their participation was voluntary and their responses were anonymous. No identifying information (e.g., name or contact information) was included in the questionnaire. The survey took between 5-15 minutes to complete. To prevent any loss of the collected data, the responses were entered into the 
FIU Qualtrics online system as soon as was possible. The paper documents were stored in the researcher's home in a safe cabinet. Subsections below describe in detail data collection process in different sites.

Nonprofits in Poland. The list of nonprofit organizations from Podlaskie Wojewodstwo was created from information available at www.bazy.ngo.pl, which is an online portal of a Polish nonprofit umbrella institution Klon/Jawor. This websource is the largest and the most popular Polish database of foundations, associations and entities whose activities are associated with the non-governmental sector (NGO.pl 2014). The interactive platform allows for searching for non-governmental organizations according to their geographical location and area of activity. It also includes databases, where organizations have been already grouped according to various factors, e.g., area of activity, target population, type of registration of an organization, etc.

According to Bazy.ngo.pl, as of June 2014, the total number of nonprofit organizations registered in Podlaskie Wojewodstwo was 4,811. Despite the fact that this number also includes organizations that have been recently closed or are currently inactive, it still represents the volume of civil society initiatives that matured sufficiently to reach legal registration.

As previous research in Poland shows, the majority of nonprofit organizations are located in large urban areas (Bartkowski 2002). Therefore, the first sample was taken from Bialystok, which is a central administrative, cultural, and educational center of Podlaskie Wojewodstwo. To create a database of active nonprofits suitable for the study, the researcher checked for the organizations that provide public services in this city. The most widely represented nonprofits that provide actual services for citizens in Bialystok 
are organizations that (1) care for individuals who are handicapped or sick, or experiencing addition; (2) address unemployment problems; and (3) provide social care and assistance. It is necessary to mention that some of the organizations are presented in two or three category groups, because they address two or three of the abovementioned social issues.

More specifically, the organizations were selected if their area of activity covers the following services:

1) Social aid (charity; assistance to families and individuals facing difficult situations, ensuring equal opportunities; aid to victims of calamities, natural disasters, armed conflicts and warfare; supporting the disabled, supporting the retired; supporting veterans and victims of oppression; supporting the family and foster care system);

2) Health care (only if the services provided includeassisting social pathologies and addiction prevention);

3) Unemployment and economic development (supporting economic and entrepreneurship development; supporting vocational and social integration and reintegration of people threatened with social exclusion; promoting employment, activation of the unemployed and of individuals threatened with job loss).

The chosen organizations have been verified as organizations that provide actual services to the population. Advocacy organizations, sport clubs, professional associations, and freedom, democracy, religious and health promotion organizations were omitted. After applying these filters, the number of the nonprofits in Bialystok suitable for testing the hypotheses of this study was reduced to 94 organizations (See Table 5).

For example, the following organizations from Bialystok participated in the survey: 
Foundation for Health Protection "Support", Club of Abstainers "Azylum", the Foundation for Helping Children of Grodno region, "Europartner" Academic Club of European Integration, European Association for Education and Development "Idea", Podlasie Regional Development Foundation, and the Foundation Development Initiatives. Table 5: Nonprofit organizations that provide public services in Bialystok

\begin{tabular}{|l|l|}
\hline Target population and Area of activity & Number of organizations \\
\hline Handicapped, sick, addicted & 45 \\
\hline Unemployment, labor market services & 40 \\
\hline Social assistance & 65 \\
\hline Homeless & 5 \\
\hline Total & $\mathbf{9 4} *$ \\
\hline
\end{tabular}

Note: * total sum of organizations is not equal to the sum of subgroups, because some organizations find themselves in several categories

Similar steps were taken to expand the database with the regional organizations that operate in other towns in Podlaskie Wojewodstwo. After adding regional nonprofits, the initial database was expanded by 104 organizations from towns other than Bialystok, resulting in a total of 198 nonprofit organizations in Podlaskie Wojewodstwo that provide social assistance and labor market services. Taking into consideration the total number of nonprofit organizations registered in Podlaskie Wojewodsto (4904), non-religious service providing nonprofit organizations constitute only $4 \%$ of all organizations registered in this administrative unit of Poland.

Some organizations were not accessible via email; email accounts were neither found in Klon/Jawor databases nor in general searches for the organizations over the Internet. For example in Bialystok, the researcher could not locate email accounts for five out of 40 organizations in the unemployment category, 11 of 65 organizations in the 
social care category, and nine out of 45 organizations in the handicapped/sick/addicted category. An introductive email about the study (its aims, scope, and funding sources) was sent to encourage participation in the study and also ask whether this organization has the capacity to fill out an online survey.

The response rate to the introductory email was four percent, where three percent constituted positive responses, and one percent constituted refusal to participate in the survey. The organizations that responded positively received a follow-up email with the link to the online survey.

The organizations that did not respond to the introductory email within ten days were reached via phone, asking whether the email address listed in the researcher's database was a correct one. Those who did not receive an initial email received introductive information about the study (its aims, scope, funding sources) and were asked whether their organizations were interested in participation as well as what form of a survey (online or paper-and-pen) was more suitable for their organizations. About $37.9 \%$ or seventy-five organizations of 198 reached agreed to fill out a survey. The researcher either provided an online link or visited those organizations in person, where paper based surveys were distributed. As a result, seventy-eight respondents filled out a survey online and forty-eight respondents completed paper-and-pen form. For example, the following organizations that provide non-religious services agreed to participate in the survey: Łomża Association "Health and Sobriety", Association for Disabled with Alzheimer and Memory Disorders "Open You Eyes" in Siemiatycze, Augustow Association "Helping Hand", Suwalki Social Organization of Children's Friends 
"Marina", Dabrowa Bialostocka Association for People with Disabilities "Joy of life ", Puńsk Association for Children and Youth" You are not alone ".

Public Organizations in Poland. In addition to nonprofit service providers, Podlaskie Wojewodstwo also has public organizations that fight similar social issues. Established by each Gmina/Powiat — the smallest territorial unit—as required by Polish law, namely, by the Act of March $12^{\text {th }}, 2004$, on Social Assistance, Centers of Social Assistance provide diverse types of social care, e.g. for families with many children, individuals with disabilities, elderly people, and the homeless. According to the law, each territorial unit is obligated to have such a center: for urban areas they are City Centers of Social Assistance (CCSA) [in Polish: Miejski Ośrodek Pomocy Społecznej) and for rural areas they are Gmina Centers of Social Assistance (GCSA) (in Polish: Gminny Ośrodek Pomocy Społecznej). Other types of public organizations that often share target populations with social centers are Labor Offices (LO). The lowest level of LOs are Powiat Labor Offices (PLO) that operate on the local level and provide labor market services directly to unemployed persons and organizations looking for employees. LOs operate only in urban areas. Podlaskie Wojewodstwo has a LO in each town.

The main public institutions that aim to help handicapped/sick/addicted individuals in Podlaskie Wojewodstwo are hospitals. Yet, hospitals are excluded from the analyses for several reasons. Firstly, the health system in Poland is undergoing a series of serious reforms, one of which is healthcare privatization. Being public before, more and more hospitals today become either joint ventures with some part of a state share or completely private. Hospital structure is complicated: some of the departments in the same hospital remain public; other departments are private or belong to the unions. Thus, hospital 
employees cannot be considered entirely public, which is the main requirement for the analyses. Secondly, when including services for handicapped/sick/addicted individuals, this study mainly considers organizations that deal with social issues related to disabilities, like re-employment and employment activation and social care, rather than health care.

The most comparable to the nonprofit organizations, in terms of organizational goals, are CSA and PLO. The database of CCSA/GCSA functioning in the Podlaskie region was created using the www.bazy.ngo.pl web service. The database of PLO functioning in Podlaskie region was created using the database of the Wojewodski Labor Office http://www.up.podlasie.pl/, which is a supervisory organization for PLOs. There are seventy-four CCSA/GCSA in the Podlaskie region and 16 LOs.

Because LOs and CSAs are public organizations, they have a code of conduct defined by the law and local regulations. Any study of their employees requires an official letter addressed to a top manager of an organization, who is in charge of issuing permission. Therefore, PLOs received regular post letters introducing the survey and encouraging participation and a separate email with similar information. Those who did not respond within two weeks were reached via phone. As a result, eleven LOs agreed to participate in the survey and five LOs refused. The LO in Bialystok completed forty-one online surveys and other LOs in the Podlaskie region completed fifty online surveys, making a total of ninety-one surveys completed by LOs in the Polish sample.

Centers of Social Assistance received an email encouraging participation, and those organizations who agreed received a survey link in a separate email. The only exception was the City Center of Family Assistance, which is a center of social assistance 
in Bialystok (major city). This organization is the largest center of social assistance in Wojewodstwo and employs around 150 individuals. After obtaining permission from the top manager, both online and paper-based surveys were distributed to the employees of this Center. Online survey was chosen by twenty-four of employees from the City Center of Family Assistance, and forty-five employees completed a pen-and-paper version, making a total of sixty-nine respondents for the City Center of Family Assistance at forty-six percent response rate $(69 / 150 * 100 \%)$. In addition, twenty individuals from Podlaskie Centers of Social Assistance completed the survey online. In total, eighty-nine respondents that are employed by CSAs participated in the survey.

Nonprofit Organizations in Belarus. In order to develop a database of pro-social nonprofit organizations, the researcher used two online sources: the Portal of Belarusian NGOs www.ngo.by and the Bureau of Social information belbsi.by. According to the cumulative results of searches in two databases, Hrodna Voblasc has seventy-seven nonprofit organizations dealing with social issues: fifty-one of these organizations are located in the largest city of the oblast and its administrative center Hrodna, and twentysix are located in towns. A screen search of the Belarusian nonprofit database at the largest NGO portal www.ngo.by revealed that there are 202 nonprofit organizations of various types registered in Hrodna Voblasc. This means that as much as thirty-eight percent of all registered nonprofit organizations in Hrodna Voblasc are pro-social service providers.

Examples of the local organizations that participated in the study are the following: Public Charity "Grodno Children's Hospice", Volkovyssk Association of Parents and Children with Disabilities "Oridi", Grodno Jewish Welfare Fund "Nochum", Grodno 
Regional Association of Young Scientists "VIT", NGO Center of Informational Support for Community Initiatives "Third Sector", University of the Golden Age, Smorgon Public Association of Parents with Many Children, and Smorgon Association "Christian Association of Belarusian Young Women". In addition, including local chapters of national organizations such as the Red Cross, the Society for the Deaf, the Society for the Blind, or the Association of Afghanistan War Veterans expanded the database of participating organizations. Despite officially being responsible to the Voblasc level organization, these chapters usually function locally—-for instance, they independently fundraise and spend their funds. Therefore, the data on these forty-two chapters was expanded by the information sheets obtained from the abovementioned nonprofit organizations in Hrodna Voblasc sections.

The selected organizations include independent nonprofits financed from abroad and the chapters of the republican organizations that are mainly funded by membership fees and, in some cases, partly by government donations or subsides. The total number of organizations in the pro-social nonprofit in Hrodna Voblasc sample consisted of 119 units.

In-person visits to the organizations from the database showed that seventeen of them do not exist at all or moved to another address. These organizations also did not pick up the phone numbers found in the database. The chairs of existing organizations suggested that due to the recent increase in rent fees, the missing organizations might have moved to another location or simply closed. Communication though email with some of the leaders of the missing organizations proved that they in fact closed due to some technical constraints. 
Organizations were contacted via phone and visited in person. In Hrodna and Hrodna Voblasc, thirty-five nonprofit organizations agreed to participate in the survey (the response rate was $34.31 \%$, calculated as $35 /(119-17) * 100 \%)$. These nonprofit organizations provide, for instance, the following services: financial and material support, special assistance including representation and job placement, at-home care, job training, organizing social events and networking, improvement of entrepreneurial skills, distribution of vouchers for rehabilitation and health improvement sanatoriums, and social activation of retired individuals.

The paper-based surveys were distributed during the site visits to organizations, and only four organizations preferred the electronic version of the survey. Most of the organizations either lack computer equipment and the internet access, or their staff members spend most of their time on site providing services and thus, do not have a working place in the office. Also, as often observed during visits to the chapters of national organizations, individuals working in these nonprofits are primarily at retirement age and they do not possess enough experience to operate a computer. The total number of the respondents is 161 , where only eleven respondents preferred to complete the online survey, and the remaining 150 individuals completed paper-based surveys.

It is important to emphasize that the chapters of the national organizations usually have only two staff members hired as a full time employees: a chair for the organization and an accountant. The independent nonprofits also usually attract many volunteers for particular projects, who were not in the focus of the study.

Public Organizations in Belarus. The Belarusian government has designated special organizations under the Ministry of Labor and Social Protection that attend to 
social issues. These organizations provide services to the unemployed, families with many children, retirees, and sick and handicapped individuals who need at-home services.

The database of the public organizations was created using the information from the website of the Ministry of Labor and Social Protection http://mintrud.gov.by/. Organizations that deal with unemployment problems locally and under the supervision of the Voblasc Committees of Labor and Social Protection are town branches of "Departments of Employment" (DE) (in Belarusian: "Аддзелы Занятасці Насельніцтва"). "Territorial Centers of Social Services for Citizens" (TCSSC) (in Belarusian "Тэрытарыяльны Цэнтр Сацыяльнага Абслугоўвання Насельніцтва") provides social support for families with many children and poor and elderly individuals. In contrast to Polish public organizations that provide public services, public service organizations under the Ministry of Labor and Social Protection of Belarus do not serve homeless people - who are under the jurisdiction of the Ministry of the Internal Affairs. Both types of organizations have a branch in each district center with the exception of Hrodna city, which that has two centers of social services, making it eighteen DEs and nineteen TCSSCs for Hrodna Voblasc. These organizations are the representatives of the central government on the ground, and are responsible to the Voblasc Committee of Labor and Social Protection, which is under the direct supervision of the Ministry of Labor and Social Protection.

Employees of TCSSCs assist citizens who find themselves in difficult situations. These organizations provide social, psychological, legal, consulting help, financial assistance, assistance in social adaptation and rehabilitation. Varying from organization 
to organization, the TCSSC might have an urgent social services department; a social adaptation and rehabilitation department; an at-home social care; a day care center for people with disabilities, and a day care center for senior citizens. Departments of Employment provide various services related to the labor market, for instance: assistance to the unemployed in finding a suitable job, assistance to employers to find proper workforce; redirection of the unemployed to proper training; psychological and legal counseling; encouraging entrepreneurship and self-employment of unemployed individuals; providing temporary jobs in paid public works, traded for assistance in finding employment; an distribution of information concerning job vacancies and the labor market situation in town.

As a result of cultural peculiarities, the most secure way to obtain permission to conduct a survey without an official request from the Ministry is to visit public organizations in person and obtain permission from the top manager. Therefore, the researcher visited nine DEs and ten TCSSCs in person. Only one organization refused to participate in the survey. After obtaining official permission from a top manager from the rest of the town branches, 210 employees who are involved in public service provision agreed to participate and completed a paper-based survey: 157 respondents are the employees of the Hrodna city and district Centers of Social Services and fifty-three respondents are from the Citizens' Employment Sections.

\section{Summary of Data Collection}

The summary of surveys filled out in each sector in Belarus and Poland is presented in Table 6 below. Because the main aim of the study is to compare individual motivation across the sectors using a sample of pro-social service providers, both labor 
market and social care organizations of the public sector were pooled together within each country. The obtained samples represent individuals that work in service provision in the public sector in Poland and in Belarus.

According to the Klon/Jawor surveys, most of the nonprofit organizations in Poland employ less than five people and have up to fifteen volunteers (as cited by Chimiak, 2006). Similar observations were true for Belarus. Therefore, in order to get a number of responses comparable to the public sector, it was required to contact more nonprofit organizations than the public ones.

Table 6: Summary of Data Collection

\begin{tabular}{lc|c|l|c|l|l|}
\hline \multicolumn{4}{c}{ Podlaskie Wojewodstwo } & \multicolumn{3}{c}{ Hrodna Voblasc } \\
\cline { 2 - 7 } & $\begin{array}{l}\text { Organizations } \\
\text { in Region }\end{array}$ & $\begin{array}{l}\text { Participating } \\
\text { Organizations }\end{array}$ & $\begin{array}{l}\text { Surveys } \\
\text { Completed }\end{array}$ & $\begin{array}{l}\text { Organizations } \\
\text { in Region }\end{array}$ & $\begin{array}{l}\text { Participating } \\
\text { Organizations }\end{array}$ & $\begin{array}{l}\text { Surveys } \\
\text { Completed }\end{array}$ \\
\cline { 2 - 8 } Nonprofit & 198 & 75 & 126 & 119 & 35 & 161 \\
Public & 90 & 23 & 180 & 37 & 19 & 210 \\
\hline
\end{tabular}

The survey has a good response rate and the volume of the completed questionnaires is substantial and sufficient to compare the staff of public service providers across sectors and across countries. The number of responses obtained is sufficient to conduct both descriptive and inferential quantitative analyses. The data collected allows for the examination of differences between public service providers in Poland and Belarus and allows the researcher to test the hypothesized divergence in Public Service Motivation across sectors. The analysis and its results are presented in the following chapters. 


\section{CHAPTER 5: DATA ANALYSIS AND RESULTS}

Chapter 5 integrates previous sections of the dissertation. It is devoted to the analysis of the collected data within the framework of the hypotheses formulated in the second and third chapters. Before conducting the regression analysis aiming to test the factors that might influence individual PSM scores of employees from the public and nonprofit sectors, the applicability of the 16-item Kim et al. (2013) scale is tested for the Polish and Belarusian context. The PSM and centralization models are further tested for the measure invariances between the studied groups. The descriptive statistics of the samples, such as demographics and involvement in pro-social activities of the survey participants, is briefly reviewed afterwards. The end of this chapter presents results of the regression analysis for several models for the total PSM score and 16 models for each sample group and each PSM dimension. The chapter concludes with a discussion of the results and their relation to the hypotheses stated in the previous chapters.

\section{Models and Measure Invariance between Countries}

The analysis begins by testing the PSM theoretical construct using the LISREL 9.1 Diagonally-Weighted Least Squares (DWLS) as the most proper method for ordinal variables and a dataset of severely non-normal data (Kline 2011). Models were analyzed according to a two-step approach: first, an asymptotic covariance matrix was created, and second, this matrix was analyzed with DWLS estimation.

The basic idea in assessing model fit is to determine the degree of similarity between the sample correlation matrix and the predicted covariance matrix. For this purpose, separate robust DWLS were run for each country. Relative fits of the models were compared based on the Satorra-Bentler chi-square and approximate fit indexes 
(RMSEA and CFI) as important indices of fit that should be reported (Kline 2011, Bryne 1998). The Satorra-Bentler statistic accounts for non-normality of the data with the typical for PSM skewedness toward high end responses.

LISREL estimation for 16-item models revealed a poor fit for both countries. Results suggested that a statistically better model could be attained by eliminating the items that make the model mal-fitting. Moreover, it was required to find a model that equally works for the Belarusian and Polish populations, and as a result, allows for meaningful comparison. First, the Commitment to Public Interest item CPI1 was eliminated from the Belarusian dataset, because this item was not collected for the Polish sample due to technical reasons. Second, after analyzing the alternative models for each population separately, items that should be omitted for each model to run properly were identified. Elimination of SS2 was necessary for both Polish models and for the Belarusian nonprofit sector. Dropping COM5 was necessary for Belarusian models, but Polish models also significantly improved without this item. Despite working for some models, APP5 severely disturbed the fit of the Belarusian nonprofit model, and therefore, was removed for cross-national and cross-sector comparability.

Finally, Commitment to Public Values (CPV) provided ambiguous suggestions. In the Belarusian public sector, CPV1 and CPV7 were found to strongly reduce the goodness of fit statistics, while the model for Polish public sector suggested omitting CPV6. This finding warrants attention because it suggests differences between constituent elements of the Commitment to Public Values (CPV) dimension, namely, public values in equal opportunities, consideration of future generations, and ethics as perceived by the Polish and Belarusian public sector employees (See Chapter 4 for the 
complete list of items). Because three out of four items disturbed the goodness of fit of public sector models, CPV dimension was entirely dropped from the initial 16-item comparative model offered by Kim et al. (2013).

The following conditions were applied to retain items in the current study: at least two items represented each PSM factor, the minimum values for factor loadings were set at .55 . The resulting model was examined in terms of its theoretical meaningfulness and interpretability, which was suggested as the definitive factor-retention criterion (Fabrigar et al. 1999, Worthington \& Whittaker 2006).

Table 7: Goodness-of-fit Statistics for the 8-item PSM model

\begin{tabular}{|c|c|c|c|c|c|c|}
\hline & \multicolumn{2}{|c|}{ Belarus } & \multicolumn{2}{|c|}{ Poland } & \multirow[b]{2}{*}{ Configurative } & \multirow[b]{2}{*}{ Metric } \\
\hline & Public & Nonprofit & Public & Nonprofit & & \\
\hline SB $\chi^{2}(\mathrm{df})$ & $12(12)$ & $14(11)$ & 17 (14) & $12(10)$ & $80(61)$ & $82(63)$ \\
\hline $\mathrm{p}$-value & 0.451 & 0.218 & 0.245 & 0.226 & 0.051 & 0.056 \\
\hline RMSEA & 0.023 & 0.036 & 0.049 & 0.091 & 0.121 & 0.111 \\
\hline CFI & 1.000 & 0.990 & 0.992 & 0.993 & 0.988 & 0.987 \\
\hline GFI & 0.995 & 0.993 & 0.988 & 0.991 & 0.877 & 0.874 \\
\hline $\mathrm{N}$ & 210 & 120 & 174 & 119 & 623 & 623 \\
\hline
\end{tabular}

The final model consisted of Attraction to Public Service, Compassion and SelfSacrifice dimensions measured by nine items. Goodness-of-fit indices are very similar and within thresholds indicating good fit, as can be observed in Table 7. High factor loadings suggest good reliability of the model. The last step required testing for invariant factorial structure of scores from the measuring instrument in four populations. Tests for the measurement invariance showed significant positive results, also presented in Table 7, meaning that the final 8-item model works well in the studied populations. 
Figure 2: PSM 8-item Configurative Model with Standardized Factor Loadings

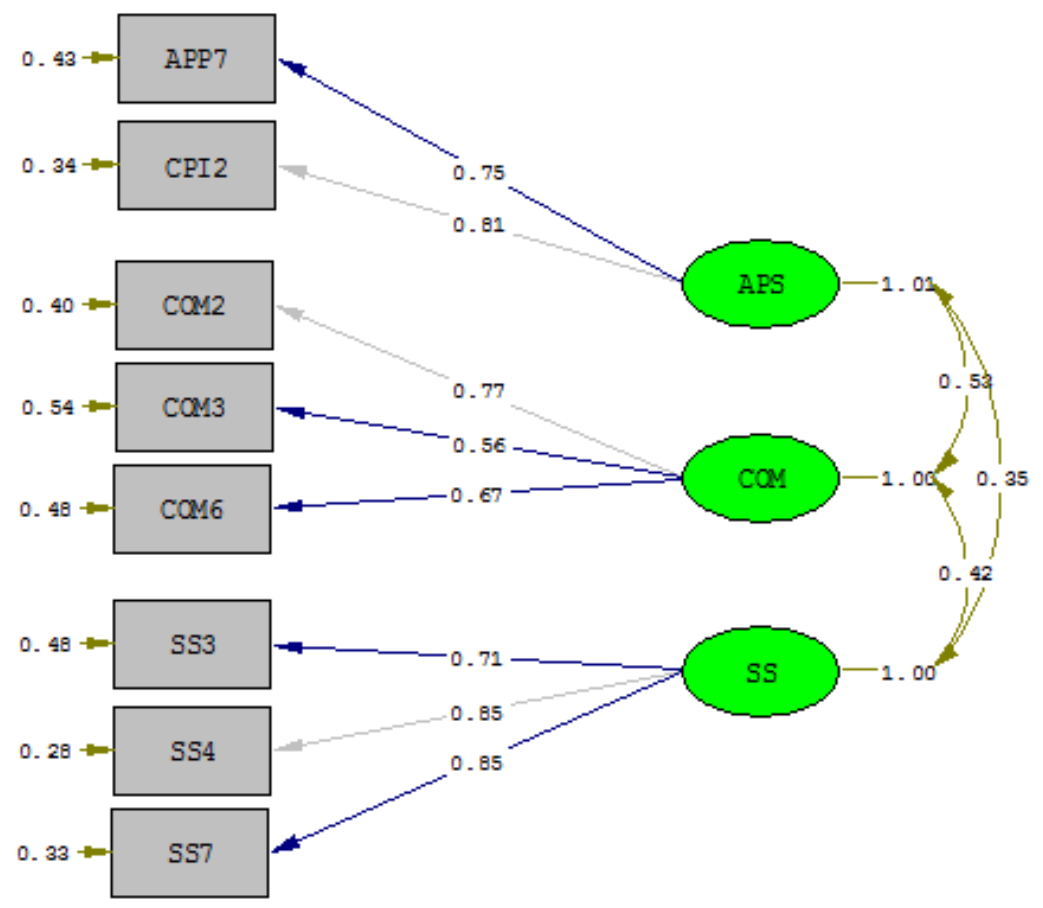

The analysis of the separate models without each CEN item for Poland and Belarus, and also comparison of the differences of fit between the configurative and metric models, showed that the first centralization item (CEN1) should be omitted to ensure the best comparability of the measurement scales between the countries. Because Diagonally-Weighted Least Squares (DWLS) analysis for the Centralization concept cannot be run with only two measurement items due to the fact that a two-item model will show general overfit, the two items (CEN 2 and CEN 3) and latent Centralization concept were added to the PSM model to confirm further analysis of centralization scale comparability between sectors and countries.

The results of the tests in Tables 8 and 9 present an overall score for the model that includes three PSM dimensions and Centralization. Because the concepts of PSM and 
Centralization are not related to the one latent concept and are put into the one model for technical purposes, the fit statistics show lower scores than they might have for separate models of the two concepts. Yet, these models allow for the assessment of differences in statistics between a configurative and a matrix model, which provides enough information to draw conclusions of the statistical fit for the centralization scale. The tests for the RMSEA and CFI differences between configurative and metric models are not significant when CEN1 is excluded, which again supports an overall good fit of the model without this item. The results of Tables 8 and 9 are provided for the comparison of four different organization centralization models: full model that consists of three items and separate models without one of the items. Another justification to drop CEN1 is the fact that while in Poland three centralization items are highly correlated; only CEN2 and CEN3 in Belarus show some significant correlation.

Table 8: Configurative Centralization Models

\begin{tabular}{|c|c|c|c|c|}
\hline & Full & !CEN1 & !CEN2 & !CEN3 \\
\hline$\overline{\mathrm{SB} \text { chi-square }(\mathrm{df})}$ & $128(87)$ & $92(72)$ & $94(72)$ & $99(72)$ \\
\hline $\mathrm{p}$-value & 0.003 & 0.063 & 0.041 & 0.019 \\
\hline RMSEA & 0.119 & 0.105 & 0.107 & 0.111 \\
\hline CFI & 0.972 & 0.986 & 0.983 & 0.979 \\
\hline GFI & 0.886 & 0.914 & 0.906 & 0.897 \\
\hline
\end{tabular}

Note: != without

Table 9: Metric Centralization Models

\begin{tabular}{|c|c|c|c|c|}
\hline & Full & !CEN1 & !CEN2 & !CEN3 \\
\hline$\overline{\text { SB chi-square (df) }}$ & $133(89)$ & 93(76) & $113(75)$ & $129(71)$ \\
\hline$p$-value & 0.002 & 0.087 & 0.003 & 0.000 \\
\hline RMSEA & 0.115 & 0.099 & 0.115 & 0.128 \\
\hline CFI & 0.968 & 0.986 & 0.968 & 0.949 \\
\hline GFI & 0.882 & 0.915 & 0.896 & 0.763 \\
\hline
\end{tabular}

Note: != without 


\section{Descriptive Statistics}

This section presents the results of the descriptive analysis for the entire data set as well as separate groups for countries and sectors. The findings provide evidence for rejecting and supporting several hypotheses of the study. The section proceeds as follows: first, the descriptive statistics for the sample demographics, job related variables, and pro-social activities of the respondents are presented; second, the descriptive characteristics for the 8-item PSM model and separate dimensions are contrasted within the countries and sectors; and third, the comparison of centralization in different organizations is conducted.

Sample Groups. Data analysis begins with calculation of descriptive statistics (means and standard deviations) on demographic characteristics of the sample. Demographics for the sample are shown in Table 10.

Table 10: Means and Standard Deviations for Demographics

\begin{tabular}{lcccccc}
\hline \multirow{2}{*}{ Variables } & \multicolumn{2}{c}{ Belarus } & & \multicolumn{2}{c}{ Poland } \\
\cline { 2 - 3 } \cline { 5 - 6 } & \multicolumn{2}{c}{$\mathrm{M}$} & $\mathrm{SD}$ & & $\mathrm{M}$ & $\mathrm{SD}$ \\
Woman & \multicolumn{2}{c}{$\mathrm{N}=213$} & & Public & & $\mathrm{N}=174$ \\
Age Group & 0.93 & 0.26 & & & 0.81 & 0.39 \\
Education & 3.71 & 1.07 & & & 3.55 & 1.11 \\
& 3.33 & 0.83 & & & 3.75 & 0.64 \\
Woman & \multicolumn{2}{c}{$\mathrm{N}=120$} & Nonprofit & & $\mathrm{N}=119$ & \\
Age Group & 0.79 & 0.41 & & & 0.81 & 0.40 \\
Education & 4.18 & 1.07 & & & 3.13 & 1.20 \\
\hline
\end{tabular}

Note: $\mathrm{M}=$ mean, $\mathrm{SD}=$ Standard Deviation; for the measurements and scales of variables see Chapter 4.

The Belarusian public sector is older and strongly female dominated compared to both sectors in Poland. On average, education level is higher for public service providers in Poland as compared to Belarus, where it is equal among the sectors. The most 
educated group is Polish nonprofits. Even though the standard deviation for each group indicates a broad age range, the eldest employees are found in Belarusian nonprofits, where also most males were present. While public services are usually dominated by women, another trend in the samples in this study is that Belarusian nonprofits employ the largest percentage of men: every fifth employee is a male.

Table 11: Means and Standard Deviations for Job Characteristics

\begin{tabular}{|c|c|c|c|c|c|}
\hline \multirow{3}{*}{ Variables } & \multicolumn{2}{|c|}{ Belarus } & & \multicolumn{2}{|c|}{ Poland } \\
\hline & $\mathrm{M}$ & SD & & $\mathrm{M}$ & $\mathrm{SD}$ \\
\hline & \multicolumn{5}{|c|}{ Public } \\
\hline Time in Organization & 2.34 & 1.40 & & 3.13 & 1.28 \\
\hline Foreign Experience & 0.08 & 0.27 & & 0.25 & 0.43 \\
\hline Managing Others & 0.37 & 0.48 & & 0.34 & 0.48 \\
\hline First Contact Position & 0.69 & 0.46 & & 0.61 & 0.49 \\
\hline Org. Type: Labor & 0.26 & 0.44 & & 0.51 & 0.50 \\
\hline Major City & 0.55 & 0.50 & & 0.62 & 0.49 \\
\hline & \multicolumn{5}{|c|}{ Nonprofit } \\
\hline Time in Organization & 2.18 & 1.26 & & 2.21 & 1.43 \\
\hline Foreign Experience & 0.26 & 0.44 & & 0.28 & 0.45 \\
\hline Managing Others & 0.40 & 0.50 & & 0.58 & 0.50 \\
\hline First Contact Position & 0.60 & 0.50 & & 0.50 & 0.50 \\
\hline Service: Labor & 0.13 & 0.33 & & 0.42 & 0.50 \\
\hline Major City & 0.75 & 0.43 & & 0.66 & 0.48 \\
\hline
\end{tabular}

Polish public sector employees have the longest work experience in their organizations. The Belarusian public sector, on average, has the same as nonprofit groups. This can be explained by the compulsory contract system in the Belarusian public sector: the length of each employment contract is one year, and it must be renewed annually, which influences job mobility, but also longevity of one's employment. Belarusians in the public sector have the lowest percentage of professional foreign experience, while for three other groups — on average-every fourth person was participating in training or seminar abroad. More than half of respondents in Polish nonprofits declared themselves as managers. At the same time, managers in other groups 
constitute roughly one third of the samples and another two thirds are employees on their first contact. In the Belarusian sample, there are less respondents that primarily provide services for the unemployed than in Poland. This could be explained by the fact that in Belarus public labor offices are usually small —with two to three employees in each town - and labor market services among the nonprofits are not as developed as they are in Poland. The location variable shows that around 55-75\% of the respondents work for organizations located in the region capitals, namely Hrodna and Bialystok.

Table 12: Means and Standard Deviations for Pro-Social Activities

\begin{tabular}{|c|c|c|c|c|c|}
\hline \multirow[b]{2}{*}{ Variables } & \multicolumn{2}{|c|}{ Belarus } & & \multicolumn{2}{|c|}{ Poland } \\
\hline & $\mathrm{M}$ & SD & \multirow[b]{2}{*}{ Public } & $\mathrm{M}$ & SD \\
\hline & & & & & \\
\hline Labor Union & 0.90 & 0.30 & \multirow{11}{*}{ Nonprofit } & 0.18 & 0.39 \\
\hline Professional Org. & 0.02 & 0.15 & & 0.07 & 0.25 \\
\hline Political Party & 0.04 & 0.20 & & 0.07 & 0.26 \\
\hline Religious Practices & 0.05 & 0.21 & & 0.32 & 0.47 \\
\hline \multirow[t]{2}{*}{ Volunteering } & 0.07 & 0.26 & & 0.16 & 0.37 \\
\hline & & & & & \\
\hline Labor Union & 0.55 & 0.50 & & 0.03 & 0.18 \\
\hline Professional Org. & 0.08 & 0.26 & & 0.38 & 0.49 \\
\hline Political Party & 0.04 & 0.20 & & 0.03 & 0.18 \\
\hline Religious Practices & 0.18 & 0.38 & & 0.25 & 0.44 \\
\hline Volunteering & 0.33 & 0.47 & & 0.45 & 0.50 \\
\hline
\end{tabular}

Belarusian groups show high level of unionization in both the public and nonprofit sectors, with the highest (90\%) among the public employees. Meanwhile in Poland, only every fifth employee of a public organization is a member of a labor union, with almost none of them in the nonprofit sector. Yet, the data for the Polish nonprofit sector suggest that more than one third of these respondents belong to some sort of professional organization instead. Membership in professional organizations among other sample groups is very rare. The answers for political party memberships are similar across the groups: roughly $5 \%$ of the respondents in each country and sector belong to a 
party. The least number of religion practitioners is found in the Belarusian public sector-on average only 5\%. At the same time, in Belarusian nonprofits, every fifth respondent declared that he or she participated in religious or spiritual practices, whereas every fourth respondent declared among the Polish nonprofit employees. The highest number of employees practicing religion is found in the Polish public sector, where onethird of the respondents engage in church activities. Employees of the nonprofit sectors tend to devote more of their time to volunteering, $33 \%$ and $45 \%$ in Belarus and Poland respectively, when, on average, only $16 \%$ of public employees volunteer in Poland and $7 \%$ in Belarus.

Summarizing the pro-social activities, Belarusian public employees mainly belong to a labor union as their main social activity, Belarusian nonprofit employees-in addition to labor unions - tend to become involved in religious and volunteering practices, Polish public sector workers devote their time mainly to religious activities while also participating in labor unions and volunteering practices, and, finally, for Polish nonprofit employees, volunteering remains the main social activity, while they are also active in professional organizations and religious practices. As expected, both nonprofit groups consider volunteering to be an important social activity and score much higher on this item than the public sector employees. At the same time, the main difference between nonprofit groups remains that while Belarusian nonprofits are highly unionized, Polish nonprofit employees participate in other forms of professional organizations.

Means and t-tests for PSM. Independent t-test was run to compare means of PSM and its dimensions between two sectors. The test is conducted for the pooled sample and for each country separately (See Tables13 and 14) and the test assumed that variances for 
the public and the nonprofit sectors are the same. The results for the corresponding twotailed p-values are less than 0.01, with the exception of the Self-Sacrifice dimension in Poland. Therefore, excluding this dimension, the overall conclusion is that the differences of means in total PSM, Compassion and Attraction to Public Service, between employees in the public and nonprofit service providing organizations are distinct from 0. PSM and its dimensions are found to be higher among the nonprofit sector employees, with the exception of self-sacrifice in Poland, where both sectors exhibit similar medium-high level. These findings are in-line with Hypothesis 2, suggesting a preliminary conclusion that nonprofit employees are more motivated than public sector employees. The nonprofit sector employees exhibit higher levels of PSM than their counterparts in the public sector. The inferential statistics presented in the following sections will provide further support for Hypothesis 2.

Table 13: Sample Descriptive Using $t$-test for Equality of Means between Sectors

\begin{tabular}{|c|c|c|c|c|c|c|}
\hline & & & & & ofit & \\
\hline & $\bar{M}$ & SD & & $\mathrm{M}$ & SD & $t$-test \\
\hline & & & Belarus & & & \\
\hline PSM & 3.71 & .04 & & 4.18 & .05 & $7.75^{* * *}$ \\
\hline Compassion & 4.26 & .04 & & 4.58 & .04 & $4.68 * *$ \\
\hline Self-Sacrifice & 2.89 & .06 & & 3.55 & .08 & $6.44 * *$ \\
\hline Attraction to & 3.98 & .04 & & 4.42 & .05 & $6.18^{* *}$ \\
\hline & & & Poland & & & \\
\hline PSM & 3.87 & .04 & & 4.12 & .05 & $3.96 * *$ \\
\hline Compassion & 4.28 & .05 & & 4.57 & .05 & $4.10^{* *}$ \\
\hline Self-Sacrifice & 3.55 & .07 & & 3.40 & .09 & -1.36 \\
\hline $\begin{array}{l}\text { Attraction to } \\
\text { Public Service }\end{array}$ & 3.76 & .07 & & 4.41 & .06 & $6.93 * *$ \\
\hline
\end{tabular}

The results offer only partial support for Hypothesis 1 that the centralization level of the government affects PSM of individuals involved in public service provision. First, 
the t-test suggests no difference between nonprofit sector service providers in the two countries. Second, while total PSM score is lower for the Belarusian public sector than for the Polish public sector, the Compassion dimension remains similar and Attraction to Public Service appears to be higher in the Belarusian public sector. Thus, the higher total for PSM is mainly explained by the notably higher score in Self-Sacrifice (SS). The regression analysis, conducted in the following sections, suggests some possible explanations for the higher SS score declared by Polish public sector employees.

Table 14: Sample Descriptive Using $t$-test for Equality of Means between Countries

\begin{tabular}{|c|c|c|c|c|c|c|}
\hline & & & & & & \\
\hline & $\mathrm{M}$ & SD & & $\mathrm{M}$ & SD & $t$-test \\
\hline & & & Public & & & \\
\hline PSM & 3.71 & .04 & & 3.87 & .04 & $-2.86 * *$ \\
\hline Compassion & 4.26 & .04 & & 4.28 & .05 & -0.29 \\
\hline Self-Sacrifice & 2.88 & .07 & & 3.55 & .06 & $-6.97 * *$ \\
\hline Attraction to & 3.98 & .04 & & 3.76 & .07 & $2.79 * *$ \\
\hline Public Service & & & & & & \\
\hline & & & Nonprofit & & & \\
\hline PSM & 4.18 & .05 & & 4.12 & .05 & 0.85 \\
\hline Compassion & 4.58 & .04 & & 4.57 & .05 & 0.22 \\
\hline Self-Sacrifice & 3.55 & .08 & & 3.40 & .09 & 1.27 \\
\hline Attraction to & 4.42 & .05 & & 4.41 & .06 & 0.17 \\
\hline Public Service & & & & & & \\
\hline
\end{tabular}

For further analysis of PSM and its dimensional means, a $t$-tests was conducted for the countries' corresponding sectors. For this purpose, an independent-samples $t$-test was conducted to determine whether the mean of PSM and its dimensions are the same in the two countries, specifically, whether the mean difference between these groups are statistically significantly different from zero. The results of this test suggest that Polish public sector employees report statistically significant higher on general PSM score than their Belarusian counterparts. The same holds for the SS in the public sectors. 
Meanwhile, Compassion and Attraction to Public Service reveal other trends, namely, COM is similar within a sector when compared between countries, and APS is found to be statistically significantly higher in Belarus.

The results of the analysis above shed some light on the research questions reflected in Hypothesis 3, namely, that the administrative regime differences intensify the PSM differences between the countries. As the comparison of $t$-test scores suggest, the Belarusian data set reveals overall greater differences between the sectors, especially when the total PSM score is compared. In Poland, the significant difference between sectors is lower for the total PSM and Compassion dimensions, while Self-Sacrifice tends to be similar between sectors. Yet, the Polish sample reveals the larger difference between sectors in regard to respondents' Attraction to Public Services. Reporting lower than a pooled-sample mean (3.88), the Polish public employees tend to be the least interested in initiating or contributing to projects that benefit their communities, when compared to the respondents in any other sample group.

Bar diagrams on Figure 3 present visualization of the t-test results, which allows for the simultaneous observation of statistically significant differences and similarities between the sectors and countries. 
Figure 3: Mean scores for PSM and Constituent Dimensions

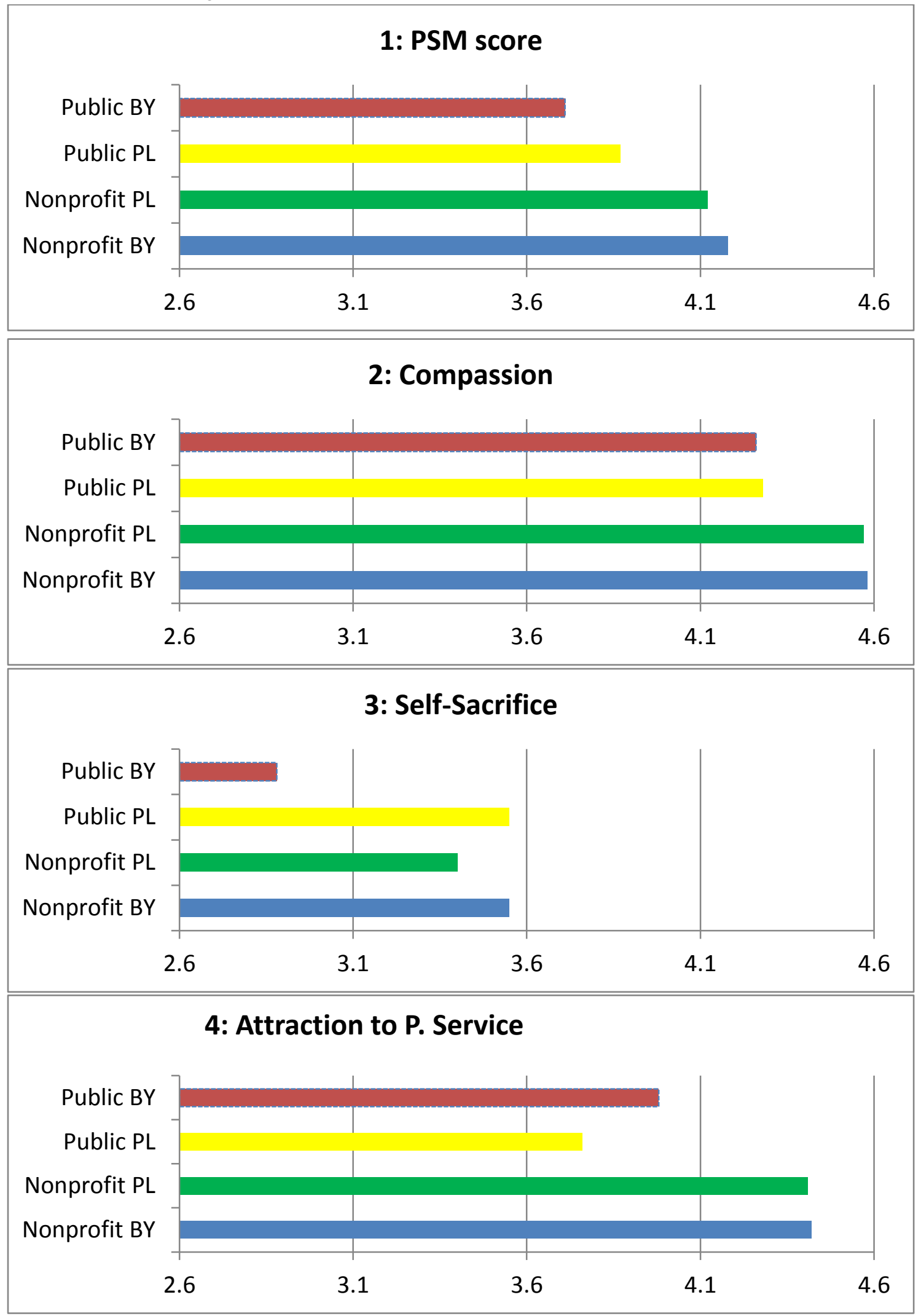


Means for Centralization. The perception of organization centralization reveals statistically significant differences between sectors in each country. The mean scores and the results of the $t$-tests are presented in Table 15. The $t$-test allows for the conclusion that both in Belarus and in Poland, centralization is on average higher in public service providers than in the nonprofits that provide similar services.

Table 15: Sample Descriptive Using $t$-test for Equality of Means between Sectors

\begin{tabular}{|c|c|c|c|c|c|c|}
\hline & \multicolumn{2}{|c|}{ Public } & & \multicolumn{2}{|c|}{ Nonprofit } & \multirow{2}{*}{$t$-test } \\
\hline & $M$ & SD & \multirow[b]{2}{*}{ Belarus } & $\mathrm{M}$ & SD & \\
\hline & & & & & & \\
\hline CEN2 & 2.94 & .08 & & 2.26 & .11 & $-5.10 * *$ \\
\hline CEN3 & 3.27 & .09 & \multirow{4}{*}{ Poland } & 2.62 & .12 & $-4.34 * *$ \\
\hline & & & & & & \\
\hline CEN2 & 3.18 & .10 & & 2.33 & .10 & $-5.93 * *$ \\
\hline CEN3 & 3.43 & .10 & & 2.53 & .11 & $-5.78 * *$ \\
\hline
\end{tabular}

The comparison of the means between countries suggests less homogeneous results than for the means between the sectors (See Table 15). When the corresponding sectors are compared between the countries, a question about discouragement to undertake initiative (CEN2) reveals a significant difference: in Belarus, respondents provided neutral answers, whereas in Poland, they declared more situations like this occuring at their work place. The CEN3 item about the obligation to refer to someone higher up for a final decision in small matters appeared to have no significant difference between two samples. The evidence suggests that the hypothesized assumption that centralization of service provision is reflected in the centralization level of public organizations could not be confirmed, meaning that the organization centralization scale cannot be used as a proxy for centralization of public service provision. 
Thus, a medium-high degree of centralization in public service providers occurs in both centralized and decentralized administrative regimes. This finding is consistent with previous theoretical propositions. As Mintzberg (1983) points out, the high level of centralization is common in large organizations-in our case, in service provision systems - because they must control their employees' behavior, reducing employee variability and attempting to predict and control employee actions. This finding suggests, therefore, that the organization centralization variable is not a critical factor when discriminating between public entities located in regimes with different levels of administrative centralization.

Table 16: Sample Descriptive Using $t$-test for Equality of Means between Countries

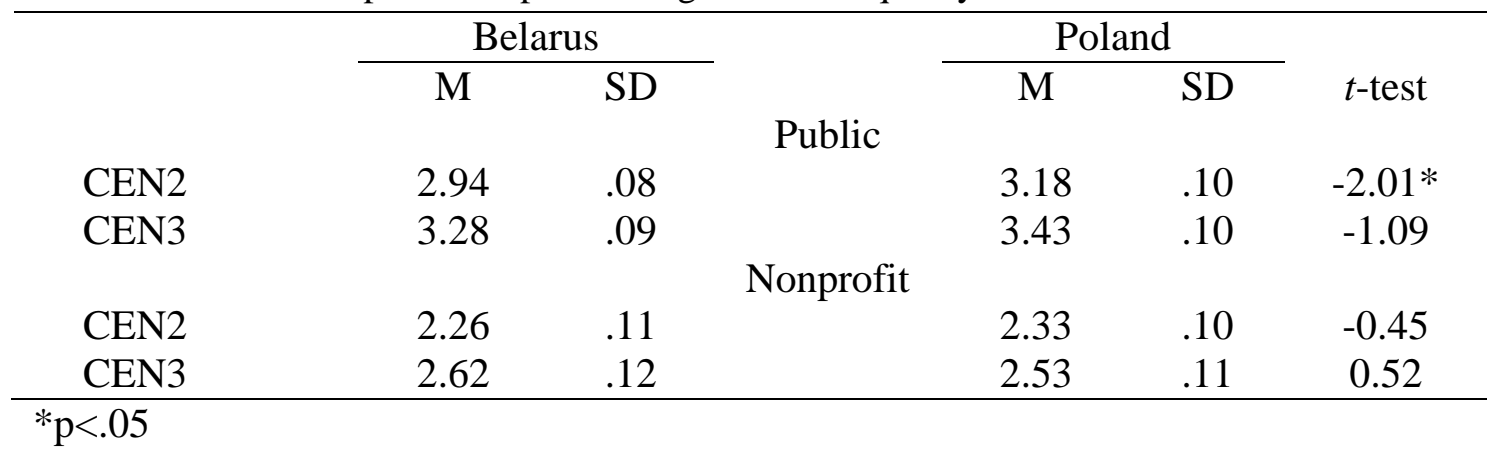

\section{Inferential Statistics}

The relations between PSM and centralization, as well as ascendants of PSM in different sample groups, are further examined via regression analysis. Because centralization, PSM, and its dimensions are represented for each respondent as mean scores of their constituent items, these initially ordinal variables transformed into continuous variables. Therefore, OLS was selected as the most proper method for estimating parameters in the models. The study acknowledges that using a Generalized Linear Model or a Tobit model might improve the estimation, but, because the primary 
interest is the significance level and the signs of the coefficients rather than their value, the benefits of using these more sophisticated methods are marginal.

PSM and Dimensions for Pooled Sample. The analysis of the pooled sample allows for further testing the significance and the direction of the hypothesized differences between sectors and countries. It also reveals whether the hypothesized relations between PSM and centralization occur in the region under study. The regressions in this section included the entire sample from the two sectors and the two countries with a total $\mathrm{N}$ varying from 626 to 557.

First, the simple model that includes only a dependent and two independent variables was tested. The results revealed that CEN2 (initiative discouragement) is negatively correlated with the total PSM score, while CEN3 (necessary approvals for action) has a significant positive relation with the general motivation in the region under study. Due to the strong (.63) and significant correlation between CEN2 and CEN3, an additional test for colleniarity was conducted for Model 1 and revealed no significant problems with this model. Variance inflation factor (VIF) values were less than 10 and thus do not require additional investigation. Therefore, for further analysis, the results of the tests recommend a model that includes two centralization items simultaneously.

Model 2 elaborates on Model 1 and consists of variables that allow for testing of the major hypothesis of this study, namely, the difference between countries and sectors in regard of PSM. The regression of centralization items and the dummy variables for countries and sectors revealed that on average taking the differences of organization structures into account, Polish employees report statistically significantly higher PSM than Belarusians, and public sector employees in both countries have a lower PSM score 
than their nonprofit sector counterparts. These findings hold up the conclusions reached in the descriptive analysis earlier in this Chapter.

Model 3 expands Model 2 by individual demographics, such as gender, age, and education level. The results show that on average in the pooled sample, being a woman suggests lower PSM score and that with age, the motivation of the employees involved in public service provision increased significantly.

In addition to demographics, Model 4 included personal and organizational characteristics related to the workplace. Out of six variables, only the one referring to the position that includes first-hand contact with citizens has statistically significant and positive relations with the PSM score. The most complete model, Model 5, introduces pro-social activities performed by respondents and suggests that labor union membership is negatively correlated with motivation. This model also displays positive significance of the professional foreign experience for PSM.

A comprehensive list of personal and organizational characteristics of Model 5 reduced the significance of the country dummy variable, suggesting that these differences are rigorously reflected in the chosen control variables. Moreover, R-squared has constantly grown with the advancement of the model. The R-squared value usually increases when more variables are added to the models. Meanwhile, it also partly reflects the improvement of the percentage of the response variable variation that is explained by a more advanced linear model. As will be observed later on when Model 5 will be applied for separate sample groups, the R-square value will show different scores depending on the model fit for a particular population. 
Further analysis consists of regressions for each PSM dimension that allows for the identification of possible variations in the relations of these dimensions with the independent variables. Three models were tested for the heteroskedasticity (HSK) using the Breusch-Pagan test. Based on the p-values of BP test for COM and APS, which is less than alpha (5\%), the conclusion suggested some HSK in the model. The test for SS revealed some marginal results $($ Prob $>$ chi2 $=0.0680$ ). In order to correct for HSK, the robust option was added to the regressions.

The results for Self-sacrifice show that this dimension negatively correlates with discouragement to take initiative and positively with the necessity to ask for permission for actions. The same pattern was found in Attraction to Public Service, with the only difference in significance levels. CEN3 is marginally correlated to APS.

The multiple regression analysis of the pooled sample also suggests strong negative correlation of the public sector with the three PSM dimensions at a very high significance level. As for the variables that reflect individual differences, educational level is found to have a negative impact on compassion, while positively correlating with the attraction to public service. This means that on average, keeping other variables constant, with additional education, individuals in all four groups become slightly less compassionate about the misfortunes of others while also becoming more willing to participate or initiate actions that benefit their community. The results also reveal that with age, individuals involved in service provision begin to more often place their civic duties before self, and also, as with the case of education, become more willing to contribute to their communities. 
Variables that control for the organization and job characteristics reveal the following relations. The longer a respondent stayed in an organization, the higher levels of self-sacrifice he or she reported. Significantly higher levels of self-sacrifice are also correlated with organization type: the employees involved in the labor market services have higher scores than individuals involved in social assistance. At the same time, opposite results are revealed for the attraction to public service, with employees in the labor market provision scoring notably lower than those that provide social care. Individuals in managerial positions also have considerably higher attraction to public service than individuals in any other positions in an organization.

Out of all the pro-social activities, only labor unions reveal some significant correlations with PSM dimensions — namely, a strong negative correlation between union membership and self-sacrifice.

Despite being relatively low, R-squared (.090) in the Compassion model signifies that even noisy, high-variability scores of this item might still have some significant trend. The trend indicates that the predictor variables, such as education or belonging to a public sector, provide information about the response even though the data points fall further from the regression line. Higher R-squares for Self-Sacrifice and Attraction to Public Service (.196 and .202 respectively) imply a larger percent of variance explained by the model.

PSM and Dimensions by Country and by Sector. Separate regressions for the pooled sectors for countries revealed statistically significant coefficients for the sector dummy variables. For better interpretation of the findings and in order to observe relations between PSM and the independent and control variables, separate regressions 
were run for total PSM, COM, SS and APS for each country and sector. Compete results of these 16 regressions are presented in the Appendix, while Tables 15-18 below present a summary of statistically significant coefficients of the variables that correlate with PSM and its dimensions.

Table 15: Summary for Regression Results for the total PSM Score

\begin{tabular}{|c|c|c|}
\hline & Belarus & Poland \\
\hline Public & $\begin{array}{l}\text { - Major City }\left(.20^{* *}\right) \\
\text { - Labor Union }\left(-.26^{*}\right) \\
\text { - Political Party }\left(.39^{*}\right) \\
\text { - Volunteering }\left(-.34^{*}\right)\end{array}$ & $\begin{array}{l}\text { - } \text { Initiative Discouragement }\left(-.19^{* * *}\right) \\
\text { - Prior Approval }\left(.15^{* * *}\right), \\
\text { - Labor Union }\left(-.21^{*}\right), \\
\text { - } \text { Religious Practices }\left(.26^{* * *}\right)\end{array}$ \\
\hline Nonprofit & - Political Party $(.42 * * *)$ & $\begin{array}{l}\text { - Prior Approval }\left(.12^{*}\right) \text {, } \\
\text { - Age Group }\left(.10^{*}\right) \text {, } \\
\text { - Religious Practices }(-.29 *)\end{array}$ \\
\hline
\end{tabular}

Note: Regression coefficients marked with an asterisk were statistically significant at * $\mathrm{p}<0.10 ; * * \mathrm{p}<0.05 ; * * * \mathrm{p}<0.01$

Public Organizations. The most informative result regarding the impact of organization and state centralization on motivation is that in Poland, centralization indeed correlates with PSM, while in Belarus, almost no significant correlations were found between the two concepts. This suggests that despite medium-high centralization in both countries, the centralization of organizations providing public services in Belarus fails to affect the motivation of separate employees, while in democratic Poland the organization centralization has a more apparent effect on PSM.

As the results suggest, increasing the centralization level by discouraging initiative, Polish service providing organizations are likely to lose compassionate and dedicated employees or not attract them at all. Analysis of the relations between the centralization and separate PSM dimensions in Poland suggests that the environment that 
discourages employees to undertake independent decisions (CEN2) corresponds to the reduced attraction to public service. This also means that highly independent and enterprising individuals in Poland are less likely to be interested in tackling social problems and contributing to the common good, even if they work for the public sector.

Table 16: Summary of Regression Results for Compassion

\begin{tabular}{|c|c|c|}
\hline & Belarus & Poland \\
\hline Public & $\begin{array}{l}\text { - First Contact Position }\left(.30^{* *}\right) \\
\text { - Major City }\left(.21^{*} \pm\right) \\
\text { - Political Party }\left(.35^{* *}\right)\end{array}$ & $\begin{array}{l}\text { - Initiative Discouragement }\left(-.11^{* *}\right) \\
\text { - Prior Approval }\left(.11^{* *}\right) \\
\text { - Foreign Experience }\left(.19^{*} \pm\right) \\
\text { - Major City }\left(-.26^{* *}\right) \\
\text { - Political Party }\left(-.61^{* * *}\right)\end{array}$ \\
\hline Nonprofit & $\begin{array}{l}\text { - Foreign Experience }(-.29 *) \\
\text { - Political Party }(.19 *) \\
\text { - Volunteering }(-.22 *)\end{array}$ & $\begin{array}{l}\text { - Prior Approval }\left(.12^{* *}\right) \\
\text { - Managing Others }\left(-.27^{*}\right) \\
\text { - Service: Labor }\left(.36^{* *}\right) \\
\text { - Major City }\left(-.53^{* *}\right)\end{array}$ \\
\hline
\end{tabular}

Note: Regression coefficients marked with an asterisk were statistically significant at $*$ $\mathrm{p}<0.10 ; * * \mathrm{p}<0.05 ; * * * \mathrm{p}<0.01$

Centralization, measured by the necessity to obtain approval for any action, showed a positive correlation with the total PSM score and with every separate dimension. Thus, Compassion, Self-Sacrifice, and Attraction to Public Service reveal positive relations with the tight accountability in a public organization. In addition to stronger compassionate feelings, higher centralization in a public organization increases the desire to participate in activities that benefit the community and to place civic duty before self and to support the poor, even if it causes personal losses. Self-sacrifice and increased centralization seem to go hand in hand with reducing individualism of employees in Polish public organizations.

Individuals who live in the capital are also found to be less compassionate than those in smaller towns. This finding is consistent with an Australian study, which showed 
that living in a metropolitan area has a negative result on pro-social acts (Taylor 2010). This indicates that the community ties in smaller towns tend to be stronger. In addition, employees of labor services score significantly higher on self-sacrifice, and significantly lower on attraction to public service, than their colleagues in social care organizations. Public employees with some professional foreign experience might have higher level of compassion.

Religion plays a special role in Polish society, which is supported by highly significant results for the public sector employees. Individuals who participate in religious practices have statistically significant higher levels of self-sacrifice, attraction to public service, and overall PSM score. Thus, they are more likely to feel the importance to contribute to the common good and become involved in activities that address social issues. They are ready to place the civic duty before self and forfeit their own money to help the poor.

Table 17: Summary of Regression Results for Self-Sacrifice

\section{Belarus}

- Foreign Experience (.51*)

- Major City $(.30 *)$

Public

- Labor Union (-.52**)

- Political Party $\left(.65^{*}\right)$

\section{Poland}

- Initiative Discouragement (-.19**)

- Prior Approval (.20***)

- Service: Labor (1.14***)

- Religious Practices (.33**)

\section{Nonprofit}

- First Contact Position (.29**)

Note: Regression coefficients marked with an asterisk were statistically significant at * $\mathrm{p}<0.10 ; * * \mathrm{p}<0.05 ; * * * \mathrm{p}<0.01$

Contrary to religious affiliation, belonging to a political party negatively correlates with compassion of public sector employees. Thus, for the Polish public sector, party membership means less empathy for those in need. This finding goes contrary the 
typical image that a party presents to voters. Moreover, the reduced compassion for others suggests that the internal climate of political parties in Poland is likely to be very competitive, which negatively influences their morality. Such results suggest that it is hard for a party member in Poland to be successful and compassionate toward others at the same time. This finding is consistent with Jackall's (1983) ideas of the "moral maze" created by the competitive environment in a bureaucratic organization, which in this case is a political party. According to Jackall (1983), "moral maze" of the bureaucratic ethic occurs when bureaucracy destroys internal and external standards of morality in matters of individual success and failure and in routine issues that managers face at work. The results of the regression analysis of this study reveal that labor union membership has a similar negative correlation with total PSM score for public sector employees.

Table 18: Summary of Regression Results for Attraction to Public Service

\begin{tabular}{|c|c|c|}
\hline & Belarus & Poland \\
\hline Public & $\begin{array}{l}\text { - Prior Approval }(.09 * *) \\
\text { - Age }\left(.90^{*}\right) \\
\text { - Education }(.14 *)\end{array}$ & $\begin{array}{l}\text { - Initiative Discouragement }(-.27 * * *) \\
\text { - Prior Approval }(.16 * * *) \\
\text { - Service: Labor }(-.73 * * *) \\
\text { - Religious Practices }(.30 * *) \\
\end{array}$ \\
\hline Nonprofit & $\begin{array}{l}\text { - Prior Approval }(.15 *) \\
\text { - Woman }\left(-.48^{* *}\right) \\
\text { - Service: Labor }(-.69 * *) \\
\text { - Political Party }(.87 * * *)\end{array}$ & $\begin{array}{l}\text { - Prior Approval }(.23 * *) \\
\text { - Age }\left(.20^{* *}\right) \\
\text { - Professional Organization }\left(.32^{*} \pm\right) \\
\text { - Political Party }\left(-.94^{*}\right) \\
\text { - Religious Practices }(-.50 * *) \\
\text { - Volunteering }\left(.320^{*}\right)\end{array}$ \\
\hline
\end{tabular}

In Belarus, the level of centralization of public organizations turns out to have relatively little influence on individual motivation of employees. The only exception here is the negative correlation between the necessity to receive permission (CEN3) and attraction to public service. The more approvals an employee needs to obtain in order to 
act, the stronger is his or her desire to get involved in the activities that contribute to the common good. Or vice versa, the stronger the desire to participate in actions beneficial to the community, the higher the perception of the lack of discretion. In any case, the connection between both concepts is relatively weak.

Nevertheless, what shapes PSM of Belarusian service providers is to a larger extent the affiliation with labor unions and political parties, location in the capital and, foreign professional experience, and to a lesser extent volunteering, age, education level and first-contact positions.

Consistent with the findings in Poland, labor union membership reduces the level of PSM, especially its self-sacrifice dimension. In Belarus, by becoming a union member, a person seems to transfer his/her social responsibilities. Unions take care of social problems - for instance, they provide material assistance in case of child birth or death of a relative. Unionized public sector employees do not feel the urge to help out their colleagues, because they know that these issues are covered by their membership fees.

Political party affiliation takes an unexpected direction in all models for Belarus. Contrary to Polish public service, party membership is strongly and significantly associated with higher PSM and especially with self-sacrifice and compassion dimensions. Individuals are either indoctrinated by the party on the importance civic duty, participation in activities that tackle social problems, and assisting others at personal cost, or those who have such beliefs find that they can realize them in a party. Due to a specific political situation in Belarus-for example, rare occurrence of opposition candidates in the parliament - these results signify that the role of a political party shifted from representing a certain ideology in the government to actually binding 
individuals together to fight social problems. Thus, the findings suggest that for Belarus a party remains a center of social rather than political life, and is likely to play the same role of social organization, as the church does in Poland. Indeed, careful observation of the results for these two variables suggests that they similarly impact total PSM and selfsacrifice, while political parties are associated with higher compassion in Belarus and higher attraction to public service in Poland. In general, Belarusian public sector respondents reported low participation in religious activities, which reflects a heritage from the former Soviet system, where religiosity was not recognized and even ridiculed. Consistent with low religiosity, Belarusians reported very low on self-sacrifice. This can be explained by the fact that Belarusians simply do not have anything they can sacrifice. After the waves of collectivization, expropriation, and execution of the rich during the establishment of the Soviet system, Belarusians were left with no property of any kind. After the privatization reforms in the 1990s, individuals are allowed to own their apartments and houses, at the same time, the land remains available only for the life-long rent.

Contrary to Poland, Belarusian public service workers have higher compassion when they live in a region capital. Inhabitants of the regional capital are more concerned about others, because their basic needs are better satisfied in the developed infrastructure of a larger settlement. Meanwhile, infrastructure remains relatively poor in Belarusian towns, where individuals are primarily concerned about their own problems, which is also supported by this finding.

The professional foreign experience of the public sector employees very strongly correlates with the general PSM score and especially, with self-sacrifice dimension. The 
results of the regression suggest that either employee who go abroad learn new ways to contribute to their community or, the other way around, those who put their civic duty first are more likely to travel for more knowledge. In the Belarusian public sector, the exchange of foreign practices remains rare, but those respondents who participated in these types of events reported that they went either to Poland or to Lithuania. The significance and the positive correlation of this variable with PSM suggests that the government should encourage professional foreign exchanges and seminars, because they appear beneficial for public service workers in terms of increased motivation to serve citizens.

Volunteering is negatively and significantly correlated the compassion element of PSM. This finding indicates the distortion of the volunteerism concept in Belarus. Specifically, volunteering had a compulsory character during the Soviet era and therefore, the majority still views it as a forced obligation rather than an expression of goodwill. Moreover, in small Belarusian towns, the public organizations often remain the only organizations that provide volunteer opportunities, because the nonprofit sector in such places is either completely absent or not fully developed. Individuals who declared their participation in volunteering activities might only have experience with a compulsory "volunteering" service required by their employer.

The results further demonstrate that Belarusian pubic employees become slightly more attracted to public service with age. They admire others involved in actions that contribute to their community, and also sense the importance of participating in these activities. Education also has some positive impact on the PSM dimension of being 
attracted to serve the population. The results show that being in a position that involves direct contact to citizens significantly influences the compassion dimension.

Nonprofit Organizations. Similarly to their public sector counterparts, nonprofit employees reveal similar positive correlations between the necessity to obtain approval for action and PSM. Total PSM score, Compassion, and Self-Sacrifice are higher for people with less discretion in their organization.

Age slightly positively impacts total PSM, but more strongly its Self-Sacrifice dimension, meaning that with age individuals become more motivated-especially to place their civic duties before their personal needs. Analysis of job characteristics in Polish nonprofit service providers suggests that managers have a lower level of Compassion and employees whose position includes first contact with citizens score higher on attraction to public service. Organizations that provide labor market assistance tend to have more compassionate employees. The results regarding organization location in the capital city reveal the same direction but with stronger impact on Compassion: those working in the regional towns are significantly more interested to become involved in the projects that contribute to their communities. Pro-social activities of Polish nonprofit employees are strongly correlated with Self-Sacrifice; belonging to a professional organization and volunteering have a positive impact, while political party membership and participation in religious activities have a strong negative impact. The church in general has a negative correlation with total PSM score in nonprofit organizations. This is a notable finding, because it is contrary to the religion-PSM correlations for public sector employees. Thus, this result suggests that in Poland 
religious practices are related to higher PSM scores for public sector employees and lower PSM scores for the nonprofit sector.

In Belarusian nonprofit organizations, self-sacrifice positively correlates with the necessity to ask for permission. These results could mean two things. On the one hand, it might signify that nonprofit employees who have higher self-sacrifice level see their organizations as more centralized in this regard. On the other hand, it might imply that in organizations where more approvals are required for further action, employees may feel that they place their civic duties before self.

Being a woman in nonprofit organizations has a strong negative impact on the self-sacrifice dimension. The declared level of compassion is significantly lower for those employees that had any form of professional foreign experience. Nonprofit organizations that provide labor market services on average employ individuals that score notably lower on self-sacrifice dimension than employees in social assistance services. Following the pattern of public organization in Belarus, nonprofit organizations are heavily influenced by political parties. Employees that belong to a party score significantly higher on total PSM, moderately higher on compassion, and much stronger on selfsacrifice dimension than nonpartisan nonprofit employees.

If a nonprofit employee is involved in any volunteering activities, his/her compassion is also significantly reduced. This phenomenon supports the idea that volunteerism as a concept has a reverse meaning in Belarus. Because volunteering activities are mostly associated with obligatory service in a public institution, the participation in such activities would raise a negative set of attitudes. In the Belarusian public sector, volunteering reveals the same strong negative impact. 
Nonprofit employees across the studied countries share only one common finding: the need to obtain prior approval for any actions from employees in upper positions in a hierarchy positively correlates with the self-sacrifice dimension. Meanwhile, it is interesting that political party membership has the opposite impact on the self-sacrifice dimension: positive for Belarus and negative for Poland.

Cross-sector Comparison within Countries. Foreign experience has opposite effects on employees of different sectors in Belarus: while participation in foreign practices strengthens self-sacrifice dimension in pubic organizations, compassionate feelings are reduced for nonprofit sector employees. Volunteering coefficients have negative signs for all dimensions, but are significant only for total PSM in the public sector and compassion in the nonprofit sector. Political party in Belarus reveals strong positive trend across sectors and dimensions: being a member of a party is strongly and positively correlated with total PSM, but also compassion and self-sacrifice level.

In Poland, initiative discouragement is negatively associated with all PSM dimensions across the sectors. Yet, the coefficients are statistically significant only for the public sector. Meanwhile, the need to obtain approval for even small matters is statistically significant and positively related with PSM and its dimensions for both the public and nonprofit sectors. Organizational location matters as well. If a service providing organization is located in a region capital, the compassion dimension is significantly lower for both sectors. And as already mentioned above, religious practices have an opposing impact on PSM for different sectors: positive correlations are found for public sector employees and negative ones for nonprofit workers. 


\section{CHAPTER 6: CONCLUSION}

This dissertation tested the hypotheses of the study using quantitative descriptive and inferential methods. After conducting a factor analysis of Kim et al.'s (2013) international scale for the four studied populations, the PSM measurement was reduced to the eight indicators and three dimensions: attraction to public service, self-sacrifice, and compassion. Using a modified Aiken and Hage's (1968) scale, centralization was operationalized by two marker items: discouragement to undertake initiative and compulsory approval for any further action. The study tested several models to examine the impact of organizational structure, job characteristics, and employees' pro-social activities and their demographics on the individual PSM in different administrative regimes.

Mainly serving as an introduction into PSM debates, Chapter 1 revealed that PSM observed in North America and developed Western countries appears everywhere across Europe, despite the internal social, cultural, political, and administrative differences that exist among European countries. When asked about how important it is for a person to be rich and to help others, public sector employees in 26 European nations revealed higher level of PSM that private sector employees (Prysmakova 2014a). While supporting PSM presence in Eastern Europe, Chapter 1 provided contrary evidence of PSM level among public sector employees in that region. One study showed the largest gap between the public and the private sector employees for the importance to help others and explained it by inherited communitarian culture of the public sector (Prysmakova 2014b), Another study revealed an overall low PSM level explained by the least exposure to democracy (Vandenabeele \& de Walle 2008). The analyses of the dissertation did not question the 
presence of PSM for Polish and Belarusian public sector employees. Yet, it examined how far their PSM level falls short of the even more pro-social sector of nonprofits and whether the shared communist past and present exposure to administrative decentralization have any impact on individual motivation.

The evidence from the communist past presented in Chapter 2 suggested that the centralization of the state and the centralization of the organization determine individual work motivation in the public sector to a great extent. The review of the selected literature showed that the malfunctions of the communist motivation system were caused by the discordance of management intentions and management actions. The centralized system put forward objectives that were impossible to achieve simultaneously: ensured full employment and raised motivation and performance within the communist ideology. The difficulties occurred when the regime tried to eliminate the profit motive or replace individual competition with group competition when it attempted to suppress feelings of individual superiority by equalizing the pay of high and low-skilled employees, while requesting greater effort at the workplace.

What the communist regime succeeded in doing - and what the findings of this dissertation also support-was to replace religious concepts with beliefs in social betterment. The Communist Party was there to replace the church. Having a longer and more intensive exposure to the Communists than the Polish, the Belarusian population more commonly sees party membership as their individual chance to contribute to the improvements of their communities, towns, and cities. In Poland, the same role is assigned to the local churches. 
The direct actions of communist administration on both governmental and organizational levels led to the liquidation of entrepreneurial individuals and discouraging detachment of individual benefits from completed work. Awareness that presence at work was more important than its results and dysfunctions of monetary based incentive schemes caused overwhelming work lethargy and discouraged the employees from being creative or displaying initiative. With some changes, the work culture established by the communist regime could still be observed in the public sector in both Poland and Belarus. The statistical analysis in Chapter 5 proves that enterprising and creative individuals would rather work for the nonprofit sector than the public sector. Thus, the propositions in Chapter 2-those regarding how inherited work attitude continues to influence employee motivation after the fall of communism-found their empirical support in the data collected. The findings were also in line with the propositions that the newly emerged nonprofit sector might have become an employment solution for highly motivated individuals that were not able to realize their ambitions in the public sector. These conclusions partly explain why the scarcity of empirical comparatives of motivation in the two sectors raised the challenges in the Chapter 4, which introduced factors that might affect PSM. The theory offered many distinctive motivators for public and nonprofit employees separately, while remaining relatively silent on sector comparisons.

Chapter 3 aimed to combine the separate theoretical and empirical literatures on motivation in public and nonprofit sectors and offered sound grounds to assume that in terms of public values employees of public and nonprofit organizations indeed speak different 'languages.' These differences were shown to be intensified by institutional 
conditions - for instance, the hierarchical relations between sectors in highly centralized systems places pressure on employees, leaving little chance for mutual understanding. By enjoying superior power, the public sector in centralized systems tends to neglect the nonprofits as partners. At the same time, public employees might lose their motivation to serve the citizens because they are overwhelmed by the responsibility to address all social issues simultaneously. The review of the literature suggested that neither decentralized system provides a unique solution to improve the motivation level of service providers. Abundant cooperation of the nonprofits with the public sector in decentralized systems might limit nonprofits' independence and dictate the ways to address the social issues in exchange of funding guarantees. The motivation of such nonprofits to help others might also decrease. The overall conclusion of Chapter 3 was that the independence of the nonprofit sector remains the key factor that determines the abilities of the service providing employees in both sectors to adhere to and prioritize public values in any administrative regimes. The findings of the dissertation moved this proposition further, showing that in regard of motivation, nonprofit employees constitute a special caste of individuals involved in service provision and their PSM and its constituent dimensionsself-sacrifice, compassion and attraction to public interest-remain high and consistent across the borders.

Chapter 4 described every step of the research process: from the translation and adaptation of survey items into the native languages of respondents to data collection for each sector in Belarus and Poland. This chapter paid special attention to the scale translation and validation procedures, to the strategies used to recruit samples and collect data for this study, and to the measures for the constructs of interest. Research in each 
sector in Poland and Belarus had its own specificities in terms of the methods used to contact sample organizations and to distribute surveys. At the same time, in each case, participants were informed that their participation was voluntary and their responses were anonymous. The survey had a good response rate and the volume of the completed questionnaires is substantial and sufficient to compare the individuals involved in public service provision across sectors and across countries. The number of responses obtained is sufficient to conduct both descriptive and inferential quantitative analyses.

As Chapter 4 revealed, the centralization of the social service provision is high in Belarus, where its government has designated special organizations under the Ministry of Labor and Social Protection that attend to social issues. Meanwhile, in Poland, local governments are responsible for the establishment of centers for social and employment assistance. In both countries, public organizations are primary providers of services to the unemployed, families with many children, retirees, and sick and handicapped individuals who need at-home services.

The results of the statistical tests presented in Chapter 5 revealed an overall good score for the model fits for the three dimensional PSM and two dimensional organization centralization. This study acknowledges the limitations of putting the concepts of the PSM and the Centralization into one model when the items for the centralization were tested. The two notions are not related to the one latent concept and were put together purely for technical purposes; the fit statistics showed lower scores than they might have for separate models for the two concepts. Nevertheless, this model allowed for assessment of the differences in the statistics between a configurative and a matric model 
and provided enough information to draw the conclusions of the statistical fit for the centralization scale.

Before going into detail of the regression analysis, Chapter 5 started with an independent $t$-test that showed significant differences between means of PSM and its dimensions for two sectors. With the exception of Self-Sacrifice dimension in Poland, the overall conclusion was that PSM and its dimensions are found to be higher among nonprofit sector employees. These findings supported the propositions of Chapter 3 that the nonprofit sector employees exhibit higher levels of PSM compared to their counterparts in the public sector. The inferential statistics allowed for the similar conclusions.

Does the degree of government centralization influence employees' motivation in public and nonprofit service providers? The findings of the study only partially support Hypothesis 1 - that the centralization level of the government affects employees' PSM. Vandenabeele and Van de Walle (2008) suggested that public service motivation level is affected by the political situation in the country. The results of this dissertation showed no confirmation that the centralization of the government has a univocal influence on PSM across the sectors. For public sector employees, administrative centralization may affect PSM dimensions in opposite ways. The Belarusian public sector provides an example where the self-sacrifice dimension of PSM is significantly lower than in the nonprofit sector - as well as in both sectors in Poland. Meanwhile, attraction to public service is higher among Belarusian public sector employees than among Polish public sector employees. This finding is in-line with March and Olsen's (1989) proposition that by setting social values, institutions tend to standardize behavioral patterns. Polish public 
sector employees have another set of social values than Belarusian public sector employees, which is reflected in different scores of PSM's constituent dimensions. Evidence from the public sector suggests that government affiliation plays an important role in setting social values of employees.

At the same time, centralization of the administrative system has almost no impact on the nonprofit sector. As the empirical evidence suggests, the scores for total PSM and separate dimensions are found equal in Polish and Belarusian samples. Thus, being relatively independent from the government, the nonprofit sector shows a similar set of values and attitudes across the border. Contrary, as the public sector employees reported different priorities in the opposite administrative regimes, this finding suggests that the public sector employees indeed guard some regime values (Frederickson \& Hart 1985). The homogeneity of the values and attitudes in both countries' nonprofit sectors could be also explained by their anti-governmental stance: in Poland, the nonprofits appeal entrepreneurially to the EU rather than the national capital, whereas in Belarus they are expressions of discontent with the current administrative regime.

The second research question addressed centralization at the organizational level and how it might affect PSM. Public organizations have higher level of organization centralization than the nonprofit ones in both countries and public sector employees also exhibit lower levels of PSM than their nonprofit counterparts. Therefore, Hypothesis 2 posing that the nonprofit sector employees will exhibit higher levels of PSM than their public sector counterparts has been supported. The results reveal the motivational difference between sectors, therefore, substantiating Goodin's (2003) propositions of cross-sector differences in commitment and going contrary to Rotolo and Wilson's 
(2006) and Houston's (2008) findings that suggested similar patterns of PSM-related attitudes between public and nonprofit workers.

The research showed no universal relations between PSM and the centralization level of organizations. The findings only partly support a proposition that being constrained by central rules and having little authority and incentive to manage, public sector employees may depreciate the real work of responding to citizens' needs (Moynihan \& Pandey 2007, Rainey 1991). The empirical evidence suggests almost no correlation between organization centralization and PSM in a highly centralized administrative regime. The results of the regression analysis show no significant impact of organization centralization items on PSM. There were only two regressionsAttraction to Public Service in the public sector and Self-Sacrifice for the nonprofitswhere the necessity to obtain permissions was found to have some weak positive effect.

Statistically significant correlations, nevertheless, were found between both centralization variables and PSM in Polish samples. As the results suggest for the public organizations in the decentralized administrative settings, individuals with higher PSM are less likely to perceive discouragement for independent decision-making (CEN2). Attraction to public service exerts the greatest influence on the reduced perception of discouragement among public sector employees. These findings are consistent with Scott and Pandey's (2005) results, who found managers reporting lower levels of red tape if they have higher levels of PSM. In their study, attraction to public policy making provided the greatest influence on perceptions of red tape among all the dimensions of PSM. 
The propositions of Young and Tavares (2004) that autonomy might create more frustration than motivation is supported by the findings for both sectors in Poland. In the Polish public service provision, requirement to refer for the higher-up in the hierarchy for approvals (CEN3) corresponds to the higher levels of PSM and especially, to the increased self-sacrifice dimension. This means that the less autonomy an employee possesses, the higher this individual scores on the PSM scale and the more he/she is ready to sacrifice. Thus, following the rigid set rules that are believed to be proper might improve motivation to help others. The self-sacrifice dimension exhibits a similar, but much weaker correlation for Belarusian nonprofit employees.

Having an impact on PSM or not, a medium-high degree of centralization in public service providers occurs in both Belarusian and Polish samples. This finding is consistent with previous theoretical propositions found in the literature. As Mintzberg (1983) points out, the high level of centralization is common in large organizations-in our case in service provision systems - because they have to control their employees' behavior, reducing employee variability and attempting to predict and control employee actions.

Hypothesis 3, which addresses the effects of government centralization on sectoral differences in PSM, also found a partial confirmation. The nonprofit organizations in Poland and Belarus exhibit similar levels for all PSM dimensions, and therefore, in regard to motivation, employees of these organizations constitute a single population that exists atop the administrative borders. The findings of the current study reveal distinctions in individuals' values and motivation to work only between the Belarusian and Polish public sectors. The results of two-sample comparisons and 
regression analyses suggest strong and statistically significant differences between the two countries. The lowest level of PSM among the public sector employees is registered in the regime with highly centralized service provision.

The revealed PSM differences might be caused by the differences in the service provision centralization, considering that previous research shows that countries' administrative and political systems correspond to individuals' values and motivation to work (Vandenabeele 2008, Naff \& Crum 1999, Houston 2008). Yet, it should be acknowledged that despite the close similarity of the compared regions and the comprehensive list of control variables, the country differences in PSM level might be caused by factors other than centralized service delivery (especially taking into consideration the findings that the centralization of government has not translated into the ubiquities centralization of public sector organizations). Contrary to expectations, Polish data revealed the centralization being equal to or, in the case of discouragement of independent decision-making, even higher than in Belarus. Thus, decentralized service provision in Poland co-exists with more centralized practices at the organizational level, and the highly centralized system in Belarus reveals less centralization at the service delivery stage. This finding suggests, therefore, that the organization centralization variable is not a critical factor when discriminating between public entities located in regimes with different levels of administrative centralization.

Common in human resource management for the business sector (Liu 2004), a situation when subsidiaries adopt managerial practices from the center occurred neither in Polish nor in Belarusian service providers. While in the private sector, highly centralized networks might use coercive pressure to ensure administrative conformity (Mizruchi 
1993), this empirical study suggests slightly different practices for the public sector. Contrary to Foster's (2001) and Tschirhart's (2006) propositions, the strong governmental system in Belarus does not necessarily undermine decentralized administrative practices on the service provision level. Financial and decision-making linkages with the non-democratic state in Belarus signified no additional impact on the degree of centralization in service providing organizations. Moreover, the findings suggest that Polish organizations discourage bottom-up initiative more often than in Belarus.

The findings also shed light on the question of whether democracy is a necessary determinant of public service motivation, as was previously stated by Vandenabeele and Van de Walle (2008) and Vandenabeele (2008). The answer is "no," if the democracy is measured by decentralization of the state's power delegated to the lowest levels in the administrative hierarchy. The findings show that the absence of administrative decentralization in a country might not necessarily translate into the reduced level of PSM in the public and nonprofit sectors. Nonprofits' employees report no difference in PSM and its dimensions in the two countries. Belarusian public organizations that work under the authoritarian government indeed show significantly lower overall PSM score, but almost no significant relations have been found between this score and the organization centralization levels.

Moreover, the PSM score in the Belarusian public sector occurred lower than in Poland mainly due to the statistically significant difference in self-sacrifice. The explanation for why Belarusians refuse to self-sacrifice could be found in Chapter 2 that describes the communist systems: generations after generations, Belarusians were forced 
into self-denial for the good of future generations by the Soviet regime. The low levels of self-sacrifice are also explained by limited private property; when individuals possess very little of their own and mostly use public facilities, and thus, have the feeling they already share much. Despite the low score on self-sacrifice, Belarusian public sector respondents scored significantly higher on the attraction to public service, as measured by the desire to participate in initiatives that tackle social problems. While the Belarusian public employees are less likely to place civic duties before self, and therefore, remain more individualistic in this regard than the Polish public employees, they a feel stronger urge to help others.

The models proposed in this dissertation attempted to account for the complex effect of country and organization specific variables on PSM in a comprehensive way. Yet, they were less efficient for the case of Belarus. In contrast to Poland where the models worked fairly well, for the three dimensions and total PSM, only two models revealed some significant positive correlations with one of the centralization items- the initiative discouragement - in Belarusian service providing organizations. Yet, on the side of the organization centralization, the regression analysis reveals a number of factors with significant impact on PSM. Beyond the centralization impact, participation in religious practices, political party, and labor union membership, location in a major city and type of social service provided correlates with the PSM score in Poland. For Belarus, also being dependent on a party/union membership and an organization location, PSM score is related to professional foreign experience, volunteering, demographics and firsthand contact with citizens. In contrast to Poland, PSM in Belarusian service providing 
organizations revealed no significant correlation with any centralization items used in the study.

Inglehart's (1997) 'scarcity' theory posits that gradual change of individual values takes generations. Applied to this study, it means that the PSM level today is affected by the values established by previous regimes. Findings from Belarusian service providers show some evidence that the Soviet institutes, which shaped morality in the past, have survived through the decades and continue to affect public values. For instance, belonging to a political party in Belarus significantly increases PSM level. Because the opposition parties are not present in smaller Belarusian towns, the respondents that declared their party membership in these places most probably belong to progovernmental parties. Meanwhile, nonprofit employees in the region's capital might equally belong to the opposition or to the pro-governmental parties. Despite the different political agendas of these parties, participation in any of them on average significantly improves the PSM level of service providers. Thus, despite the collapse of the Soviet system 25 years ago, political organizations remain a major substitute for any form of social activities, which in other countries can be performed by religious or volunteering organizations. Individuals willing to sacrifice for the good of the society and wiling to perform public service know of no other places for self-realization but a political party.

The PSM today, to a certain extent, reflects the importance of institutions established by the former communist government. As the findings suggest, pro-social institutions indeed define social values and thus, directly and indirectly influence motivation (Hughes 1939, Scott 1987, Friedland \& Alford 1987, Perry \& Vandenabeele 2008). The role of political parties, labor unions, and church shapes individual PSM to a 
large extent. As in case of authoritarian Belarus, these organizations have even stronger effect than the centralization of the administrative regime or the organization centralization of service providers.

The ability to generalize from the samples is widely recognized as an essential part of the learning process. The current research acknowledges that the studied administrative and territorial units in Poland and Belarus exhibit certain peculiarities of the border lands. There might be difficulties in comparing the samples to other parts of the countries, for instance, to the Polish and Belarusian capitals. Yet, the findings are generalizable beyond the studied region to the extent that despite the similarities within the cross-border region, two territorial units under the study - Hrodna Voblasc in Belarus and Podlaskie Wojewodstwo in Poland - have already been administrated by the different type of the government for more than twenty years. Administrative and political decentralization of the service provision systems in Poland modifies the dynamics of government-nonprofits relations differently than the centralized systems on the Belarusian side. The limitation of this generalization suggests an interesting problem for further research: developing explanation-based methods that can overcome the fundamental difficulty associated with the inductive methods, namely to justify the generalizations that they produce.

Combined results of four studied groups raise some further questions for future research. Measuring nonprofit PSM in other countries in the region will allow for examination of whether levels of PSM and its dimensions observed in this dissertation similarly occur due to the homogeneity of the sector in Poland and Belarus, or the homogeneity of the sector in general. PSM data from nonprofits in other countries would 
show whether, despite the organizational and financial differences of organizations in various systems, the nonprofit sector as a whole indeed knows no administrative borders and brings together individuals with a special kind of strong pro-social motivation.

Future research could also benefit from examining the relations between PSM and pro-social activities in other highly centralized administrative regimes, e.g. religious or military regimes. While receiving a fair amount of attention from scholars who focus their research activities on developed countries, little is known about the PSM of individuals in service provision where the public sector is in formation or transition, or where public service provision is neglected and distressed or contrary is of a high quality that ensures citizens' support of the government. Deeper qualitative research is required to examine what concepts such as volunteering, political party, and church mean to individuals employed in public organizations in these countries and whether the definitions of these concepts are different for other sectors.

Expanding the scope of the studied organizations would strengthen the conclusions about correlations of PSM and centralization levels. The dissertation used only social assistance services in its sample, and these organizations are expected to score relatively high on the level of PSM. Will this be the case for other public services that serve other population groups? Will the employees involved in service provision like schools, public transportation, and local public administration exhibit similar patterns of self-sacrifice, compassion, or desire to contribute to the common good in the studied countries?

Further examination might be necessary to strengthen the conclusions on the relations between work motivation and the centralization of organizations and the state. 
Hopefully, this study will stimulate future research interventions in Eastern Europe as well as in the neighboring countries where the long-lasting legacy of the former centralized administrative regimes could become a valuable reference for the scientific work on public service motivation elsewhere in the world. 


\section{REFERENCES}

Aiken, M., and Hage, J. (1968). Organizational interdependence and intra-organizational structure. American Sociological Review: 912-30.

Alderman, H. (1998). Social Assistance in Albania: Decentralization and Targeted Transfers. LSMS Working Paper No. 134, World Bank.

Andersen, L. B., Beck Jørgensen, T., Kjeldsen, A-M., Pedersen, L. H., and Vrangbæk, K. (2012). Public Value Dimensions: Developing and Testing a Multi-Dimensional Classification. International Journal of Public Administration 35(11): 715-28.

Andersen, L. B., Jørgensen, T. B., Kjeldsen, A. M., Pedersen, L. H., \& Vrangbæk, K. (2013). Public Values and Public Service Motivation Conceptual and Empirical Relationships. The American Review of Public Administration 43(3): 292-311.

Anheier, H. K. (1995) Theories of the nonprofit sector: three issues. Nonprofit and Voluntary Sector Quarterly 24(1): 15-23.

Ardichvili, A. (2009). The relationship between meaning of working and socioeconomic transformations: The case of post-communist Russia. Advances in Developing Human Resources 11(2): 218-34.

Aslund, A. (2007). Russia's capitalist revolution: Why market reform succeeded and democracy failed. Peterson Institute.

Baldwin, J. N. (1987). Public versus private: Not that different, not that consequential. Public Personnel Management 16(2): 181-93.

Bardhan, P. (2002). Decentralization of Governance and Development. The Journal of Economic Perspectives 16(4): 185-205.

Barnett, A. (2011). Putting Trusts and Foundations at the Heart of the Big Society. In Civil Dialogue: Ideas For Better Working Between Government and Civil Society. . UK: Civil Exchange and DHA Communications Ltd.

Bartkowski, J. (2002). Spoleczne determinanty geograficznego rozmieszczenia organizacji pozarzadowych w Polsce (Social determinants of the geographical distribution of NGOs in Poland). In Glinski P., B.Lewenstein B., A. Sicinski (Eds.), Samoorganizacja społeczeństwa polskiego: Trzeci sektor. Warsaw: IFiS PAN.

Bath, C. (2011) What Lies at the Heart of an Effective Relationship between Civil Dialogue, In Civil Dialogue: Ideas For Better Working Between Government and Civil Society. UK: Civil Exchange and DHA Communications Ltd.

Belarusian Republican Youth Union (2010). http://brsm.by/ [Accessed August 10th 2014]. 
Belsat (2010). Zaire Azgur's Ark. http://www.belsat.eu/be/films/38114/ [Accessed August 10th 2014].

BELSAT (2011). BRYU Absorbs Almost 100\% of the Money Allocated for Youth Policy (Амаль 100\% грошай, вылучаных на моладзевую палітыку, забярэ БРСМ).

Belsat TV, January 17th 2011. http://bielsat.inventor.com.pl/be/wiadomosci/a,1221,amal100-ghroshai-vyluchanykh-na-moladzievuiu-palityku-zabiare-brsm.html [Accessed August 2nd 2014].

Benington, J. (2011). From Private Choice to Public Value. Public Value: Theory and Practice: $31-49$.

Berger, P.L. and R.J. Neuhaus (1977). To Empower People: The Role of Mediating Structures in Public Policy. Washington, DC: American Enterprise Institute for Public Policy Research.

Bird, R.M. (1995). Decentralizing Infrastructure: For Good or For Ill? In Estache A. (Edt.), Decentralizing Infrastructure: Advantages and Limitations. Washington, D.C: World Bank Discussion Papers 290.

Bishop, J. (2011). Civil Society is in Trouble. In Civil Dialogue: Ideas For Better Working Between Government And Civil Society. UK: Civil Exchange and DHA Communications Ltd.

Board, D.(2011). The Strategic Impact of Personal Experience. In Civil Dialogue: Ideas For Better Working Between Government And Civil Society. UK: Civil Exchange and DHA Communications Ltd.

Brewer, G. A., \& Selden, S. C. (1998). Whistle Blowers in the Federal Civil Service: New Evidence of the Public Service Ethic. Journal of Public Administration Research and Theory 8(3): 413-40.

Bright, L. (2008). Does public service motivation really make a difference on the job satisfaction and turnover intentions of public employees? The American Review of Public Administration 38(2): 149-66.

Bureau of Social information (2014). http://belbsi.by [Accessed May 10th 2014].

Byrne, B.M. (1998), Structural Equation Modeling with LISREL, PRE-LIS, and SIMPLIS: Basic Concepts, Applications, And Programming. New Jersey, NJ: Lawrence Erlbaum Associates.

Castaing, S. (2006). The Effects of Psychological Contract Fulfilment and Public Service Motivation on Organizational Commitment in the French Civil Service. Public Policy and Administration 21(1): 84-98. 
Castineira, A. and Vidal. P (2003). Libre Blanc del Tercer Sector Civico-Social.

Barcelona: CETC - EADOP.

Chanlat, J. F. (2003). Le Managérialisme Et L'éthique Du Bien Commun: La Question Et La Motivation Au Travail Dans Les Services Publics [Managerialism and the common interest: work motivation management in the public service]. In T. Duvillier ,J.-L. Genard and A. Pireaux (Edt.). L a motivation au travail dans les services publics [Work motivation in the public service] $(51-64)$. Paris :L' Harmattan .

Cherniss, C. (1980). Staff Burnout: Job Stress in the Human Services. Beverly Hills, CA: Sage Publications.

Chimiak, G. (2006). How Individualists Make Solidarity Work. Warsaw: Ministry of Labour and Social Policy.

Chubb, J. E., and Moe, T. M. (1988). Politics, Markets, and the Organization of Schools. American Political Science Review 82(4): 1065-87.

Chusmir, L. H. (1986). Personalized vs. Socialized Power Needs among Working Women and Men. Human Relations 39(2): 149-59.

Civil Society Contact Group (2006) Civil Dialogue: Making it Work Better. European Union.

Clemens, E. S. (2006). The Constitution of Citizens: Political Theories of Nonprofit Organizations. In J. S. Ott, L. Dicke (Edt.). The Nature of the Nonprofit Sector (166-178). Colorado: Westview Press.

Cofer, C. N., \& Appley, M. H. (1964). Motivation: Theory and Research. New York: Wiley.

Conway, M. M. (2000). Political Participation in the United States. Washington, DC: Congressional Quarterly Press.

Coursey, D. H., \& Pandey, S. K. (2007). Public Service Motivation Measurement Testing an Abridged Version of Perry's Proposed Scale. Administration \& Society 39(5): 547-68.

Coursey, D. H., Perry, J. L., Brudney, J. L., \& Littlepage, L. (2008). Psychometric Verification of Perry's Public Service Motivation Instrument Results for Volunteer Exemplars. Review of Public Personnel Administration 28(1): 79-90.

Coursey, D., Yang, K., \& Pandey, S. K. (2012). Public Service Motivation (PSM) and Support for Citizen Participation: A Test of Perry and Vandenabeele's Reformulation of PSM Theory. Public Administration Review 72(4): 572-82. 
Cox, T. And D. Harris (2011). Reform without Accountability: The Zero Sum Game. In Civil Dialogue: Ideas For Better Working Between Government and Civil Society. UK: Civil Exchange and DHA Communications Ltd.

Crewson, P. E. (1997). Public Service Motivation: Building Empirical Evidence of Incidence and Effect. Journal of Public Administration Research and Theory 7(4): 499518.

Dilulio, J. D. (1994). Principled agents: The Cultural Bases of Behavior in a Federal Government Bureaucracy. Journal of Public Administration Research and Theory 4(3): 277-318.

Dimaggio, P. J. and H.K. Anheier (1990). The Sociology of Nonprofit Organizations and Sectors. Annual Review of Sociology 16: 137-59.

Dimaggio, P. J. and W.W. Powell (1983). The Iron Cage Revisited: Institutional Isomorphism and Collective Rationality in Organizational Fields. American Sociological Review: 147-60.

Dobkin, H. P. (2011) Historical Perspectives on Nonprofit Organizations in the United States. In Herman R.D. \& Associates (Eds.), The Jossey-Bass Handbook of Nonprofit Leadership and Management. John Wiley \& Sons.

Ekonomicheskaya Gazeta (1962). November 10: 10-11.

Fabrigar, L. R., Wegener, D. T., MacCallum, R. C., \& Strahan, E. J. (1999). Evaluating the Use of Exploratory Factor Analysis in Psychological Research. Psychological Methods 4: 272-299.

Fey, C. F. (2005). Opening the Black Box of Motivation: a Cross-Cultural Comparison of Sweden and Russia. International Business Review 14(3): 345-367.

Foster, A.D. and M.R. Rosenzweig (2001). Democratization, Decentralization and the Distribution of Local Public Goods in a Poor

Foster, K.W. (2001). Associations in the Embrace of an Authoritarian State: State Domination of Society? Studies in Comparative International Development 35(4): 84109.

Fouad, N. A., and Bynner, J.(2008). Work Transitions. American Psychologist 63(4): 241.

Frank, S. A., and Lewis, G. B. (2004). Government Employees: Working Hard or Hardly Working? American Review of Public Administration 34(1): 36-51.

Frederickson, H. G. and Hart, D.K. (1985).The Public Service and the Patriotism of Benevolence. Public Administration Review 45(5): 547-53. 
Friedland, R., and Alford, R.R. (1987). Bringing Society Back In: Symbols, Structures And Institutional Contradiction. Paper presented at Conference on Institutional Change, Center for Advanced Study in the Behavioral Sciences, Stanford, CA, May 15-16.

Gabris, G. T., and Simo, G. (1995). Public Sector Motivation as an Independent Variable Affecting Career Decisions. Public Personnel Management 24(1): 33-51.

Galasso, E. and M.Ravallion (2001). Decentralized Targeting of an Anti-Poverty Program. Development Research Group Working Paper, World Bank.

Georgellis, Y., E.Iossa, and Tabvuma, V. (2008). Crowding Out Public Service Motivation. Working Paper no. 08-07, Centre for Economic Development and Institutions, Brunel University.

Goodin, R. E. (2003). Democratic Accountability: The Third Sector and All. Working Paper no. 19, Hauser Center for Nonprofit Organizations: Harvard University.

Guyot, J. F. (1962). Government Bureaucrats Are Different. Public Administration Review 22(4): 195-202.

Hall, D. T., Schneider, B., and Nygren, H. T. (1970). Personal Factors in Organizational Identification. Administrative Science Quarterly 15(2): 176-190.

Handy, C. (1998). The Hungry Spirit: Beyond Capitalism-A Quest for Purpose in the World. New York: Broadway Books.

Hartman, R. W. And Arnold R. W.(1980).The Rewards of Public Service: Compensating Top Federal Officials. Washington, D.C.: Brookings Institution.

Horton, S. (2006). The Public Service Ethos in the British Civil Service: An Historical Institutional Analysis. Public Policy and Administration 21(1): 32-48.

Houston, D. J. (2006).“Walking the Walk” of Public Service Motivation: Public Employees and Charitable Gifts of Time, Blood, and Money. Journal of Public Administration Research and Theory 16(1): 67-86.

Houston, D. J. (2011). Implications of occupational locus and focus for public service motivation: Attitudes toward work motives across nations. Public Administration Review 71(5): 761-71.

Houston, D.J. (2000). Public-Service Motivation: A Multivariate Test. Journal of Public Administration Research and Theory 10(4):713-27.

Houston, D.J. (2008) Behavior in the Public Square. In J. L. Perry and A. Hondeghem (Edt.), Motivation in Public Management: The Call of Public Service. Oxford: Oxford University Press. 
Hughes. E. (1939). Institutions. In R.Park (Edt.), An Outline of the Principles of Sociology (283-346). New York: Barnes and Noble.

Inglehart, R. (1990). Culture shift in advanced industrial society. Princeton University Press.

Inglehart, R. (1997). Modernization and Postmodernization: Cultural, Economic, and Political Change In 43 Societies (Vol. 19). Princeton, NJ: Princeton University Press.

Inglehart, R. and Welzel, C. (2005). Modernization, Cultural Change, and Democracy: The Human Development Sequence. Cambridge University Press.

International Test Commission (2010). International Test Commission Guidelines for Translating and Adapting Tests. Retrieved from

http://www.intestcom.org/upload/sitefiles/40.pdf [Assessed July 1st, 2014].

Jackall, R. (1983). Moral mazes: Bureaucracy and Managerial Work. Harvard Business Review Case Services.

Jenkins, C. (2006). Nonprofit Organizations and Political Advocacy. In W.W. Powell and R.S. Steinberg (Edt.), The Nonprofit Sector: A Research Handbook. Yale University Press.

Jørgensen, T. B., \& Bozeman, B. (2007). Public Values an Inventory. Administration and Society 39(3): 354-81.

Jurkiewicz, C. L., T.K. Massey, and Brown, R.G. (1998). Motivation in Public and Private Organizations. Public Productivity and Management Review 21(3): 230-50.

Kazanecki, P. (2014). Personal interview. Warsaw [May 15th 2014].

Kilpatrick, F. P., Cummings Jr, M. C., \& Jennings, M. K. (1964). Source Book of a Study of Occupational Values and the Image of the Federal Service. Books by Alumni. Book 400. http://works.swarthmore.edu/alum-books/400 [Assessed June 14th, 2014].

Kim, S. (2005). Individual-level Factors and Organizational Performance in Government Organizations. Journal of Public Administration Research and Theory 15(2): 245-261.

Kim, S. (2009a). Revising Perry's Measurement Scale of Public Service Motivation. The American Review of Public Administration 39(2): 149-63.

Kim, S. (2009b). Testing the Structure of Public Service Motivation in Korea: A Research Note. Journal of Public Administration Research and Theory 19(4): 839-51.

Kim, S. And Vandenabeele. W. (2010). A Strategy for Building Public Service Motivation Research Internationally. Public Administration Review 70 (5): 701-9. 
Kim, S., Vandenabeele, W., Wright,B.E., Andersen, L.B., Cerase, F.P., Christensen, R.K., Desmarais, C., Koumenta, M., Leisink, P., Liu, B., Palidauskaite, J., Pedersen, L.H., Perry, J.L., Ritz, A., Taylor, J. and De Vivo, P. (2013). Investigating the Structure and Meaning of Public Service Motivation across Populations. Journal of Public Administration Research and Theory 23(1): 79-102.

Kline, R.B. (2011). Principles and Practice of Structural Equation Modeling. New York: The Guilford Press.

Klon/Jawor (2014). http://www.bazy.ngo.pl [Accessed May 10th 2014].

Kurczewski, J., Dzieniszewska-Naroska, K., Laciak, B., Smigielska, J., Zakrzewski, L. (2000). Local Civil Society, Elections and Governance: A Comparative Analysis of Local Democracy and Civil Society in Action in Poland. Civil Society and Governance Programme. IDS.

Lee, Y. And V. M. Wilkins (2011) More Similarities or More Differences? Comparing Publicand Nonprofi t Managers' Job Motivations. Public Administration Review. January/February. p. 45-56.

Leisink, P., \& Steijn, B. (2009). Public Service Motivation and Job Performance of Public Sector Employees in the Netherlands. International Review of Administrative Sciences 75(1): 35-52.

Leung, T., T.Fong, N.M. Yip, R. Huang, and Y. Wu (2012). Governmentality and the Politicisation of Social Work in China. British Journal of Social Work 42:1039-59.

Light, P.C. (2002). The Content of Their Character: The State of the Nonprofit Workforce. Nonprofit Quarterly 9(3): 6-16.

Lipset, S. M. (1992). The Work Ethic, Then and Now. Journal of Labor Research 13(1): 45-54.

Lipsky, M. (1980). Street-Level Bureaucracy. Russell Sage Foundation.

Liu, B., Tang, N., and Zhu, X. (2008). Public Service Motivation and Job Satisfaction in China: An Investigation of Generalisability and Instrumentality. International Journal of Manpower 29(8): 684-99.

Liu, W. (2004). The Cross-National Transfer of HRM Practices in MNCs: An Integrative Research Model. International Journal of Manpower 25(6): 500-17.

Luthans, F., Luthans, K. W., Hodgetts, R. M., and Luthans, B. C. (2000). Can High Performance Work Practices Help in the Former Soviet Union? Business Horizons 43(5): 53-60. 
Lyons, S. T., Duxbury, L. E., and Higgins, C. A. (2006). A Comparison of the Values and Commitment of Private Sector, Public Sector, and Parapublic Sector Employees. Public Administration Review 66(4): 605-18.

Maidani, E. A. (1991). Comparative Study of Herzberg's Two-Factor Theory of Job Satisfaction among Public and Private Sectors. Public Personnel Management 20(4): 44148.

March, J.G. and Olsen, J. P. (1989). Rediscovering Institutions. New York : Free Press.

Marino, K.E., and White, S. E. (1985). Departmental Structure, Locus of Control, and Job Stress: the Effect of a Moderator. Journal of Applied Psychology 70(4): 782-4.

Maslow, A. H. (1970). Motivation and personality. New York: Harper \& Row.

McAdams, D. P., \& De St Aubin, E. (1992). A Theory of Generativity and Its Assessment through Self-Report, Behavioral Acts, and Narrative Themes in Autobiography. Journal of Personality and Social Psychology 62(6): 1003.

Mendoza, X. (1995). Las Transformaciones Del Sector Público En Las Democracias Avanzadas: Del Estado Del Bienestar Al Estado Relacional. Santander: Universidad Internacional Menéndez y Pelayo.

Ministry of Labor and Social Protection (2014). http://mintrud.gov.by/ [Accessed May 10th 2014].

Mintzberg, H. (1979). The Structuring of Organizations. Englewood Cliffs, N.J. : Prentice-Hall.

Mishler, W. and Rose, R. (1997). Trust, Distrust and Skepticism: Popular Evaluations of Civil and Political Institutions in Post-Communist Societies. The Journal of Politics 59(2): 418-51.

Mishler, W., and Rose, R. (2001). What are the Origins of Political Trust? Testing Institutional and Cultural Theories in Post-Communist Societies. Comparative Political Studies, 34(1): 30-62.

Mizruchi, M.S. (1993). Cohesion, Equivalence, and Similarity Of Behavior: A Theoretical And Empirical Assessment. Social Networks 15(3): 275-307.

Moore, M.H. (1995). Creating Public Value: Strategic Management in Government. Cambridge, Mass.: Harvard University Press.

Moore, M.H. (2000). Managing for Value: Organizational Strategy in For-Profit, Nonprofit, and Governmental Organizations. Nonprofit and Voluntary Sector Quarterly 29(1): 183-208. 
Moseley, J. (2011). Working Successfully with Government through Promoting the Voluntary and Community Sector and Government? In Civil Dialogue: Ideas For Better Working Between Government And Civil Society. Civil Exchange and DHA Communications Ltd: UK.

Mowday, R. T., Porter, L. W., and Steers, R. M. (1982). Employee-organization Linkages: The Psychology of Commitment, Absenteeism, and Turnover. New York: Academic Press.

Moynihan, D. P., and Pandey, S. K. (2007). The Role of Organizations in Fostering Public Service Motivation. Public Administration Review 67(1): 40-53.

Moynihan, D.P. (2008). The Normative Model in Decline? Public Service Motivation in the Age of Governance. In Perry, J. and Hondeghem, A. (Edt.), Motivation in Public Management: The Call of Public Service (223-44). Oxford, UK: Oxford University Press.

Naff, K. C., and Crum, J. (1999). Working for America Does Public Service Motivation Make a Difference? Review of Public Personnel Administration 19(4): 5-16.

NDA Assembly (2014). Асамблея НДА Беларусі. http://belngo.info/ [Assessed August 15th 2014].

Neimanis, G. J. (1997). Business Ethics in the Former Soviet Union: A report. Journal of Business Ethics 16(3): 357-62.

NGO.pl (2014). Portal of Nongovernmental Organizations. http://www.ngo.pl/[Accessed May 10th 2014].

Pandey, S. K., and Stazyk, E. C. (2008). Antecedents and Correlates of Public Service Motivation. In Perry, J. and Hondeghem, A. (Edt.), Motivation in Public Management: The Call of Public Service (101-117). Oxford, UK: Oxford University Press.

Pandey, S. K., Wright, B. E., and Moynihan, D. P. (2008). Public Service Motivation and Interpersonal Citizenship Behavior in Public Organizations: Testing a Preliminary Model. International Public Management Journal 11(1): 89-108.

Park, S. M., and Rainey, H. G. (2008). Leadership and Public Service Motivation in US Federal Agencies. International Public Management Journal 11(1): 109-42.

Parsons, T. (1940). The Motivation of Economic Activities. Canadian Journal of Economics and Political Science/Revue canadienne de economiques et science politique 6(02): 187-202.

Pastwa, J. (2014). Personal interview. The Poland's National School of Public Administration [August 15th 2014]. 
Pedersen, L. H. (2014). Committed to the Public Interest? Motivation and Behavioural Outcomes among Local Councillors. Public Administration 92(4): 886-901.

Perry, J. L. (1996). Measuring Public Service Motivation: an Assessment of Construct Reliability and Validity. Journal of Public Administration Research and Theory 6(1): 522.

Perry, J. L. (1997). Antecedents of Public Service Motivation. Journal of Public Administration Research and Theory 7(2): 181-97.

Perry, J. L. and Hondeghem, A.(2008a). Directions for Future Theory and Research. In Perry, J. and Hondeghem, A. (Edt.), Motivation in Public Management: The Call of Public Service (294-313). Oxford, UK: Oxford University Press.

Perry, J. L. and Wise, L. R. (1990). The Motivational Bases of Public Service. Public Administration Review 50(3): 367-73.

Perry, J. L., and Hondeghem, A. (2008b). Building Theory and Empirical Evidence about Public Service Motivation. International Public Management Journal 11(1): 3-12.

Perry, J. L., and Vandenabeele, W. (2008). Behavioral dynamics: Institutions, identities, and self-regulation. In Perry, J. and Hondeghem, A. (Edt.), Motivation in Public Management: The Call of Public Service (56-79). Oxford, UK: Oxford University Press.

Perry, J.L. (2012). Guest Lecture at the Department of Public Administration of Florida International University, Miami, Florida.

Portal of Belarusian NGOs (2014). http://www.ngo.by [Accessed June 10th 2014].

Prysmakova, forthcoming. Do Public and Nonprofit Sector Employees Speak Same Language? Questioning Possibilities of Civil Dialogue. In M. Sienkiewicz (Edt.), Forms and Determinants of Development of Civil Dialogue. Lublin: Centre for Local Development.

Prysmakova, P. (2014a). Where are We on European Map? Comparing Public Service Motivation in Central and Eastern Europe to Our Neighbors. Warsaw East European Review (4): 103-19.

Prysmakova, P. (2014b). Public Service Motivation in Europe: Testing Attitudes toward Work Motives". NISPAcee Journal of Public Administration and Policy 7(1): 131-56.

Pučètaitè, R., \& Lämsä, A. M. (2008). Developing Organizational Trust through Advancement of Employees' Work Ethic in a Post-Socialist Context. Journal of Business Ethics 82(2): 325-37. 
Pučetaitė, R., \& Lämsä, A. M. (2008). Developing organizational trust through advancement of employees' work ethic in a post-socialist context. Journal of Business Ethics, 82(2), 325-337.

Puffer, S.M. (1994). Understanding the Bear: A Portrait of Russian Business Leaders. The Academy of Management Executive 8(1): 21-41.

Rainey, H. G. (1982). Reward Preference among Public and Private Managers: In Search of the Service Ethic. American Review of Public Administration 16(4): 288-302.

Rainey, H. G. (1991/2009). Understanding and Managing Public Organizations. JosseyBass/John Wiley \& Sons.

Rainey, H. G. (1997). Understanding and Managing Public Organizations. 2d ed. San Francisco, CA: Jossey-Bass Publishers.

Rainey, H. G., \& Bozeman, B. (2000). Comparing Public and Private Organizations: Empirical Research and the Power of the a Priori. Journal of Public Administration Research and Theory 10(2): 447-70.

Rainey, H.G. (1983). Public Agencies and Private Firms: Incentive Structures, Goals, and Individual Roles. Administration and Society 15(2): 207-42.

Rainey, H.G. (1991). Understanding and Managing Public Organizations. San Francisco: Jossey Bass, Inc.

Raub, S. (2008). Does bureaucracy kill individual initiative? The impact of structure on organizational citizenship behavior in the hospitality industry. International Journal of Hospitality Management 27(2): 179-86.

Richman, B. M. (1963). Employee motivation in soviet industry. Annals of Public and Cooperative Economics 34(4): 551-71.

Richman, B.M. (1963b). Managerial Motivation in Soviet and Czechoslovak Industries: A Comparison. The Academy of Management Journal 6(2): 107-128.

Ritz, A. (2009). Public Service Motivation and Organizational Performance in Swiss Federal Government. International Review of Administrative Sciences 75(1): 53-78.

Rondinelli, D., J.R. Nellis, and G. S. Cheema (1984). Decentralization in Developing Countries: A Review of Recent Experience. Washington, D.C.: World Bank.

Rosenthal, J.E. (1982). A Study of Single, Single Career and Dual Career Workers. Ph.D. diss., Kent State University. 
Rotolo, T. and Wilson J. (2006). Employment Sector and Volunteering: The Contribution of Nonprofit and Public Sector Workers to the Volunteer Labor Force. The Sociological Quarterly 47(1): 21-40.

Rubio, D. M., Berg-Weger, M., Tebb, S. S., Lee, E. S., and Rauch, S. (2003).

Objectifying Content Validity: Conducting a Content Validity Study in Social Work

Research. Social Work Research 27(2): 94-104.

Salamon, L. M. and Anheier, H.K. (1994). The Emerging Sector: The Nonprofit Sector in Comparative Perspective-An Overview. Johns Hopkins University: Institute for Policy Studies.

Savas, E. S. (1987). Privatizing: The key to better government. Chatham, NJ: Chatham House.

Schneider, A. (2003). Decentralization: Conceptualization and Measurement. Studies in Comparative International Development 38(3): 32-56.

Schultz, R. S., and McFarland, R. A. (1935). Industrial psychology in the Soviet Union. Journal of applied psychology 19(3): 265-308.

Scott, J.C. (1998). Seeing Like A State: How Certain Schemes to Improve the Human Condition Have Failed. Yale University Press.

Scott, P. G., and Pandey, S. K. (2005). Red Tape and Public Service Motivation Findings from a National Survey of Managers in State Health and Human Services Agencies. Review of Public Personnel Administration 25(2): 155-80.

Scott, W.R. (1987). The adolescence of institutional theory. Administrative Science Quarterly: 493-511.

Siciński, A. (1999). Społeczeństwo obywatelskie. In Władza i Obywatel w Społeczeństwie Informacyjnym. Warszawa: Instytut Problemów Cywilizacji Współczesnej.

Slocock, C. (2011). Introduction to Civil Dialogue. In Civil Dialogue: Ideas For Better Working Between Government And Civil Society. Civil Exchange and DHA Communications Ltd: UK.

Smith, S. R., and Grønbjerg, K. A. (2006). Scope and Theory of Government-Nonprofit Relations. In W.W. Powell and R.S. Steinberg (Edt..). The Nonprofit Sector: A Research Handbook (221-242). Yale University Press.

Stam, K., Verbakel, E., and De Graaf, P. M. (2013). Explaining Variation in Work Ethic in Europe: Religious Heritage Rather Than Modernisation, The Welfare State And Communism. European Societies 15(2): 268-89. 
Steen, T. (2008). Not a Government Monopoly: The Private, Nonprofit, and Voluntary Sectors. New York: Oxford University Press.

Steers, R. M. (1977). Antecedents and Outcomes of Organizational Commitment. Administrative Science Quarterly: 46-56.

Steinhaus, C. S., and Perry, J. L. (1996). Organizational Commitment: Does Sector Matter? Public Productivity and Management Review: 278-88.

Taylor, J. (2005). The Next Generation of Workers in Australia: Their Views on Organizations, Work and Rewards. The International Journal of Human Resource Management 16(10):1919-33.

Taylor, J. (2007). The Impact of Public Service Motives on Work Outcomes in Australia: A Comparative Multi-Dimensional Analysis. Public Administration 85(4): 931-59.

Taylor, J.(2010). Public Service Motivation, Civic Attitudes and Actions of Public, Nonprofit and Private Sector Employees. Public Administration 88(4):1083-98.

Taylor, J., and Taylor, R. (2011). Working Hard for More Money or Working Hard to Make a Difference? Efficiency Wages, Public Service Motivation, and Effort. Review of Public Personnel Administration 31(1): 67-86.

Taylor, M. (1992). The Changing Role of the Non-Profit Sector in Britain: Moving toward the Market. Government and the Third Sector-Emerging Relationships in Welfare States: 147-75.

Tidmarsh, K. (1993). Russia's work ethic. Foreign Affairs, Spring: 67-77.

Tiebout, C.M. (1956). A Pure Theory of Local Expenditures. Journal of Political Economy 64(5): 416-24.

Trompenaars, F. (1995). Rifding the Waves of Culture. New York: Irwin.

Tschirhart, M. (2006). Nonprofit Membership Associations. In Powell, W. W., and Steinberg, R. (Edt.). The nonprofit sector: A research handbook. Yale University Press.

United States Agency for International Development. 2012. CSO Sustainability Index for Central and Eastern Europe. Assessed on August 23, 2014, http://www.usaid.gov/sites/default/files/documents/1863/2012CSOSI_0.pdf

Van Til, J. (2008). A Paradigm Shift in Third Sector Theory and Practice: Refreshing the Wellsprings of Democratic Capacity. American Behavioral Scientist 52(7): 1069-1081.

Vandenabeele, W. (2007). Toward a Public Administration Theory of Public Service Motivation: An Institutional Approach.' Public Management Review 9(4): 545-56. 
Vandenabeele, W. (2008a). Government Calling: Public Service Motivation as an Element in Selecting Government as an Employer of Choice. Public Administration 86(4): 1089- 105.

Vandenabeele, W. (2008b). Development of a Public Service Motivation Measurement Scale: Corroborating and Extending Perry's Measurement Instrument. International Public Management Journal 11(1): 143-67.

Vandenabeele, W. V., Leisink, P. L. M., and Knies, E. (2013). Public Value Creation and Strategic Human Resource Management: Public Service Motivation as a Linking Mechanism. In Leisink, P., Boselie, P., Hosking, D. M., and van Bottenburg, M. (Edt.). Managing social issues: a public values perspective (37-54). Edward Elgar Publishing.

Vandenabeele, W., and n Van de Walle, S. (2008). International Differences in Public Service Motivation: Comparing Regions across the World. In . Perry, J. and Hondeghem, A. (Edt.). Motivation in Public Management: The Call of Public Service (223-44). Oxford, UK: Oxford University Press.

Vernis, A., M. Iglesias, B. Sanz, and A.Saz-Carranza (2006). Nonprofit Organizations: Challenges and Collaboration. Palgrave Macmillan.

Wamer, W. L., Van Riper, P.P., Martin, N. H. and Collins, O. F.(1963). The American Federal Executive. New Haven, Conn.: Yale University Press.

Wenclik, M. (2014). Personal interview. Stanislaw Staszic College of Public Administration in Bialystok, Poland [August 2nd 2014].

Werth, N. (1999). A State against Its People: Violence, Repression, and Terror in the Soviet Union. In Courtois, S., \& Kramer, M. (Edt.). The Black Book of Communism: Crimes, Terror, Repression (33-268). Harvard University Press.

Wilkie, N. (2011). Government and Civil Society: A Youth Sector Perspective. In Civil Dialogue: Ideas For Better Working Between Government And Civil Society. Civil Exchange and DHA Communications Ltd: UK.

Wittmer, D. (1991). Serving the People or Serving for Pay: Reward Preferences among Government, Hybrid Sector, and Business Managers. Public Productivity and Management Review 14(4): 369-83.

Wojewodski Labor Office. 2014. http://www.up.podlasie.pl/ [Accessed May 10th 2014].

Wombacher, J., Tagg, S. K., Bürgi, T., and MacBryde, J. (2010). Measuring Sense of Community in the Military: Cross-Cultural Evidence for the Validity of the Brief Sense of Community Scale and Its Underlying Theory. Journal of Community Psychology 38(6): 671-87. 
Worthington, R. L., and Whittaker, T. A. (2006). Scale Development Research a Content Analysis and Recommendations for Best Practices. The Counseling Psychologist 34(6): 806-38.

Young, S., and Tavares, A. T. (2004). Centralization and Autonomy: Back to the Future. International Business Review 13(2): 215-37.

Załuska, M. (1996). Społeczne Uwarunkowania Angażowania się w Działalność Organizacji Pozarządowych. In Załuska, M., Boczoń, J. (Edt.). Organizacje Pozarządowe w Społeczeństwie Obywatelskim. Warszawa: Biblioteka Pracownika Socjalnego. 


\section{APPENDIX}

Regression Results for the Pooled Sample

\begin{tabular}{|c|c|c|c|c|c|}
\hline & & PSM & & & \\
\hline & Model 1 & Model 2 & Model 3 & Model 4 & Model 5 \\
\hline Intercept & 4.043 & 4.098 & 3.903 & 3.790 & 3.887 \\
\hline CEN2 & $\begin{array}{c}-.093 * * * \\
(.025)\end{array}$ & $\begin{array}{c}-.066 * * * \\
(.023)\end{array}$ & $\begin{array}{c}-.064 * * * \\
(.023)\end{array}$ & $\begin{array}{c}-.067 * * * \\
(.024)\end{array}$ & $\begin{array}{c}-.065 * * * \\
(.024)\end{array}$ \\
\hline CEN3 & $\begin{array}{r}\mathbf{. 0 4 4} * * \\
(.022) \\
\end{array}$ & $\begin{array}{c}\mathbf{. 0 6 4} * * * * \\
(.021) \\
\end{array}$ & $\begin{array}{c}\mathbf{. 0 6 3} * * * \\
(.020) \\
\end{array}$ & $\begin{array}{c}\mathbf{. 0 7 2} * * * * \\
(.022) \\
\end{array}$ & $\begin{array}{c}\mathbf{. 0 6 7} * * * \\
(.022) \\
\end{array}$ \\
\hline Poland & & $.083 *$ & $.126 * * *$ & $.096^{*}$ & -.005 \\
\hline Public & & $\begin{array}{c}(.044) \\
-. .371 * * * \\
(.047)\end{array}$ & $\begin{array}{c}(.046) \\
-. .376 * * * \\
(.0473)\end{array}$ & $\begin{array}{c}(.051) \\
-\mathbf{. 3 9 2} * * * \\
(.053)\end{array}$ & $\begin{array}{c}(.068) \\
-. .361 * * * \\
(.059)\end{array}$ \\
\hline Woman & & & $\begin{array}{l}.112 * \\
(.061)\end{array}$ & $\begin{array}{c}\mathbf{- 1 3 6} * * \\
(.066)\end{array}$ & $\begin{array}{l}.113 * \\
(.067)\end{array}$ \\
\hline Age Group & & & $\begin{array}{c}. \mathbf{0 8 2} * * * \\
(.020)\end{array}$ & $\begin{array}{c}. \mathbf{0 7 3} * * * \\
(.023)\end{array}$ & $\begin{array}{c}.072 * * * \\
(.023)\end{array}$ \\
\hline Education & & & $\begin{array}{l}-.007 \\
(.030)\end{array}$ & $\begin{array}{l}-.002 \\
(.034)\end{array}$ & $\begin{array}{l}-.009 \\
(.035)\end{array}$ \\
\hline $\begin{array}{l}\text { Foreign } \\
\text { Experience }\end{array}$ & & & & $\begin{array}{l}.010 \\
(.062)\end{array}$ & $\begin{array}{l}.110^{*} \\
(.064)\end{array}$ \\
\hline $\begin{array}{l}\text { First Contact } \\
\text { Position }\end{array}$ & & & & $\begin{array}{l}.110 * * \\
(.054)\end{array}$ & $\begin{array}{l}.106 * \\
(.055)\end{array}$ \\
\hline $\begin{array}{l}\text { Time in } \\
\quad \text { Organization }\end{array}$ & & & & $\begin{array}{l}.019 \\
(.019)\end{array}$ & $\begin{array}{l}.021 \\
(.019)\end{array}$ \\
\hline $\begin{array}{c}\text { Managing } \\
\text { Others }\end{array}$ & & & & $\begin{array}{c}.049 \\
(.056)\end{array}$ & $\begin{array}{l}.051 \\
(.057)\end{array}$ \\
\hline $\begin{array}{l}\text { Org. Service: } \\
\text { Labor }\end{array}$ & & & & $\begin{array}{l}.057 \\
(.052)\end{array}$ & $\begin{array}{l}.050 \\
(.053)\end{array}$ \\
\hline Major City & & & & $\begin{array}{l}-.021 \\
(.051)\end{array}$ & $\begin{array}{l}-.027 \\
(.051)\end{array}$ \\
\hline Labor Union & & & & & $\begin{array}{l}-.136 * * \\
(.066)\end{array}$ \\
\hline $\begin{array}{l}\text { Professional } \\
\text { Organization }\end{array}$ & & & & & $\begin{array}{l}.049 \\
(.080)\end{array}$ \\
\hline Political Party & & & & & $\begin{array}{l}.087 \\
(.120)\end{array}$ \\
\hline $\begin{array}{l}\text { Religious } \\
\text { Practices }\end{array}$ & & & & & $\begin{array}{l}.052 \\
(.061)\end{array}$ \\
\hline Volunteering & & & & & $\begin{array}{l}-.047 \\
(.062)\end{array}$ \\
\hline R-Squared & .025 & 0.121 & 0.161 & 0.176 & 0.186 \\
\hline Adj. R-Squared & .022 & 0.116 & 0.151 & 0.157 & 0.159 \\
\hline $\mathrm{N}$ & 626 & 626 & 610 & 557 & 557 \\
\hline HSK & no & no & no & no & no \\
\hline
\end{tabular}

Note: Regression coefficients marked with an asterisk were statistically significant at $* p<0.10$; $* * \mathrm{p}<0.05 ; * * * \mathrm{p}<0.01$. 
Robust Regression Results for the Pooled Sample

\begin{tabular}{|c|c|c|c|}
\hline & \multicolumn{3}{|c|}{ PSM } \\
\hline & Compassion & Self-Sacrifice & $\begin{array}{c}\text { Attraction to Public } \\
\text { Service }\end{array}$ \\
\hline Intercept & 4.862 & 2.912 & 3.886 \\
\hline CEN2 & $\begin{array}{l}-.026 \\
(.027)\end{array}$ & $\begin{array}{l}\mathbf{- . 0 8 6 *} \\
(.045)\end{array}$ & $\begin{array}{c}\mathbf{- . 0 8 2} * * * \\
(.031)\end{array}$ \\
\hline CEN3 & $\begin{array}{l}.009 \\
(.022)\end{array}$ & $\begin{array}{c}. \mathbf{1 4 9} * * * \\
(.042) \\
\end{array}$ & $\begin{array}{l}.044 \pm \\
(.027) \\
\end{array}$ \\
\hline Poland & $\begin{array}{l}-.013 \\
(.070)\end{array}$ & $\begin{array}{l}.124 \\
(.111)\end{array}$ & $\begin{array}{l}-.124 \\
(.085)\end{array}$ \\
\hline Public & $\begin{array}{c}-.336 * * * \\
(.067) \\
\end{array}$ & $\begin{array}{c}-. .301 * * * \\
(.103)\end{array}$ & $\begin{array}{c}-.447 * * * \\
(.073) \\
\end{array}$ \\
\hline Woman & $\begin{array}{l}-.032 \\
(.064)\end{array}$ & $\begin{array}{l}.213 * \\
(.110)\end{array}$ & $\begin{array}{l}-.096 \\
(.085)\end{array}$ \\
\hline Age Group & $\begin{array}{l}.019 \\
(.024)\end{array}$ & $\begin{array}{c}. \mathbf{1 2 9} * * * \\
(.040)\end{array}$ & $\begin{array}{l}.070 * * \\
(.028)\end{array}$ \\
\hline Education & $\begin{array}{c}-.073 * * \\
(.037)\end{array}$ & $\begin{array}{l}-.057 \\
(.057)\end{array}$ & $\begin{array}{l}. \mathbf{1 0 3} * * \\
(.043)\end{array}$ \\
\hline Foreign Experience & $\begin{array}{l}-.005 \\
(.069)\end{array}$ & $\begin{array}{c}.336 \\
(.108)\end{array}$ & $\begin{array}{c}0 \\
(.083)\end{array}$ \\
\hline First Contact Position & $\begin{array}{l}.089 \\
(.058)\end{array}$ & $\begin{array}{l}.127 \\
(.090)\end{array}$ & $\begin{array}{l}.101 \\
(.067)\end{array}$ \\
\hline Time in Organization & $\begin{array}{c}.008 \\
(.020)\end{array}$ & $\begin{array}{l}.052 * \\
(.031)\end{array}$ & $\begin{array}{c}.003 \\
(.023)\end{array}$ \\
\hline Managing Others & $\begin{array}{l}-.008 \\
(.063)\end{array}$ & $\begin{array}{c}.003 \\
(.094)\end{array}$ & $\begin{array}{l}\mathbf{1 5 9} * * \\
(.069)\end{array}$ \\
\hline Org. Service: Labor & $\begin{array}{l}.038 \\
(.056)\end{array}$ & $\begin{array}{c}. \mathbf{3 3 5} * * * \\
(.093)\end{array}$ & $\begin{array}{c}-.222 * * * \\
(.068)\end{array}$ \\
\hline Major City & $\begin{array}{l}-.033 \\
(.057) \\
\end{array}$ & $\begin{array}{l}-.055 \\
(.084) \\
\end{array}$ & $\begin{array}{l}.009 \\
(.067) \\
\end{array}$ \\
\hline Labor Union & $\begin{array}{l}-.033 \\
(.057)\end{array}$ & $\begin{array}{c}-.295 * * * \\
(.110)\end{array}$ & $\begin{array}{l}-.021 \\
(.082)\end{array}$ \\
\hline $\begin{array}{l}\text { Professional } \\
\quad \text { Organization }\end{array}$ & $\begin{array}{l}-.057 \\
(.084)\end{array}$ & $\begin{array}{l}.072 \\
(.130)\end{array}$ & $\begin{array}{l}.131 \\
(.092)\end{array}$ \\
\hline Political Party & $\begin{array}{l}-.061 \\
(.126)\end{array}$ & $\begin{array}{l}.279 \\
(.189)\end{array}$ & $\begin{array}{l}.044 \\
(.143)\end{array}$ \\
\hline Religious Practices & $\begin{array}{l}.072 \\
(.068)\end{array}$ & $\begin{array}{l}.002 \\
(.104)\end{array}$ & $\begin{array}{l}.083 \\
(.081)\end{array}$ \\
\hline Volunteering & $\begin{array}{l}-.104 \\
(.073) \\
\end{array}$ & $\begin{array}{l}-.053 \\
(.108) \\
\end{array}$ & $\begin{array}{l}.017 \\
(.082) \\
\end{array}$ \\
\hline R-Squared & .090 & 0.196 & 0.202 \\
\hline $\mathrm{N}$ & 557 & 557 & 557 \\
\hline HSK & yes & $\begin{array}{c}\text { Prob }>\text { chi } 2= \\
0.0680 \text { (marginally } \\
\text { no) }\end{array}$ & Yes \\
\hline
\end{tabular}

Note: Regression coefficients marked with an asterisk were statistically significant at $* \mathrm{p}<0.10$; $* * \mathrm{p}<0.05$; *** $\mathrm{p}<0.01$. 
Regression Results for PSM and Constituent Dimensions (standard deviations from the mean)

\begin{tabular}{|c|c|c|c|c|c|c|c|c|}
\hline & \multicolumn{4}{|c|}{ Belarus: Public Sector N=193 } & \multicolumn{4}{|c|}{ Belarus: Nonprofit Sector N=103 } \\
\hline & PSM & $\mathrm{COM}$ & SS & APS & PSM & $\mathrm{COM}$ & SS & APS \\
\hline Intercept & 3.600 & 4.728 & 2.775 & 3.296 & 3.719 & 4.239 & 2.867 & 4.052 \\
\hline Initiative Discouragement & $\begin{array}{l}-.019 \\
(043)\end{array}$ & $\begin{array}{c}.035 \\
(054)\end{array}$ & $\begin{array}{l}-.032 \\
(069)\end{array}$ & $\begin{array}{l}-.060 \\
(050)\end{array}$ & $\begin{array}{c}.004 \\
(046)\end{array}$ & $\begin{array}{l}.021 \\
(039)\end{array}$ & $\begin{array}{l}-.085 \\
(087)\end{array}$ & $\begin{array}{l}.076 \\
(.049)\end{array}$ \\
\hline Prior Approval & $\begin{array}{c}.025 \\
(.037)\end{array}$ & $\begin{array}{l}-.059 \\
(.041)\end{array}$ & $\begin{array}{c}.045 \\
(.059)\end{array}$ & $\begin{array}{l}. \mathbf{0 8 7} * * \\
(.043)\end{array}$ & $\begin{array}{l}.050 \\
(.047)\end{array}$ & $\begin{array}{l}-.027 \\
(.038)\end{array}$ & $\begin{array}{l}. \mathbf{1 5 1}^{*} \\
(.084)\end{array}$ & $\begin{array}{l}.025 \\
(.051)\end{array}$ \\
\hline Woman & $\begin{array}{l}-.230 \\
(.174)\end{array}$ & $\begin{array}{l}-.063 \\
(.123)\end{array}$ & $\begin{array}{l}-.429 \\
(.281)\end{array}$ & $\begin{array}{l}-.197 \\
(.203)\end{array}$ & $\begin{array}{l}-.141 \\
(.149)\end{array}$ & $\begin{array}{c}.090 \\
(.165)\end{array}$ & $\begin{array}{c}\mathbf{- . 4 8 0} \text { *** } \\
(.236)\end{array}$ & $\begin{array}{l}-.032 \\
(.173)\end{array}$ \\
\hline Age Group & $\begin{array}{c}.040 \\
(.043)\end{array}$ & $\begin{array}{l}-.079 \\
(.052)\end{array}$ & $\begin{array}{c}.109 \\
(.069)\end{array}$ & $\begin{array}{l}.090 * \\
(.050)\end{array}$ & $\begin{array}{c}.068 \\
(.063)\end{array}$ & $\begin{array}{c}.045 \\
(.055)\end{array}$ & $\begin{array}{l}.161 \\
(.106)\end{array}$ & $\begin{array}{l}-.002 \\
(.069)\end{array}$ \\
\hline Education & $\begin{array}{c}.015 \\
(.068)\end{array}$ & $\begin{array}{l}-.112 \\
(.079)\end{array}$ & $\begin{array}{c}.019 \\
(.110)\end{array}$ & $\begin{array}{l}. \mathbf{1 3 8}^{*} \\
(.080)\end{array}$ & $\begin{array}{l}-.009 \\
(.066)\end{array}$ & $\begin{array}{c}0 \\
(.056)\end{array}$ & $\begin{array}{l}-.032 \\
(.113)\end{array}$ & $\begin{array}{c}.005 \\
(.076)\end{array}$ \\
\hline Foreign Experience & $\begin{array}{c}.081 \\
(.170)\end{array}$ & $\begin{array}{l}-.217 \\
(.154)\end{array}$ & $\begin{array}{l}\mathbf{. 5 0 6}^{*} \\
(.274)\end{array}$ & $\begin{array}{l}-.048 \\
(.198)\end{array}$ & $\begin{array}{c}.053 \\
(.149)\end{array}$ & $\begin{array}{l}-.285^{*} \\
(.150)\end{array}$ & $\begin{array}{c}.287 \\
(.217)\end{array}$ & $\begin{array}{c}.159 \\
(.173)\end{array}$ \\
\hline First Contact Position & $\begin{array}{c}.122 \\
(.104)\end{array}$ & $\begin{array}{l}. \mathbf{2 9 6} * * \\
(.123)\end{array}$ & $\begin{array}{c}.094 \\
(.167)\end{array}$ & $\begin{array}{c}.004 \\
(.121)\end{array}$ & $\begin{array}{c}.196 \\
(.123)\end{array}$ & $\begin{array}{c}.064 \\
(.115)\end{array}$ & $\begin{array}{c}.326 \\
(.209)\end{array}$ & $\begin{array}{l}.197 \\
(.147)\end{array}$ \\
\hline Time in Organization & $\begin{array}{c}.026 \\
(.031)\end{array}$ & $\begin{array}{c}.051 \\
(.034)\end{array}$ & $\begin{array}{c}.052 \\
(.050)\end{array}$ & $\begin{array}{l}-.026 \\
(.036)\end{array}$ & $\begin{array}{c}.062 \\
(.048)\end{array}$ & $\begin{array}{c}.064 \\
(.057)\end{array}$ & $\begin{array}{c}.083 \\
(.076)\end{array}$ & $\begin{array}{c}.040 \\
(.069)\end{array}$ \\
\hline Managing Others & $\begin{array}{c}.113 \\
(.101)\end{array}$ & $\begin{array}{c}.099 \\
(.107)\end{array}$ & $\begin{array}{c}.133 \\
(.163)\end{array}$ & $\begin{array}{c}.108 \\
(.118)\end{array}$ & $\begin{array}{l}.106 \\
(.131)\end{array}$ & $\begin{array}{c}.039 \\
(.128)\end{array}$ & $\begin{array}{c}.096 \\
(.214)\end{array}$ & $\begin{array}{c}.183 \\
(.172)\end{array}$ \\
\hline Org. Service: Labor & $\begin{array}{c}.157 \\
(.115)\end{array}$ & $\begin{array}{l}.192 \\
(.132)\end{array}$ & $\begin{array}{c}.130 \\
(.186)\end{array}$ & $\begin{array}{c}.149 \\
(.134)\end{array}$ & $\begin{array}{l}-.301 \\
(.199)\end{array}$ & $\begin{array}{l}-.262 \\
(.222)\end{array}$ & $\begin{array}{c}\mathbf{- . 6 8 5} * * \\
(.288)\end{array}$ & $\begin{array}{c}.045 \\
(.242)\end{array}$ \\
\hline Major City & $\begin{array}{l}. \mathbf{1 9 7} * * \\
(.096)\end{array}$ & $\begin{array}{c}.205^{*} \pm \\
(.104)\end{array}$ & $\begin{array}{l}.298 * \\
(.155)\end{array}$ & $\begin{array}{c}.088 \\
(.112)\end{array}$ & $\begin{array}{l}-.103 \\
(.130)\end{array}$ & $\begin{array}{c}.087 \\
(.138)\end{array}$ & $\begin{array}{l}-.239 \\
(.192)\end{array}$ & $\begin{array}{l}-.157 \\
(.154)\end{array}$ \\
\hline Labor Union & $\begin{array}{l}.262 * \\
(.147)\end{array}$ & $\begin{array}{l}-.154 \\
(.157)\end{array}$ & $\begin{array}{c}.520 * * \\
(.237)\end{array}$ & $\begin{array}{l}-.114 \\
(.172)\end{array}$ & $\begin{array}{c}.060 \\
(.095)\end{array}$ & $\begin{array}{c}.052 \\
(.091)\end{array}$ & $\begin{array}{c}.177 \\
(.164)\end{array}$ & $\begin{array}{l}-.048 \\
(.118)\end{array}$ \\
\hline
\end{tabular}




\begin{tabular}{|c|c|c|c|c|c|c|c|c|}
\hline \multirow{2}{*}{ Professional Organization } & .077 & .030 & .021 & .182 & -.020 & .054 & -.062 & -.053 \\
\hline & $(.266)$ & $(.334)$ & $(.428)$ & $(.310)$ & $(.180)$ & $(.148)$ & $(.315)$ & $(.238)$ \\
\hline \multirow{2}{*}{ Political Party } & $.393 *$ & $.350 * *$ & $.650 *$ & .178 & $.424 * * *$ & $.193 *$ & $.866^{* * *}$ & .214 \\
\hline & $(.221)$ & $(.158)$ & $(.356)$ & $(.258)$ & $(.111)$ & $(.102)$ & $(.176)$ & $(.255)$ \\
\hline \multirow{2}{*}{ Religious Practices } & .144 & .598 & -.338 & .172 & .085 & .063 & .185 & .006 \\
\hline & $(.214)$ & $(.318)$ & $(.344)$ & $(.249)$ & $(.119)$ & (.119) & $(.205)$ & $(.147)$ \\
\hline \multirow[t]{2}{*}{ Volunteering } & $-.336 *$ & -.538 & -.249 & -.221 & -.182 & $-.222 *$ & -.231 & -.093 \\
\hline & $(.361)$ & $(.269)$ & $(.289)$ & (.209) & $(.122)$ & $(.120)$ & (193) & $(.148)$ \\
\hline R-Squared & 0.155 & 0.170 & 0.183 & 0.125 & 0.22 & 0.19 & 0.319 & 0.10 \\
\hline Adjusted R-Squared & 0.078 & & 0.109 & 0.045 & & & & \\
\hline \multirow[t]{3}{*}{ HSK Prob > chi 2} & 0.0806 & 0.0124 & 0.5539 & 0.1785 & 0.0005 & 0.0008 & 0.0044 & 0.0098 \\
\hline & \multicolumn{4}{|c|}{ Poland: Public Sector N=158 } & \multicolumn{4}{|c|}{ Poland: Nonprofit Sector N=103 } \\
\hline & PSM & $\mathrm{COM}$ & SS & APS & PSM & COM & SS & APS \\
\hline Intercept & 3.771 & 4.331 & 2.848 & 4.132 & 3.736 & 4.966 & 2.318 & 3.923 \\
\hline \multirow[t]{2}{*}{ Initiative Discouragement } & $\mathbf{- . 1 8 9} * * *$ & $-.113 * *$ & $-.185 * *$ & $-.269 * * *$ & -.062 & -.041 & -.141 & -.004 \\
\hline & $(.048)$ & $(.054)$ & $(.087)$ & $(.066)$ & $(.071)$ & $(.064)$ & (.109) & $(.069)$ \\
\hline \multirow[t]{2}{*}{ Prior Approval } & $.154 * * *$ & $.106 * *$ & $.200 * * *$ & $.157 * * *$ & $.118^{*}$ & $.115 * *$ & $.230 * *$ & .008 \\
\hline & $(.044)$ & $(.049)$ & $(.075)$ & $(.057)$ & $(.069)$ & $(.057)$ & $(.100)$ & $(.076)$ \\
\hline \multirow[t]{2}{*}{ Woman } & -.004 & -.018 & .077 & -.069 & -.088 & -.071 & -.112 & -.082 \\
\hline & $(.112)$ & $(.124)$ & $(.197)$ & $(.175)$ & $(.125)$ & $(.101)$ & $(.231)$ & $(.148)$ \\
\hline \multirow[t]{2}{*}{ Age Group } & .001 & -.002 & -.023 & .030 & $.098 *$ & .022 & $.196 * *$ & .076 \\
\hline & $(.052)$ & $(.058)$ & $(.088)$ & $(.067)$ & $(.054)$ & $(.049)$ & $(.097)$ & $(.074)$ \\
\hline \multirow[t]{2}{*}{ Education } & -.008 & .057 & -.079 & -.002 & .006 & -.096 & .025 & .090 \\
\hline & $(.071)$ & $(.080)$ & $(.126)$ & $(.118)$ & (.090) & $(.084)$ & $(.182)$ & $(.115)$ \\
\hline \multirow[t]{2}{*}{ Foreign Experience } & .106 & $.190 * \pm$ & .122 & .006 & .228 & .224 & .188 & .273 \\
\hline & (.104) & $(.115)$ & $(.163)$ & $(.169)$ & $(.165)$ & $(.182)$ & $(.247)$ & $(.219)$ \\
\hline \multirow{2}{*}{ First Contact Position } & .066 & .022 & .012 & .164 & .203 & .111 & .211 & $.286 * *$ \\
\hline & $(.113)$ & $(.126)$ & $(.157)$ & $(.167)$ & $(.123)$ & $(.116)$ & $(.203)$ & $(.141)$ \\
\hline
\end{tabular}




\begin{tabular}{|c|c|c|c|c|c|c|c|c|}
\hline Time in Organization & $\begin{array}{l}.012 \\
(.045)\end{array}$ & $\begin{array}{l}-.017 \\
(.050)\end{array}$ & $\begin{array}{l}.037 \\
(.074)\end{array}$ & $\begin{array}{l}.015 \\
(.065)\end{array}$ & $\begin{array}{l}.015 \\
(.045)\end{array}$ & $\begin{array}{l}.017 \\
(.052)\end{array}$ & $\begin{array}{l}.038 \\
(.081)\end{array}$ & $\begin{array}{l}.023 \\
(.052)\end{array}$ \\
\hline Managing Others & $\begin{array}{c}.099 \\
(.122)\end{array}$ & $\begin{array}{l}.030 \\
(.135)\end{array}$ & $\begin{array}{l}.009 \\
(.155)\end{array}$ & $\begin{array}{l}.258 \\
(.182)\end{array}$ & $\begin{array}{l}-.145 \\
(.160)\end{array}$ & $\begin{array}{l}-.272 * \\
(.159)\end{array}$ & $\begin{array}{l}-.079 \\
(.244)\end{array}$ & $\begin{array}{l}-.085 \\
(.207)\end{array}$ \\
\hline Org. Service: Labor & $\begin{array}{c}.091 \\
(.096)\end{array}$ & $\begin{array}{l}-.128 \\
(.107)\end{array}$ & $\begin{array}{c}\mathbf{1 . 1 3 5} * * * \\
(.145)\end{array}$ & $\begin{array}{c}-. \mathbf{7 3 3} * * * \\
(.137)\end{array}$ & $\begin{array}{l}.179 \\
(.163)\end{array}$ & $\begin{array}{l}\mathbf{. 3 5 6}^{* * *} \\
(.160)\end{array}$ & $\begin{array}{l}.020 \\
(.228)\end{array}$ & $\begin{array}{l}.161 \\
(.221)\end{array}$ \\
\hline Major City & $\begin{array}{l}-.070 \\
(.097)\end{array}$ & $\begin{array}{c}-.258 * * \\
(.107)\end{array}$ & $\begin{array}{l}.110 \\
(.138)\end{array}$ & $\begin{array}{l}-.061 \\
(.137)\end{array}$ & $\begin{array}{l}-.350 \\
(.232)\end{array}$ & $\begin{array}{c}-.528 * * \\
(.233)\end{array}$ & $\begin{array}{l}-.051 \\
(.293)\end{array}$ & $\begin{array}{l}-.471 \\
(.331)\end{array}$ \\
\hline Labor Union & $\begin{array}{l}-.212 * \\
(.120)\end{array}$ & $\begin{array}{l}-.205 \\
(.134)\end{array}$ & $\begin{array}{l}-.255 \\
(.203)\end{array}$ & $\begin{array}{l}-.175 \\
(.173)\end{array}$ & $\begin{array}{l}-.194 \\
(.265)\end{array}$ & $\begin{array}{l}-.134 \\
(.257)\end{array}$ & $\begin{array}{l}-.067 \\
(.537)\end{array}$ & $\begin{array}{l}-.382 \\
(.285)\end{array}$ \\
\hline Professional Organization & $\begin{array}{l}-.009 \\
(.120)\end{array}$ & $\begin{array}{l}-.303 \\
(.222)\end{array}$ & $\begin{array}{c}.401 \\
(.482)\end{array}$ & $\begin{array}{r}-.125 \\
(.292)\end{array}$ & $\begin{array}{l}.198 \\
(.125)\end{array}$ & $\begin{array}{c}.103 \\
(.121)\end{array}$ & $\begin{array}{l}.317 * \pm \\
(.194)\end{array}$ & $\begin{array}{l}.174 \\
(.142)\end{array}$ \\
\hline Political Party & $\begin{array}{l}-.149 \\
(.194)\end{array}$ & $\begin{array}{c}-.606 * * * \\
(.216)\end{array}$ & $\begin{array}{c}.292 \\
(.275)\end{array}$ & $\begin{array}{l}-.132 \\
(.325)\end{array}$ & $\begin{array}{l}-.203 \\
(.364)\end{array}$ & $\begin{array}{c}.136 \\
(.326)\end{array}$ & $\begin{array}{l}-.938 * \\
(.558)\end{array}$ & $\begin{array}{l}.191 \\
(.292)\end{array}$ \\
\hline Religious Practices & $\begin{array}{c}. \mathbf{2 5 5} * * * \\
(.092)\end{array}$ & $\begin{array}{l}.129 \\
(.103)\end{array}$ & $\begin{array}{l}. \mathbf{3 3 2} * * \\
(.141)\end{array}$ & $\begin{array}{l}.303 * * \\
(.140)\end{array}$ & $\begin{array}{l}-.286^{*} \\
(.148)\end{array}$ & $\begin{array}{l}-.153 \\
(.157)\end{array}$ & $\begin{array}{c}-.498 * * \\
(.209)\end{array}$ & $\begin{array}{l}-.207 \\
(.190)\end{array}$ \\
\hline Volunteering & $\begin{array}{c}.045 \\
(.119) \\
\end{array}$ & $\begin{array}{r}-.018 \\
(.133) \\
\end{array}$ & $\begin{array}{c}.054 \\
(.210) \\
\end{array}$ & $\begin{array}{r}.100 \\
(.146) \\
\end{array}$ & $\begin{array}{l}.179 \\
(.127) \\
\end{array}$ & $\begin{array}{c}.156 \\
(.120) \\
\end{array}$ & $\begin{array}{l}.320 * \\
(.191) \\
\end{array}$ & $\begin{array}{c}.062 \\
(.158) \\
\end{array}$ \\
\hline $\begin{array}{c}\text { R-Squared } \\
\text { Adjusted R-Squared }\end{array}$ & $\begin{array}{l}0.199 \\
0.108\end{array}$ & $\begin{array}{l}0.201 \\
0.111\end{array}$ & 0.397 & 0.355 & 0.252 & 0.209 & $\begin{array}{l}0.282 \\
0.149\end{array}$ & 0.176 \\
\hline HSK (Prob > chi2) & 0.931 & 0.493 & 0.005 & 0.039 & 0.057 & 0.0001 & 0.132 & 0 \\
\hline
\end{tabular}

Note: Regression coefficients marked with an asterisk were statistically significant at $* \mathrm{p}<0.10$; $* * \mathrm{p}<0.05 ; * * * \mathrm{p}<0.01 ; \pm$ signifies coefficients on the significance border. 
VITA

\section{PALINA PRYSMAKOVA}

Born, Minsk, Belarus

2005-2011

B.A. International Relations and B.A. Cultural Studies

College of Public Administration in Bialystok, Poland

2008

Erasmus Exchange Program, International Relations

University of Potsdam, Germany

2008-2010

M.A. European Union Studies

University of Bialystok, Poland

2010-2015

Doctoral Candidate, Public Affairs

Florida International University, Florida

\section{PUBLICATIONS AND PRESENTATIONS}

Prysmakova, P. (2014). Public Service Motivation in Europe: Testing Attitudes toward Work Motives". NISPAcee Journal of Public Administration and Policy 7(1): pp. 131-56.

Prysmakova, P. (2015). Do Public and Nonprofit Sector Employees Speak Same Language? Questioning Possibilities of Civil Dialogue. in Forms and Determinants of Development of Civil Dialogue, Mariusz Sienkiewicz (eds.), Centre for Local Development: Poland.

Prysmakova, P. (2015). Why Does China Invest in Belarus? Billions of Loans in the Eyes of Chinese Local Governments. Belarusian Political Science Review.

Prysmakova, P. (2014). Where are We on European Map? Comparing Public Service Motivation in Central and Eastern Europe to Our Neighbors. Warsaw East European Review (4), 2014: pp. 103-19.

Prysmakova, P. (2012). Expecting Heavy Rain of Chinese Yuan over Central and Eastern Europe: the First Drops in Belarus. Warsaw East European Review (2), 2012: pp. 59-74. 